\title{
Role of Rho GTPases During Primordial Germ Cell Migration In Zebrafish
}

\section{PhD Thesis}

\author{
In partial fulfillment of the requirements \\ for the degree "Doctor of Philosophy (PhD)" \\ in the Molecular Biology Program \\ at the Georg August University of Goettingen, Germany \\ Faculty of Biology
}

\author{
Submitted by \\ Elena Kardash
}

Born in Moscow

Muenster

-2008- 
Thesis committee members:

Prof. Dr. Erez Raz

ZMBE-Center for Molecular Biology of Inlammation

Institute of Cell Biology

Von-Esmarch-Strasse 56

D-48149 Muenster

Germany

Prof. Dr. med. Heidi Hahn

University of Goettingen

Institute for Human Genetics

Heinrich-Dueker-Weg

37073 Goettingen

Germany

Prof. Dr. Michael Kessel

Max-Planck-Institute for Biophysical Chemistry

Department of Molecular Cell Biology

Am Fassberg 11

37077 Goettingen

Germany 

In vivo veritas 



\section{AFFIDAVIT}

I hereby confirm that the present thesis has been written independently and with no other sources and aids than quoted. 


\section{CONTENTS}

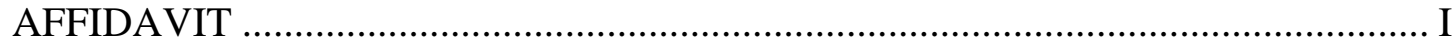

ACKNOWLEDGEMENTS ……………………………………………….....

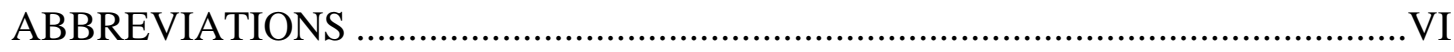

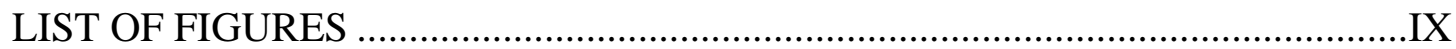

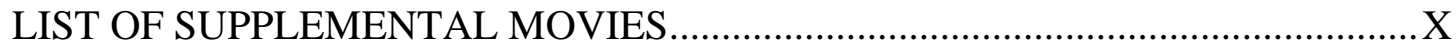

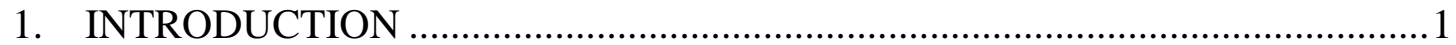

1.1. Cell Migration - general overview …………………….................................

1.1.1. Actin Cytoskeleton.................................................................................

1.1.2. Actin organization within a cell ..................................................................

1.1.3. Actin cytoskeleton is important for generating the forces required for

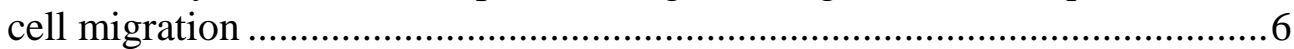

1.1.4. Models for cell migration.......................................................................

1.2. Rho GTPases are important regulators of actin cytoskeleton dynamics.........10

1.2.1. Regulation of Rho GTPases.................................................................10

1.2.2. Rho GTPases modulate actin cytoskeleton during cell migration ...........12

1.2.3. Tools used to study the function of Rho GTPases .....................................13

1.2.4. FRET-based biosensors for Rho GTPases ...........................................13

1.3. Primordial Germ Cell migration in zebrafish ................................................16

1.4. The aim of the present work ……………………….................................17

2. MATERIALS AND METHODS..............................................................19

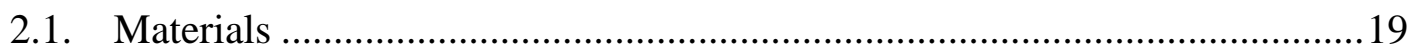

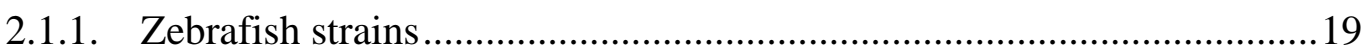

2.1.2. Bacteria for plasmid propagation ..........................................................19

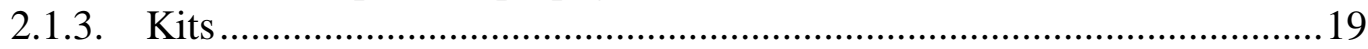

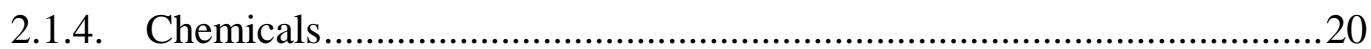

2.1.5. Molecular biology reagents..................................................................20

2.1.6. List of the constructs used in this study ...............................................20

2.1.7. List of the oligos used in this work ......................................................24

2.1.8. Morpholino antisense oligonucleotides used in this study ......................25

2.1.9. Technical Equipment …………………………....................................26

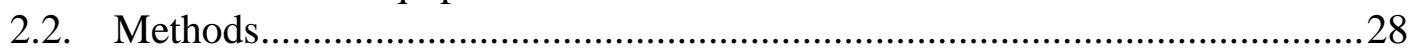

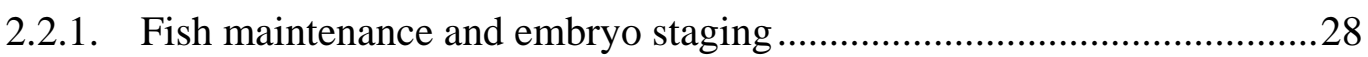

2.2.2. Transgenic fish generation ................................................................2

2.2.3. Targeting protein expression in PGCs ..................................................28

2.2.4. Knocking down protein expression in PGCs ...........................................28

2.2.5. Solutions and materials for the injection ..............................................29

2.2.6. RNA extraction from zebrafish embryos:.............................................31

2.2.7. cDNA synthesis protocol: .......................................................................

2.2.8. Cloning procedures .....................................................................................

2.2.9. Electroporation of a plasmid DNA into bacteria ......................................33

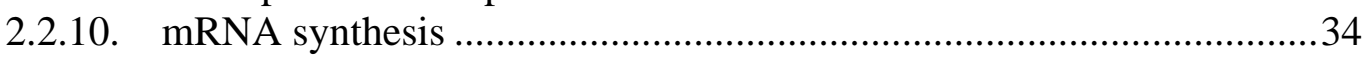

2.2.11. Plasmid isolation: Mini and Midi purification.........................................34

2.2.12. Confocal Microscopy ...............................................................................

2.2.13. Wide field Microscopy …………………………..................................35

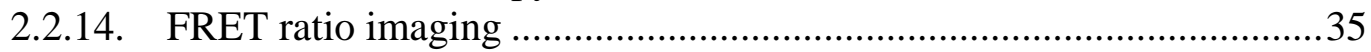

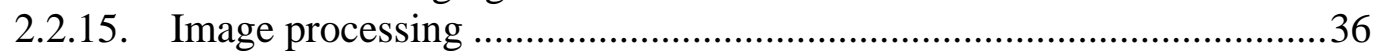

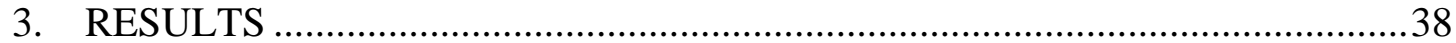


3.1. Rho GTPases control actin cytoskeleton dynamics during PGC migration ..38

3.1.1. Actin behaviour during PGC migration, wild type situation ..................38

3.1.2. Effect of SDF-1a/CXCR4b signalling on actin cytoskeleton ..................39

3.1.3. Interfering with the function of endogenous Rho GTPases affects actin cytoskeleton and PGC migration .................................................................40

3.1.4. Proper balance between Rac and RhoA activities is important for PGC migration.....

3.1.5. Actin brushes are part of the contractile machinery in PGCs .................46

3.1.6. Role of cell-cell adhesion during PGC migration...............................47

3.2. Activation of Rho GTPases during PGC migration.....................................50

3.2.1. FRET imaging setup in migrating PGCs .............................................50

3.2.2. Comparison between two different combination for Donor and Acceptor 52

3.2.3. Targeting Rac-FRET biosensor expression in PGCs............................53

3.2.4. Scale setup for measuring Rac activity .................................................56

3.2.5. Rac activation during PGC migration revealed with FRET ...................59

3.2.6. Cdc42 activation revealed with FRET in PGCs .................................62

3.2.7. RhoA activation revealed with FRET in PGCs ....................................64

3.3. Signalling events during PGC migration ................................................66

3.3.1. Calcium influx at ectopic locations is not sufficient to trigger actin

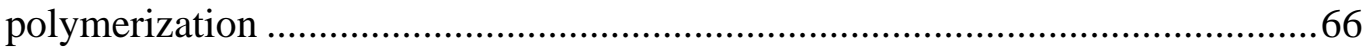

3.3.2. Signalling downstream to activated Rac..........................................67

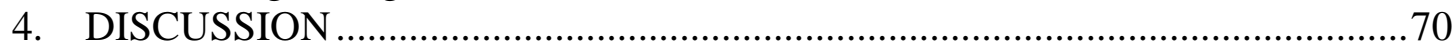

4.1. Rac and RhoA exert distinct effects on actin dynamics .............................70

4.1.1. Rac and RhoA are active at the front of migrating PGCs .......................70

4.1.2. Coordinated actions of Rac and RhoA at the front result in cell

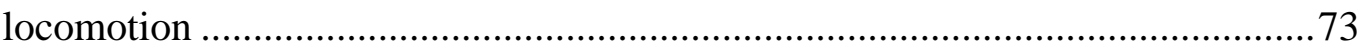

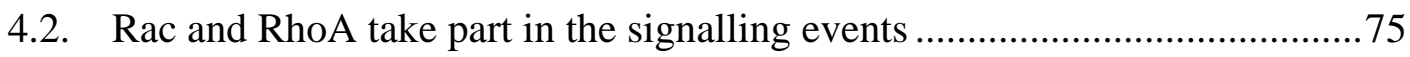

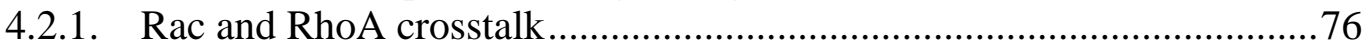

4.2.2. Signalling downstream of activated Rac............................................76

4.3. Imaging protein activities in PGCs using FRET-based biosensors (Technical notes) 79

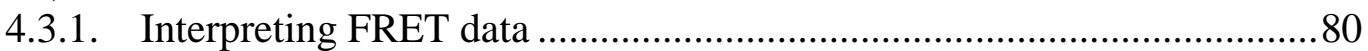

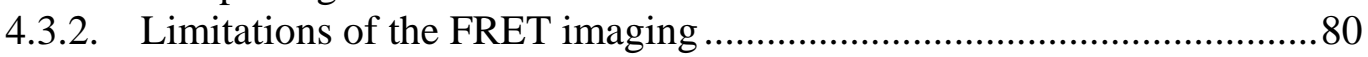

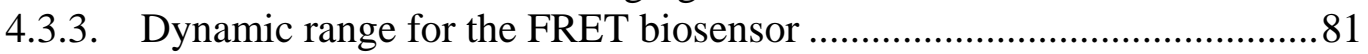

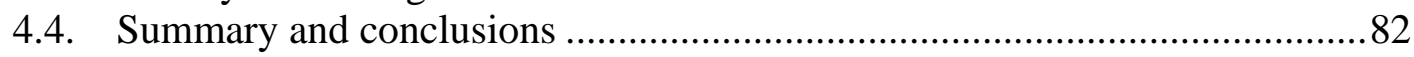

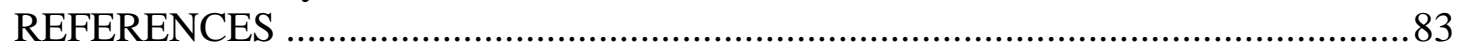




\section{ACKNOWLEDGEMENTS}

First of all I would like to thank my advisor Erez Raz for this unprecedented research experience in his lab. I am grateful to Erez for giving me the full freedom to experiment and do mistakes during my PhD time. More than that I appreciate his suggestions and advise during our discussions that helped greatly to interpret data and to develop new ideas. The most valuable lesson I learnt (and still learning) from him is the art of asking the "right" question and not wasting time doing unnecessary experiments.

I would like to thank all my colleagues, the former and the current members in our lab who create a unique atmosphere making so much fun working in. Thanks to all of you for providing enormous support and compassion, especially during the challenging times of writing the thesis. Many thanks to Maria who taught me all the fish work and who spent two months supervising me during the rotation! Thanks to Sonia and Natalia for the unforgettable three years of friendship. Thank you Harsha for your cheerful mood - day and night! Many thanks to Esther, who supported my work for the past year and made sure the experimental part was progressing the most efficiently. I am grateful to Michal for her insightful comments on my writing exercises and for the countless discussions we had. Thank you so much Bijan for your patience in helping with writing and editing documents and using the software.

This work would never be possible without an invaluable experience in microscopy and image processing I obtained in Tom Jovin's department at the MPI Biophysical Chemistry in Goettingen. I would like to thank all the members of Tom's department who spent time teaching me the art of image processing and how to use a microscope as a quantitative tool in addressing biological questions. I would like to extend my thanks to Tom, Donna, Peter, Berndt, and Rainer. Thanks to Enrique Martin-Blanco who inspired the FRET imaging part of the present work.

Thanks to all my friends and to my family who stand by me.

I dedicate this work to my mother Olga, aunt Alla, sister Esther, brother Sergej, and to the memory of my father Eugeni.

The present work was carried out at the Max Planck for Biophysical Chemistry in Goettingen (September 2004 - July 2007) and at the Center for 
Molecular Biology of Inflammation at the Institute of Cell Biology, UKM Muenster (August 2007 - September 2008). 


\section{ABBREVIATIONS}

2D

3D

ADP

Amp

Arp2/3

ATP

bp

CA

$\mathrm{Ca}^{2+}$

cDNA

CFP

CRIB

DN

DNA

E. coli

$\mathrm{Em}$

Ex

F-actin

FRET

GAP

G-actin

GDI

GDP

GEF

GFP

GPCR

GTP

Hpf

Kan

LIMK

MLCK

MO

mRNA
Two-Dimensional

Three-Dimensional

Adenosine 5'-diphosphate

Ampicyllin

Actin-related proteins 2 and 3

Adenosine 5'-triphosphate

base pair

Constitutively-active

Calcium ions

complementary DNA

Cyan fluorescent protein

Cdc42/Rac interaction binding

Dominant-negative

deoxyribonucleic acid

Escherichia coli

Emission

Excitation

Filamentous actin

Fluorescence (Foerster) Resonance Energy Transfer

GTPase activating protein

Globular actin

Guanine-nucleotide dissociation inhibitor

Guanosine-5'-diphosphate

Guanine-nucleotide exchange factor

Green fluorescent protein

G-protein-coupled receptor

Guanosine-5'-triphosphate

Hours post fertilization

Kanamycin

Lim-domain kinase

Myosin Light Chain Kinase

Morpholino antisense oligonucleotide

messenger RNA 


$\begin{array}{ll}\text { NLS } & \text { Nuclear localization signal } \\ \text { Nos1 } & \text { nanos1 } \\ \text { OD } & \text { Optical density } \\ \text { ORF } & \text { Open reading frame } \\ \text { PAK } & \text { P21 activated kinase } \\ \text { PCR } & \text { Rolymerase chain reaction } \\ \text { PGC } & \text { Rrimordial germ cell } \\ \text { PI3K } & \text { Phosphatidyl Inositol 3 kinase } \\ \text { PIP5K } & \text { Phosphatidylinositol-4-phosphate 5 kinase } \\ \text { PKC } & \text { Protein kinase C } \\ \text { PtdIns } & \text { Phosphatidyl Inositol } \\ \text { RBD } & \text { Rho binding domain } \\ \text { RNA } & \text { Ribonucleic acid } \\ \text { ROCK/ROK } & \text { RhoA activated kinase } \\ \text { RT } & \text { Room temperature } \\ \text { SCAR } & \text { Suppressor of cAR, a WASP related protein } \\ \text { SDF-1a } & \text { Stromal Cell-Derived factor 1a } \\ \text { SEM } & \text { Standard error of the mean } \\ \text { UTR } & \text { Untranslated region } \\ \text { UV } & \text { Ultra Violet } \\ \text { WASP } & \text { Wiskott-Aldrich syndrome protein } \\ \text { WAVE } & \text { WASP family verprolin-homologous protein } \\ \text { WT } & \text { Yellow fluorescent protein } \\ \text { YFP } & \end{array}$




\section{ABSTRACT}

Cell migration is an essential biological process during development, adult homeostasis, and disease. Actin cytoskeleton plays crucial role in generating forces required for cell migration. Rho GTPases are key regulators of actin cytoskeleton remodeling during cell migration. To understand the function of Rho GTPases it is important to have the information regarding their spatial-temporal activation pattern in migrating cell. Accessibility of cells migrating in vivo has proven to be a major challenge in studying molecular mechanisms underlying cell migration in their natural milieu. Primordial germ cells (PGCs) in zebrafish arise at distinct positions of the developing embryo and migrate towards their target guided by the chemokine SDF1a. PGC migration in zebrafish is an excellent in vivo model system to study cell migration processes in vertebrates. It was shown that PGC migrate by forming blebs at their leading edge.

The present work focuses at elucidating the role of Rho GTPases in actin cytoskeleton remodeling during PGC migration in zebrafish. To this end I studied actin cytoskeleton dynamics in the presence of mutant forms for three important Rho GTPases: Rac, Cdc42 and RhoA. To study the spatial-temporal activation pattern for Rho GTPases in migrating PGCs, I optimized ratio imaging with FRET biosensors in zebrafish embryo. Utilizing FRET biosensors I showed that Rac and RhoA activities are elevated at the front of the migrating PGC, while Cdc42 is active in the nucleus. Imaging actin cytoskeleton in PGCs revealed that depending on Rac activity, actin accumulates at the front of the cell forming a dense network, which then flows backwards in the process that requires RhoA activity. I propose that in migrating PGCs, Rac function promotes actin accumulation at the front of the cell, while RhoA mediates the actin backward flow thereby generating forces essential for cell locomotion. 


\section{LIST OF FIGURES}

Figure 1.1 Actin filament dynamics........................................................................

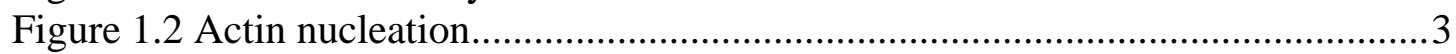

Figure 1.3 Various structures formed by actin in the metazoan cells .............................. 4

Figure 1.4 Actin role in cell adhesion ........................................................................

Figure 1.5 Differences in actin organization between the 2D and 3D ..........................6

Figure 1.6 Actin cytoskeleton in migrating fibroblast..................................................

Figure 1.7 Life cycle of a bleb ...............................................................................

Figure 1.8 Structural basis for Rho GTPases signalling ..............................................10

Figure 1.9 Regulation of Rho GTPases ..................................................................11

Figure 1.10 Rac, Rho and Cdc42 activation in migrating fibroblast ............................12

Figure 1.11 FRET biosensor for Rho GTPases ……………………………………...15

Figure 1.12 Steps in PGC migration during the first 24h of development ...................16

Figure 1.13 PGC migration is governed by blebbing ...................................................17

Figure 2.1 Injection into one-cell stage zebrafish embryos ...........................................30

Figure 3.1 Actin cytoskeleton in migrating PGCs ............................................................39

Figure 3.2 Actin citoskeleton dynamics in migrating PGCs..........................................40

Figure 3.3 Interfering with the function of endogenous Rac and Cdc42 .....................42

Figure 3.4 Interfering with the function of endogenous RhoA.....................................4

Figure 3.5 Correct balance for Rac1 and RhoA activities in PGCs...............................46

Figure 3.6 MLCK is localized to the front in migrating PGCs......................................47

Figure 3.7 PGCs migrate in close association with the somatic tissue ..........................4 48

Figure 3.8 Excitation and emission spectra for CFP and YFP ………………….........51

Figure 3.9 Ratio imaging setup in PGCs ....................................................................52

Figure 3.10 Targeting Rac-FRET biosensor expression in PGCs .................................55

Figure 3.11 Calibration for the Rac-FRET biosensor ...................................................57

Figure 3.12 Increase in FRET of the Rac-FRET biosensor with time...........................58

Figure 3.13 DH-PH domain of Tiam1 activates Rac in PGCs ......................................58

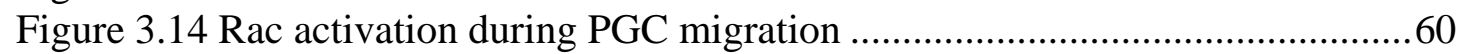

Figure 3.15 Rac activation in PGCs migrating without................................................61

Figure 3.16 Targeting Cdc42-FRET biosensor expression in PGCs .............................62

Figure 3.17 Cdc42 activation during PGC migration ......................................................63

Figure 3.18 Targeting RhoA-FRET biosensor expression in PGCs ...............................64

Figure 3.19 RhoA activation during PGCs migration ..................................................65

Figure 3.20 Calcium influx at ectopic location does not lead to ..................................67

Figure 3.21 Dissecting signalling pathways downstream to activated Rac1 in PGCs.69

Figure 4.1 A speculative model proposing how Rac and RhoA could cooperate at the front of migrating PGC regulating actin cytoskeleton ..........................................75

Figure 4.2 Dissecting Rac-induced downstream signalling pathways in PGCs ...........77

Figure 4.3 Dynamic range for the FRET biosensor ........................................................82 


\section{LIST OF SUPPLEMENTAL MOVIES}

\section{ACTIN DYNAMICS}

Movie S1. (Supplements Figure 3.2A) Actin cytoskeleton dynamics in the migrating PGC during RUN phase, wild type situation

Movie S2. (Supplements Figure 3.2B) Actin cytoskeleton dynamics in the migrating PGC during Tumbling phase, wild type situation

Movie S3. (Supplements Figure 3.2D) Actin cytoskeleton dynamics in the nondirectionally migrating PGC without functional SDF-1a/CXCR4b signalling.

Movie S4. (Supplements Figure 3.3A) Actin cytoskeleton dynamics in the PGC without functional Rac/Cdc42.

Movie S5. (Supplements Figure 3.3B) Effect of the CA Rac1 V12 mutant on the actin cytoskeleton dynamics in PGCs.

Movie S6. (Supplements Figure 3.3C) Effect of the CA Cdc42 12 mutant on the actin cytoskeleton dynamics in PGCs.

Movie S7. (Supplements Figure 3.4A) Effect of the loss of function for RhoA on the actin cytoskeleton dynamics the PGCs.

Movie S8. (Supplements Figure 3.4B) Effect of the DN ROK mutant on the actin cytoskeleton dynamics in PGCs.

Movie S9. (Supplements Figure 3.4C) Effect of CA RhoAV14 mutant on the actin cytoskeleton dynamics in PGCs

Movie S10. (Supplements Figure 3.4C') Effect of CA RhoAV14 mutant on the actin cytoskeleton dynamics in PGCs (a cell that shows that the actin pulling starts from the opposite pole of the cell)

Movie S11. (Supplements Figure 3.5, Left panel) Actin cytoskeleton dynamics in PGC that behaves like a typical cell in run phase expressing a mixture of Rac1 V12 and RhoA V14

Movie S12. (Supplements Figure 3.5, Right panel) Actin cytoskeleton dynamics in PGC that behaves like a typical cell in the tumbling phase expressing a mixture of Rac1V12 and RhoAV14

Movie S13. (Supplements Figure 3.5B) The inset from the front of the cell in Figure 4.5B shows MLCK behavior during bleb formation. 
Movie S14. (Supplements Figure 3.7B) PGC is seen to associate closely with the somatic neighbors. Actin is shown in red PGCs and the membrane is shown in green in PGCs and in somatic cells.

Movie S15. (Supplements Figure 3.6B, upper panel) Actin organization is disrupted in PGC in the embryo, where E-Cadherng was knocked down.

Movie S16. (Supplements Figure 3.6B, lower panel) The same as S16. Actin organization in PGC in the embryo, where E-Cadherng was knocked down. Actin is shown in red PGCs and membrane is shown in green in PGCs and in somatic cells.

Movie S22. (Supplements Figure 3.20) Actin dynamics in PGC expressing Stim1M mutant. Stim $1^{\mathrm{M}}$ mutant was visualized in red and actin was visualized with green.

\section{FRET MEASUREMENTS}

Movie S17. (Supplements Figure 3.14A) Rac activation in PGC during run phase Movie S18. (Supplements Figure 3.14C) Rac activation in PGC during tumbling phase

Movie S19. (Supplements Figure 3.15A) Rac activation in PGC migrating nondirectionally in the absence of CXCR4b

Movie S20. (Supplements Figure 3.17A) Cdc42 activation in PGC during run phase Movie S21. (Supplements Figure 3.19) RhoA activation in PGC during run phase 


\section{INTRODUCTION}

\subsection{Cell Migration - general overview}

Cell migration lies at the heart of a broad range of biological processes starting from embryogenesis, through adulthood, and in pathology. For example, migrating cells are found in the early embryonic development, when cells move extensively in order to form different germ layers during gastrulation [1]; in the immune system, where leukocytes migrate towards the area of injury during inflammatory response [2]; and throughout the wound healing process [3]. In the midst of metastasis, migrating cancer cells leave the region of the primary tumor to populate new sites in the organism [4]. Understanding the mechanisms governing cell migration in living organisms is thus vital to understanding many biological phenomena. Cell migration is a complex process that requires coordinated function of a large number of molecules operating together. The first focus of this introduction is aimed at actin cytoskeleton dynamics during cell migration and at Rho GTPases as key regulators of actin cytoskeleton remodeling. I will then discuss present models of cell migration and the underlying molecular mechanisms as well as introduce tools that are available to study cell migration processes in vivo.

\subsubsection{Actin Cytoskeleton}

In order to migrate, cells must acquire a polarized morphology, which is characterized by a defined front, where protrusions driving cellular locomotion occur and a back that retracts as the cell advances [5]. Actin cytoskeleton plays an indispensable role in generating forces required for cell migration [6-8]. Actin filaments are dynamic polymer structures that are assembled from a pool of actin monomers. Monomeric actin is a small protein of $43 \mathrm{kDa}$ possessing ATPase activity and is well conserved among species. Actin monomers are also called globular actin or G-actin and have the ability to self-assemble forming filamentous actin or F-actin. Actin filaments are polar structures with the fast growing end also referred to as the plus end or barbed end, and the minus end, known as the pointed end. Actin monomers can be incorporated into the existing filament at both ends with the preference given to the fast growing, barbed end. Upon actin monomer incorporation into a filament, ATP is hydrolyzed to ADP with a half time of $2 \mathrm{~s}$ [9]. ADP-bound actin has a higher tendency to dissociate from the barbed end of the filament (Figure 1.1). 


\section{QuickTime $^{\mathrm{TM}}$ and a \\ TIFF (Uncompressed) decompressor \\ are needed to see this picture.}

\section{Figure 1.1 Actin filament dynamics}

Actin filament polarity is shown. Actin monomers incorporate more readily at the fast-growing "plus" end. ATP cap protects plus end from rapid disassembly, while at the minus end the ADP-actin dissociates faster from the filament).

Actin filament formation is initiated by a process called nucleation that requires assembly of small oligomers consisting of three or four actin subunits. G-Actin posseses the tendency to self-assemble, but due to the instability of its oligomers, actin nucleation is the rate-limiting step during actin polymerization. However, once initiated, the actin filament grows rapidly [10]. Actin nucleation is regulated by a set of proteins called actin nucleators. Actin nucleators facilitate the initiation of new actin filament formation by stabilizing the initial nucleation process [11]. There are three major groups of actin nucleators: actin-related protein 2/3 (Arp2/3) complex, Spire and formins [12]. The Arp2/3 complex is thought to mimic an actin dimer or trimer and to function as a template for the initiation of a new actin filament that branches off the existing filament resulting in generation of Y-shaped networks (Figure 1.2b) [6]. The Arp2/3 complex is inefficient in forming actin filaments on its own and usually cooperates with nucleation promoting factors (NPFs) [13]. Among well-studied NPFs that cooperate with Arp2/3 complex are proteins that belong to the WASP (WiskottAldrich Syndrome Protein) family of scaffolding proteins [14]. Another group of actin nucleators, formins promotes nucleation of unbranched actin filaments through association with the barbed end of the existing filament (Figure 1.2d and [15]). Spire proteins comprise the third group of actin nucleators. Spire proteins were recently discovered in Drosophila and are conserved among metazoan species. Spire proteins are thought to nucleate actin polymerization by stabilizing actin tetramers that serve as a seed for the new actin filament formation (Figure 1.2c and [16]). 


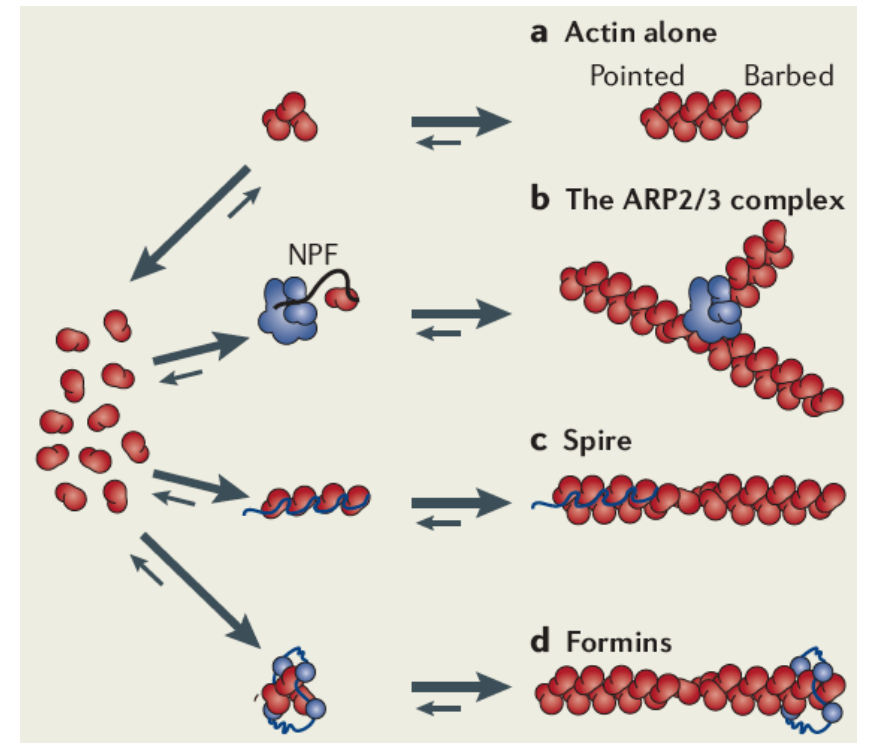

Figure 1.2 Actin nucleation

Three major classes of actin nucleators are outlined. (a) Actin oligomers that assemble spontaneously are unstable. (b) The Arp2/3 complex initiates formation of branched actin filaments. (c) Spire proteins result in the formation of the unbraunched actin filaments and might remain associated with the pointed end of the filament preventing its dissociation. (d) Formins promote the formation of unbranched actin filaments and associate with its barbed end [11].

\subsubsection{Actin organization within a cell}

Actin filaments organize into a number of various structures that contribute to the establishment of the cellular architecture. These actin-based structures result in the formation of cellular protrusions such as filopodia, lamellipodia, invadopodia and pseudopodia (Figure 1.3, [17]). Another important actin-based organization is exemplified in cortex formation where cortical actin is assembled underneath the plasma membrane forming a belt of $100-200 \mathrm{~nm}$ (Figure 1.3 [18]). The cortex contains myosin, and is often referred to as the acto-myosin cortex. The cortex plays several important functions. First, it is important for the rigidity of the cell. Second, owing to its ability to generate contractile forces that result in protrusive activity of the membrane, cortex plays an important role during cell migration [19]. Additionally, it provides a platform for the binding proteins such as ezrin that link the cortex to the plasma membrane $[14,20]$. 


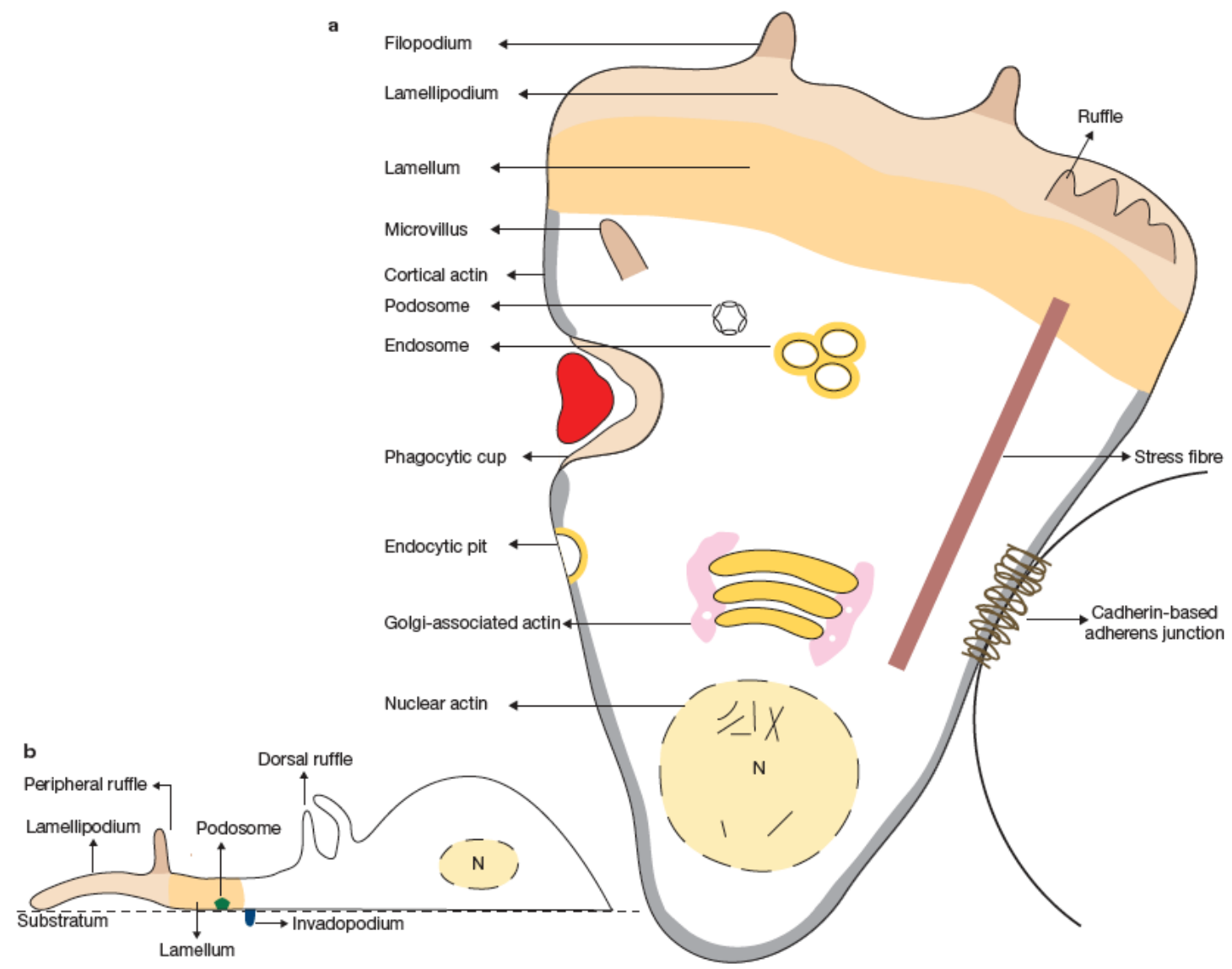

Figure 1.3 Various structures formed by actin in the metazoan cells

(a) A hypothetical cell migrating upwards. Filopodium, Lamellipodium and Lamellum are visible at the front of the migrating cell. (b) A side view of the cell showing the interaction of the cell with its substratum [17].

The higher order filamentous actin organization is dynamic and is controlled by a large group (exceeding hundred) of actin binding proteins (ABPs) [12][17]. ABPs interact directly with actin monomers or with the filamentous actin and modulate actin structure by nucleating, capping, bundling, severing, stabilizing and crosslinking [6] [12]. Bundling proteins, such as fascin, hold actin filaments together in filopodia or in stress fibers. Stress fibers form semi-sarcomere structures and are found in the nonmuscle cells. The association of Non-muscle myosin with stress fibers generates the tension that drives contraction in the cell body [28]. Severing proteins, such as cofilin, regulate actin turnover by severing existing actin filaments thus increasing the number of barbed ends available for polymerization.

Another essential role for actin cytoskeleton extends beyond the cell interior and allows cells to establish contacts with the environment such as extracellular matrix $(E C M)$ or neighboring cells. Cell-cell and cell-ECM adhesion plays an essential role in cell migration and tissues integrity. Cells connect to the ECM via 
focal adhesions that are composed of a large number of proteins performing signalling and scaffolding tasks (Figure 1.4, [21-23]). The link between the cell and the ECM in the focal adhesions is mediated by the integrins, the single passtransmembrane receptors. Integrins are linked to the actin cables, such as stress fibers at the cell interior usually with the help of adaptor proteins such as talin, vinculin, and paxillin (Figure 1.4A). Focal adhesions have functions in signalling between the cell and its environment and in cell migration [21, 23].

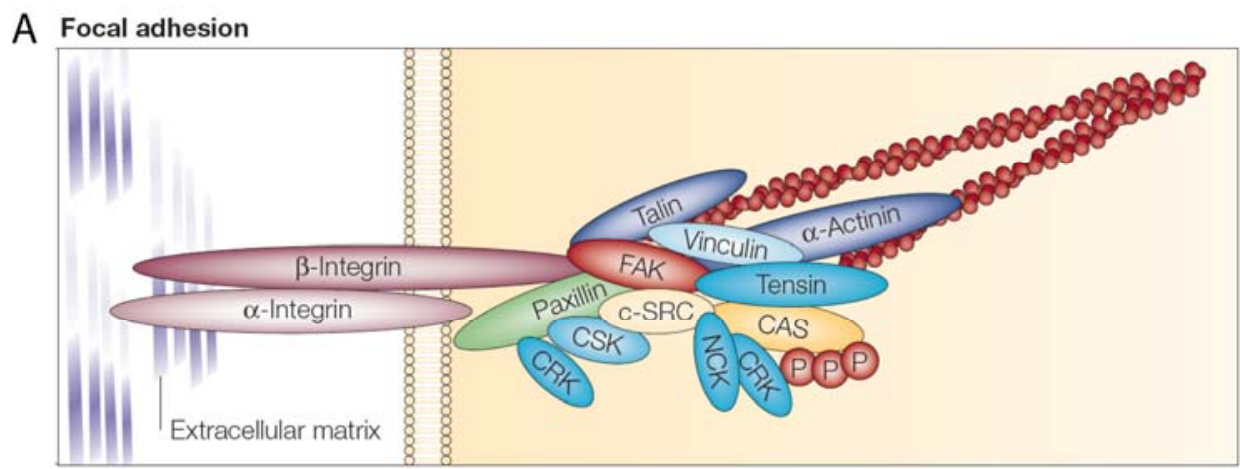

B Adherens junction

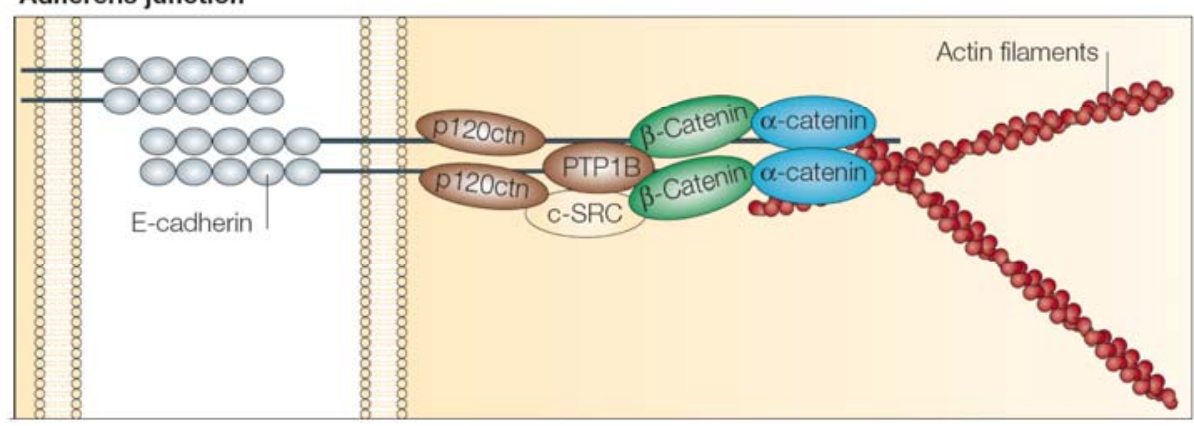

Figure 1.4 Actin role in cell adhesion

A. Focal adhesions facilitate cell-ECM adhesion through heterodimers of $\alpha$ - and $\beta$-integrin subunits. Proteins that form focal adhesion complex are depicted B. Adherent junctions facilitate cell-cell adhesion through homophilic interactions between E-cadherin molecules on two adjacent cells [22].

Cells connect with one another via adherent junctions, which are formed by cell adhesion molecules, such as E-cadherins (Figure 1.5, [24, 25]). E-cadherins belong to the cadherin family of single-pass transmembrane proteins and are known to mediate calcium-dependent, homophilic interactions. Both, integrin-mediated cellECM interactions and cadherin-mediated cell-cell interactions are known to generate traction forces that are required for cell migration [24, 26, 27].

Most of our knowledge regarding actin organization in living cells is derived from the studies performed in two-dimensional (2D) models for cell migration. However recent studies involving the placement of cells in a 3D environment that recapitulates physiological circumstances shed new light on actin organization in vivo (Figure.1.5, 
[8] [29]. For example, cells situated in a 3D environment lack stress fibers, do not form focal adhesions and have a more complex actin organization at the front during migration compared to the that in the lamellipodia formed by cells migrating in $2 \mathrm{D}$ (Figure1.5).

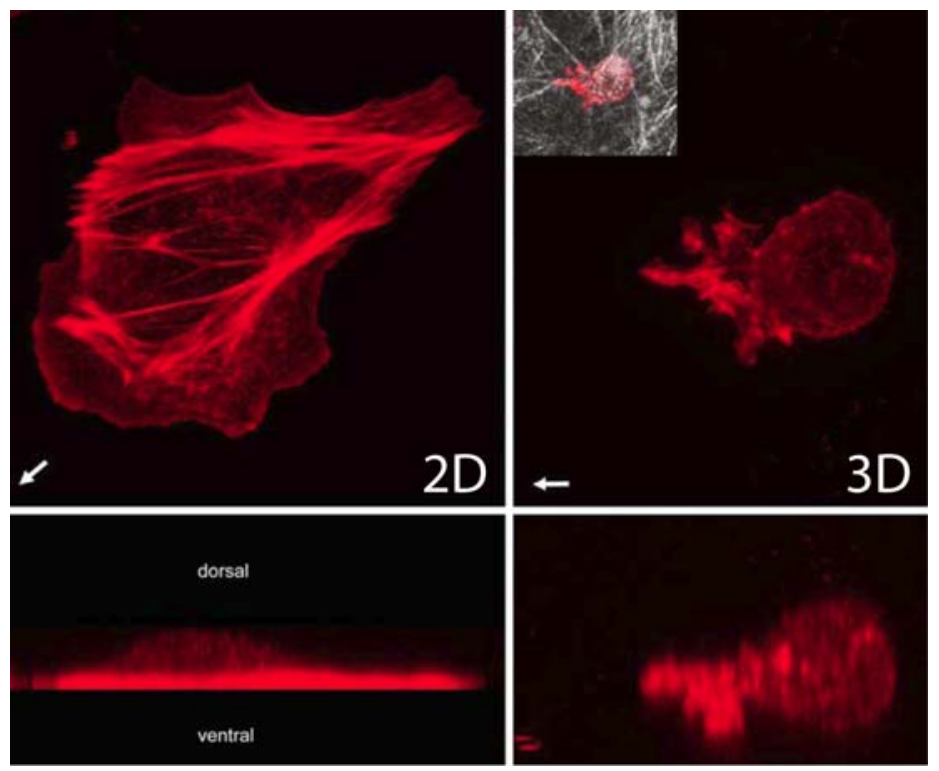

Figure 1.5 Differences in actin organization between the 2D and 3D

Left-hand panels show MTLn3 cell on 2D substrate: note broad lamellipodium, ventral stress fibres and flat cross-section of the cell. Right- hand panels show MTLn3 cell in 3D collagen gel (inset panel shows collagen fibres in white): note absence of stress fibres, more complex organisation of the F-actin at the front of the cell (no longer a planar lamellipodium) and rounded profile of the cell [8]

\subsubsection{Actin cytoskeleton is important for generating the forces required for cell migration}

There are several mechanisms of force generation by the actin cytoskeleton in living cells. Actin polymerization at the front of the cell generates the protrusive force that pushes the membrane forward. This is usually achieved by the function of Arp2/3 complex in cooperation with the proteins of the WASP family [6][14]. The other mechanism of force generation relies on acto-myosin contractions and leads to several functional outcomes. The myosin-dependent contraction of the stress fibers connected to the focal adhesions generates traction force, which is believed to be important for cell migration [27, 30]. The contraction of the acto-myosin cortex can result in the formation of non-apoptotic plasma membrane blebs, which recently have been implicated in cell migration [31][19]). Finally, acto-myosin contraction at the back of the cell is believed to result in the rear retraction by releasing the cellsubstratum attachments [5]. 


\subsubsection{Models for cell migration}

There are two major mechanisms proposed for cell migration. Cells migrating in a 2D environment, such as fibroblasts and macrophages, extend lamellipodia and filopodia in the direction of migration. These protrusions at the front are stabilized by adhering to the ECM or to the adjacent cells via integrins or cadherins. These adhesions serve as traction sites, and they are disassembled at the cell rear allowing it to detach [5, 32]. Acto-myosin contraction at the back of the cell is providing force necessary for rear retraction (Figure 1.6 and [27]). Cells migrating in 2D do so relatively slow due to their adhesion to the substratum moving at an estimated speed of about $0.4 \mu \mathrm{m} / \mathrm{min}$ [33].

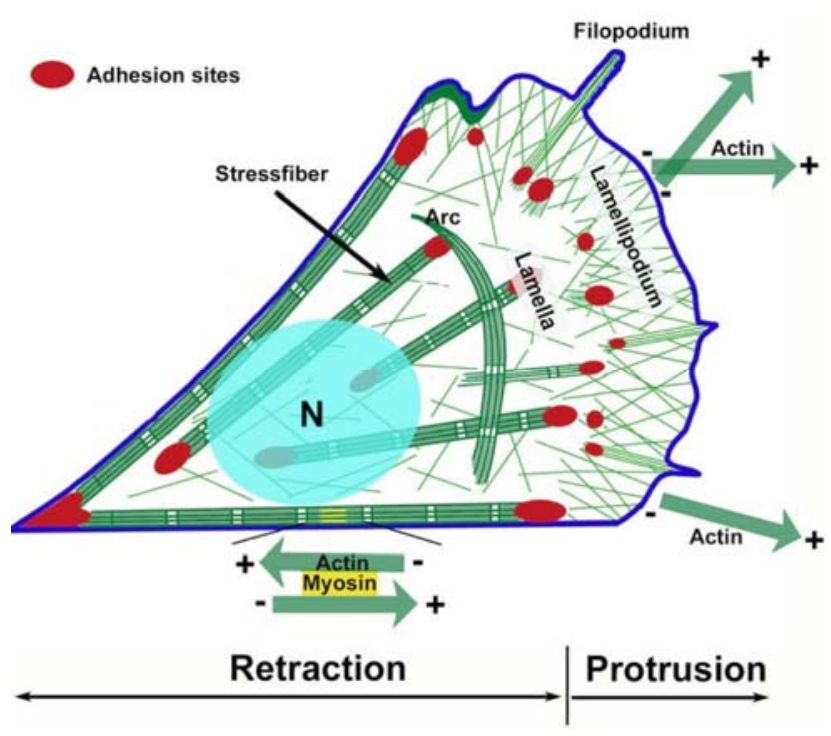

Figure 1.6 Actin cytoskeleton in migrating fibroblast.

Schematic representation of the actin cytoskeleton in a polarised fibroblast. The different organisational forms of actin filaments are depicted: diagonal actin filament meshwork in the lamellipodium, with associated radial bundles (filopodium); contractile bundles of actin (stress fiber) in the cell body and at the cell edge; and a loose actin network throughout the cell. Arcshaped bundles are sometimes observed that move inwards under the dorsal cell surface (arc). The diagram shows an idealized cell; in reality the actin arrays are interconnected in various combinations and geometries. Sites of adhesion of the cell with the substrate are also indicated, in red. The flat region behind the lamellipodium and in front of the nucleus $(\mathrm{N})$ has been termed the lamella. At the cell front, in lamellipodia and filopodia, actin filaments are all polarized in one direction, with their fast polymerizing ends forwards (for pushing); in the body of the cytoskeleton, actin filaments form bipolar assemblies with myosin to form contractile arrays (for retracting).

The other mechanism was proposed for cells migrating mainly in 3D environments, such as embryonic cells during germ layer formation, or cancer cells 
invading tissues during metastasis, and primordial germ cells in zebrafish. These cells crawl through their environment in amoeboid movement. Amoeboid moving cells migrate by generating bleb-like protrusions at their leading edge, which is believed to provide force required for cell locomotion [7, 29]. Blebs allow amoeboid moving cells like tumour cells to push their way through the connective tissue. In motile cells, blebs are formed only at the leading edge thus allowing the cell to move in one direction [7, 34].

The bleb is formed when localized acto-myosin contraction of the cortex leads to weakening of the membrane-cortex adhesion. Intracellular hydrostatic pressure results in the cytoplasmic flow into the area of local membrane detachment from the cortex and bleb expansion (Figure 1.7; [29][7]). Actio-myosin contraction necessary for bleb formation is governed by the action of myosin light chain kinase (MLCK) and/or RhoA activated kinase (ROCK) [35]. 


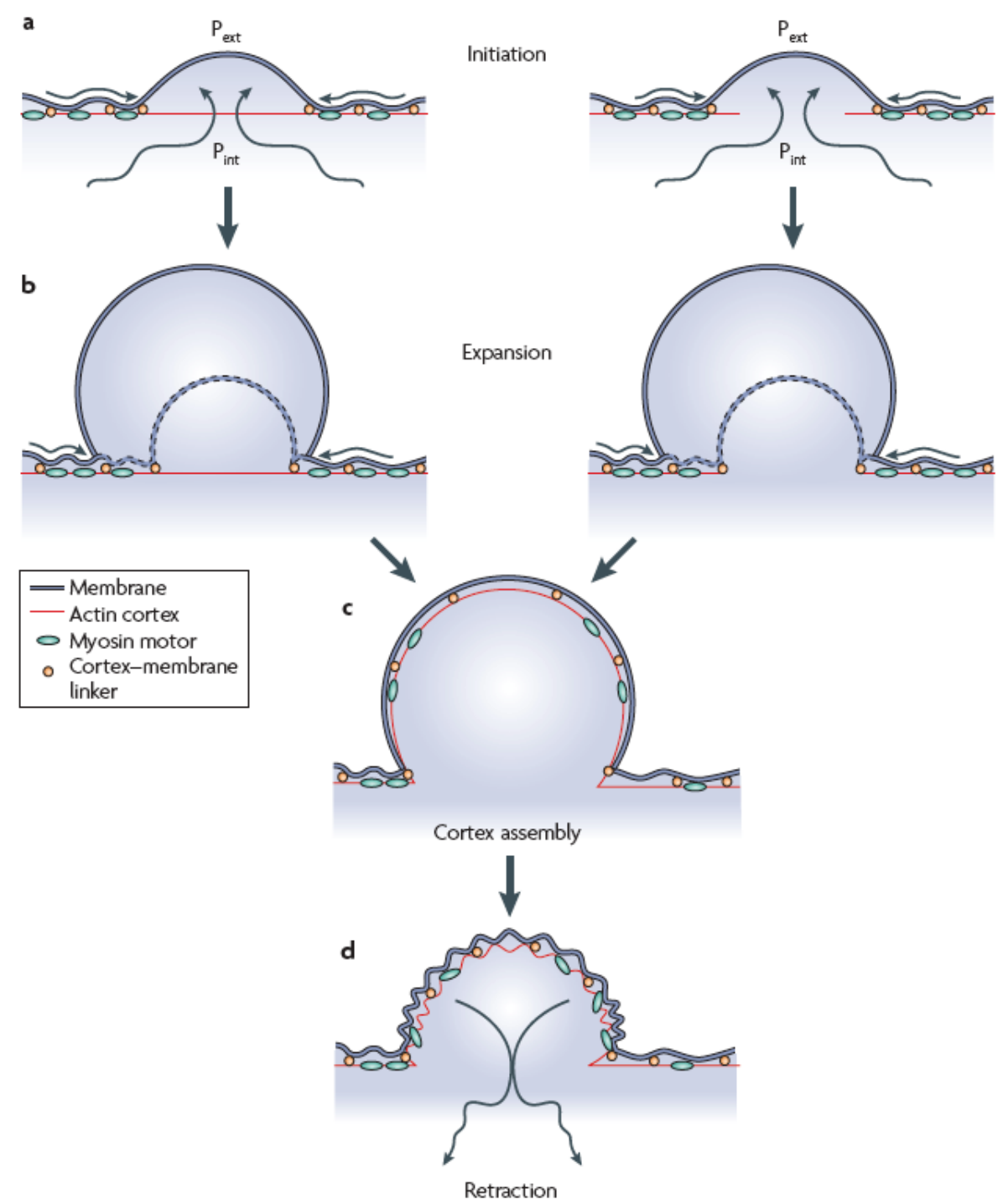

Figure 1.7 Life cycle of a bleb

Two possible mechanisms for the bleb formation are outlined. (a) Bleb initiation could result from a local detachment of the cortex from the membrane (left) or from a local rupture of the cortex (right). (b). Hytrostatic pressure in the cytoplasm (Pint) drives membrane expansion by pushing the cytopmasmic fluid through the remaining cortex (left) or through he hole (right). (c) New actin cortex forms underneath the plasma membrane. (d) Recruitment of myosin to the newly formed cortex is followed by bleb retraction [7]. 


\subsection{Rho GTPases are important regulators of actin cytoskeleton dynamics}

Rho GTPases control a vast number of processes in the cell including cell migration, cell cycle, intracellular trafficking, endocytosis, and gene transcription [36][37]. Rho GTPases belong to a Ras family of small $G$ proteins and are defined by the presence of a Rho-type GTPases-like domain. Most typical Rho proteins are small (190-250 residues) and are highly conserved among species [38]. The majority of Rho GTPases undergo C-terminal post-translational modification by isoprenoid lipids, which facilitates their subcellular localization and association with specific membranes. Rho GTPases are enzymes that hydrolyze GTP to GDP and are known to act as molecular switches cycling between the GTP-bound and GDP-bound forms. When bound to GTP, Rho GTPases are active and able to interact with their partners or effectors thus inducing various downstream signalling events [39]. The differences between the GDP- and GTP- bound structural forms of Rho GTPases are confined mainly to two segments that surround the nucleotide-binding pocket in GTPase, referred to as switch I and switch II (Figure1.8, [40]).

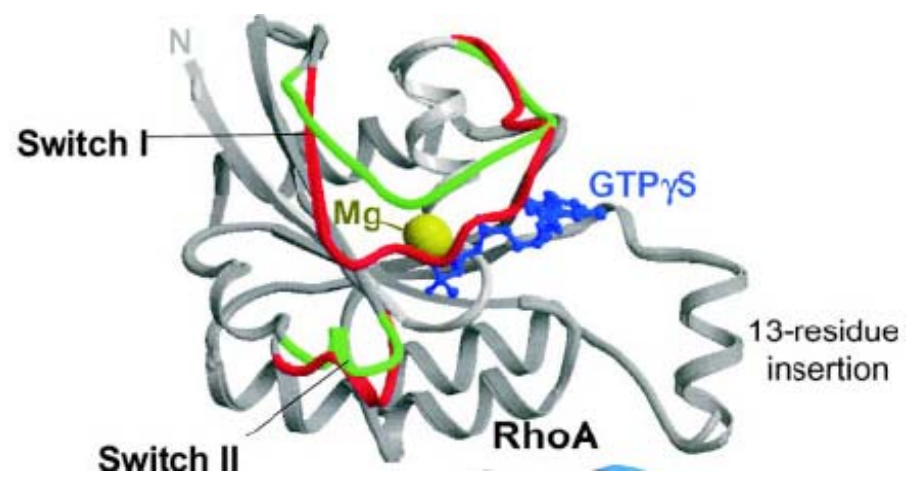

Figure 1.8 Structural basis for Rho GTPases signalling

RhoA in association with GTP. Switches I and II play major role in the nucleotide binding are shown. The conformations of switches I and II are stabilized by hydrogen bonds between the y-phosphate group and the main-chain amide groups of the invariant T37 (Switch I) and Gly 62 (switch II). $\mathrm{Mg}^{2+}$ ions are essential for guanine nucleotide binding as well as GTPase activity Adapted from [40]).

\subsubsection{Regulation of Rho GTPases}

Rho GTPases are tightly regulated by three groups of proteins (Figure 1.9). Guanine nucleotide exchange factors (GEFs) are responsible for Rho GTPase 
activation by promoting GDP to GTP exchange. GEFs comprise a large family of more than 70 distinct proteins and contain multiple domains that are essential for their function. A typical GEF contains dbl homology $(\mathrm{DH})$ and plextrin homology $(\mathrm{PH})$ domains linked in a tandem, which is called $\mathrm{DH}-\mathrm{PH}$ module and is considered to be the minimal structural unit required for GEF activity [40]. Conserved regions were identified in all $\mathrm{DH}$ domains and these are responsible for interacting with switches I and II of Rho GTPases. DH domain binding to the inactive Rho GTPases results in reshaping of their switch regions and disruption of the nucleotide binding. As a result GTP, which is present in excess concentrations in the cell, binds to the loop domains of the nucleotide-binding pocket of the Rho GTPase [40].

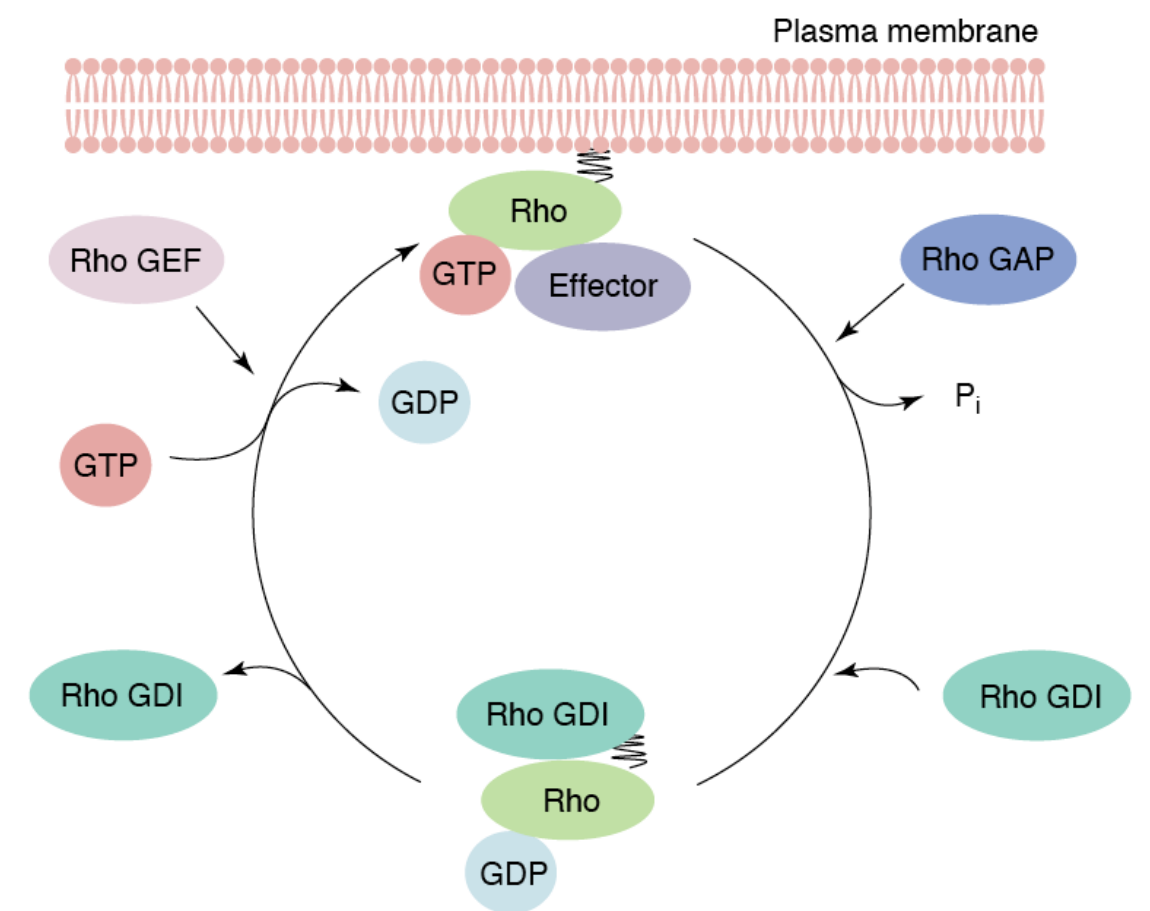

Figure 1.9 Regulation of Rho GTPases

Three groups of proteins control Rho GTPases activities in cells. RhoGEFs, RhoGAPs and RhoGDIs are outlined [41].

Some GEFs show high specificity towards Rho GTPases ensuring their controlled activation in time and space. For example, Tiam1 is a Rac specific GEF, whereas p115 Rho GEF is specific for RhoA. Other GEFs, such as Vav1, can be shared between different members of Rho GTPases [42]. GTPase activating proteins (GAPs), represent another group of regulators that enhance the rate of GTP hydrolysis by up to $10^{5}$ times [43]. Finally, GDP dissociation inhibitors (RhoGDIs), regulate Rho GTPase function by controlling the access of Rho GTP pases to GEFs, to effector targets and to membranes. RhoGDIs possess three distinct biochemical activities. First, they inhibit the dissociation of GDP, maintaining the GTPase in an 
inactive form. Second, they interact with the GTP-bound form of Rho GTPases and prevent their interaction with effectors. Third, RhoGDIs modulate the cycling of Rho GTPases between the cytosol and membranes. RhoGDIs keep Rho GTPases in the cytosol by interacting with the C-terminal domain of Rho GTPases that contains a membrane-targeting domain [44].

\subsubsection{Rho GTPases modulate actin cytoskeleton during cell migration}

The current knowledge about Rho GTPases function in cytoskeleton remodeling during cell migration is based on the experiments performed in a $2 \mathrm{D}$ in vitro studies. Rac, Cdc42 and RhoA are the best-studied Rho GTPases. Active Rac usually cooperates with nucleation promoting factors of the SCAR/WAVE family to stimulate the Arp2/3 complex. This results in the formation of branched actin networks contributing to lamellipodia and membrane ruffles [37]. Cdc42 activity drives formation of the unbranched actin structures, leading to the formation of long, thin, spike-like protrusions, which are called filopodia [37, 45]. Cdc42 is also believed to act on microtubules to regulate the position of the nucleus in the establishment of cell polarity [46]. RhoA is believed to act at the back of the migrating cell, controlling acto-myosin contraction during the tail retraction (Figure $1.10[45,47]$ ).

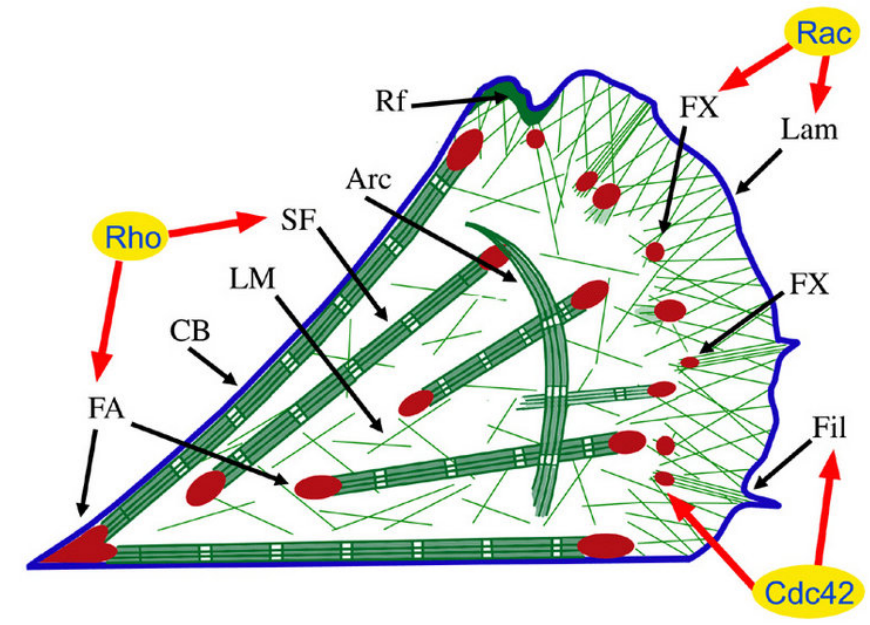

Figure 1.10 Rac, Rho and Cdc42 activation in migrating fibroblast

Rac activity induces lamellipodia and focal complexes; Cdc42 activity induces filopodia and focal complexes; Rho activity regulates stress fibre bundles and focal adhesions (modified from Kaverina et al., 2002). Abbreviations: FX, focal complexes; FA, focal adhesions, Lam, lamellipodium; Fil, Filopodium; SF, stress fibre bundle; CB, Concave bundle (essentially stress fibre bundle at non-motile cell edges); Arc, arc shaped bundles sometimes observed under the dorsal cell surface; LM, loose meshwork of actin filaments; Rf, ruffle 


\subsubsection{Tools used to study the function of Rho GTPases}

Dominant-negative (DN) and constitutively active (CA) mutants for Rho GTPases have been widely used as a tool to study their function. DN mutants for Rho GTPases contain the substitution mutation of Thr for Asn at position 17 causing the irreversible GDP binding in the mutant protein. DN Rho GTPase mutants potentially bind and titrate off the large number of GEFs thus often resulting in artefacts for example by blocking GEFs that might be shared with another Rho GTPase $[37,48]$. Indeed, in the null mutants for Rac, cellular phenotypes varied dramatically from those observed with the dominant-negative mutants [49]. CA mutants for Rho GTPases contain the substitution mutation of Gly for Val at position 12 , which renders the mutant protein unable to perform GTP to GDP hydrolysis. CA Rho GTPase mutants bind to their effectors resulting in constitutive signalling [50]. Thus, most of the information regarding Rho GTPases function in cells is derived from the experiments in which the mutant form for GTPase was overexpressed in cells and then the cellular phenotype was followed [45, 51][52]. Alternatively, the knockout technology is implemented to study the effect of null mutants for Rho GTPases on cellular behavior [50]. In another approach to study the activation state of Rho GTPases the GTP-bound form of the GTPase is usually pulled down from cell extract by the Rho binding domain (RBD) of its respective effector fused to GST. The presence of the active form of GTPase in the pull down is then detected on a Western blot [53]. However, these methods do not allow the subcellular visualization of protein activity in the real time.

\subsubsection{FRET-based biosensors for Rho GTPases}

During the past decade FRET-based biosensors have been developed to study protein activity in living cells. FRET - Foerster (Fluorescent) resonance energy transfer is a physical phenomenon of a distance-dependent non-radiative transfer of energy from a fluorophore (donor) in an excited state to another fluorophore (acceptor). FRET can occur between two fluorophores if they are within a 10-100 distance of each other, if the emission spectrum of a donor overlaps with the excitation spectra of an acceptor, and if their relative orientation to one another is appropriate [54]. Since FRET occurs within distances at which biological interactions between two proteins take place, FRET can be utilized to study biological processes such as protein-protein interactions and protein conformational changes with high 
precision in real time. There is a number of methods available that allow detecting the energy transfer from a donor to an acceptor in a fluorescence microscope [55].

A typical FRET biosensor for Rho GTPase consists of a single protein chain containing donor and acceptor molecules that are fused in a tandem with Rho GTPase and the RBD of its effector protein. The CFP (the cyan-emitting mutant of GFP) and the YFP (yellow-emitting mutant of GFP) are used in most of the FRET biosensors serving as a donor and an acceptor in the energy transfer (Figure 1.11). The prenylation site that follows the CFP molecule of the biosensor is usually consisting of the 20-22 most C-terminal amino acid region from the respective Rho GTPase. The C-terminus of Rho GTPases plays an important role in their subcellular localization and interaction with the regulatory partners. The prenylation site contains the CAAX box, where the lipid moiety is added thus, it is responsible for the subcellular localization of the biosensor, such as membrane targeting [56]. Often, in FRET biosensors the Ras C-terminal sequence is used to target the probe permanently to the membrane [57]. Since RhoGDIs bind simultaneously to the most C-terminal region of Rho GTPases and to the switches I and II, FRET biosensors described here are insensitive to RhoGDIs [58], that cannot interact with the biosensor due to sterical hindrance. Therefore such FRET biosensors allow monitoring the local balance between the GAP and GEF activities within the cell.

In the inactive, GDP-bound state of the biosensor, the donor and acceptor are distant from one another; therefore the energy transfer is low. Upon activation by GTP loading, Rho GTPase within the biosensor binds to the RBD of its effector resulting in a conformational change within the biosensor, bringing the fluorophores into close proximity, which can be detected in the increase in the energy transfer. Since in the FRET biosensor one molecule of donor corresponds to one molecule of acceptor, the typical readout in energy transfer is the emission ratio between the donor and acceptor upon donor excitation (Figure 1.11, [59, 60]. 


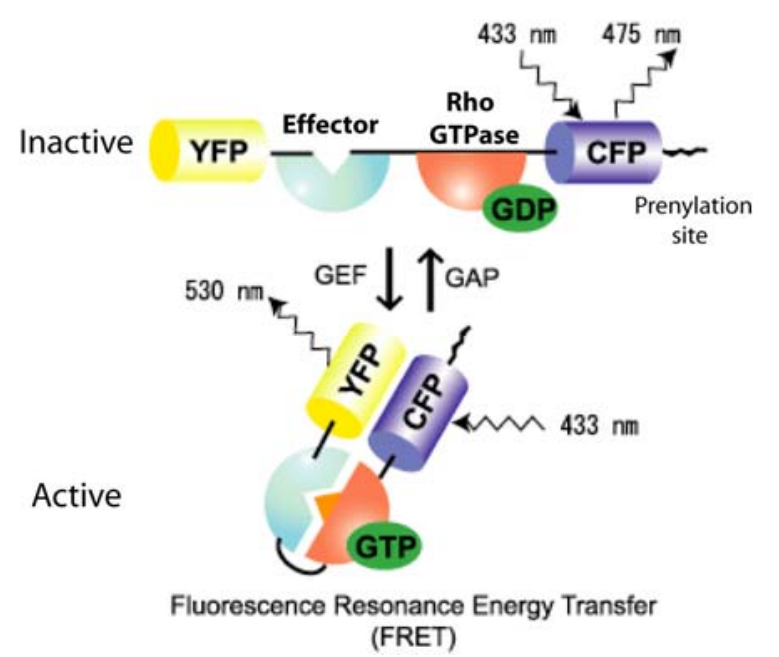

Figure 1.11 FRET biosensor for Rho GTPases

The design for the FRET biosensor is shown. When the Rho GTPase within the probe is loaded with GDP, there is no interaction with its downstream effector and the energy transfer is low. Upon GDP to GTP exchange the molecule will change its conformation resulting in increase in FRET signal. (Adapted from: Itoh et al, MCB 2002). 


\subsection{Primordial Germ Cell migration in zebrafish}

Primordial germ cells, from hereafter addressed as PGCs, will give rise to gametes in the adult organism. PGCs are set aside from the rest of the somatic tissues that form embryonic germ layers early in embryonic development. The important characteristic of the primordial germ cells is their pluripotency and their ability to remain in the non-differentiated state. Transcriptional repression of somatic differentiation and unique RNA regulation are responsible for maintaining the fate of PGCs. PGC development provides an attractive model system to study cell fate and pluripotency [61]. Another attractive aspect of PGCs biology is their migratory behavior during early developmental stages. In many organisms, including Drosophila, mouse, chick and Zebrafish, PGCs have to migrate from the region of their specification towards the location of the future gonad [62].

PGC migration in zebrafish serves as an excellent model system to study cell migration in vertebrates [63]. Due to the translucency of the embryo cell migration processes are easily accessible for non-invasive microscopy studies. PGCs in zebrafish are specified early in development at four distinct locations. At 3.5 hours post fertilization (hpf) PGCs acquire motile behavior and start migrating. During early stages PGCs migrate as individual cells (6-10 hpf), while during later stages of development, PGCs move in a cluster (Figure 1.12) [64].

a

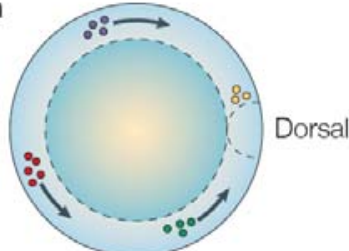

Dome, animal view

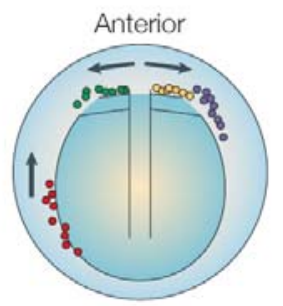

2 somites, dorsal view

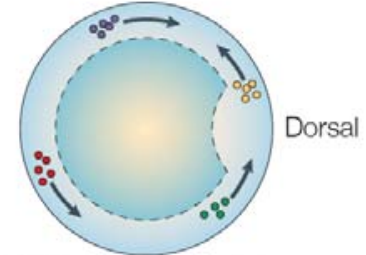

$60 \%$ epiboly, animal view

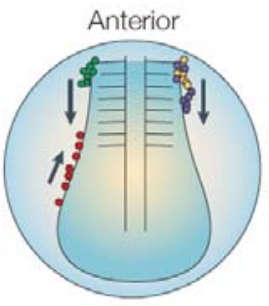

8 somites, dorsal view

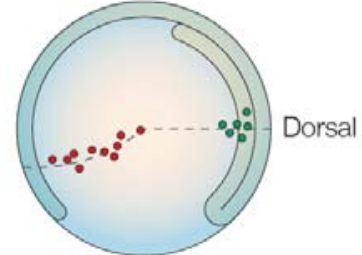

$80 \%$ epiboly, lateral view

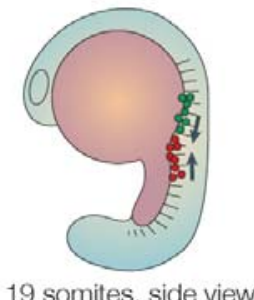

19 somites, side view

Figure 1.12 Steps in PGC migration during the first $24 \mathrm{~h}$ of development

A scheme depicting individual steps during PGCs migration during the first $24 \mathrm{hpf}$ [65].

It has been demonstrated that PGCs in zebrafish are guided towards their targets by the chemokine SDF-1a that is secreted by somatic tissues. SDF-1a binds to its receptor CXCR4b, which is expressed in PGCs and thereby forms a 
chemotactic gradient that guides PGCs to the gonad. When SDF-1a/CXCR4b signalling is abrogated, although PGCs are still migratory they are unable to reach their destination [66]. When migrating to the target, PGCs alternate between two phases: run and tumbling. During the run phase, PGCs appear polarized, often elongated and move persistently in one direction forming protrusions mainly at the leading edge. During the tumbling phase, PGCs lose their polarity and remain at one spot extending protrusions in all directions [67].

Recent findings from our lab have revealed that PGC migration is governed by bleb formation [34]. It has been demonstrated that in migrating PGCs a rise of Calcium is observed at the front of the cell. Calcium is believed to activate MLCK, which in turn phosphorylates myosin and leads to acto-myosin contraction and bleb formation [34]. In migrating PGCs, blebs are formed due to local increase in free Calcium levels downstream to SDF-1a/CXCR4b signalling and subsequent activation of MLCK, that phosphhorylates myosin light chain resulting in acto-myosin contraction. Such local increase in calcium is believed to define the leading edge in PGCs migrating towards chemoattractant (Figure 1.13 [34]).

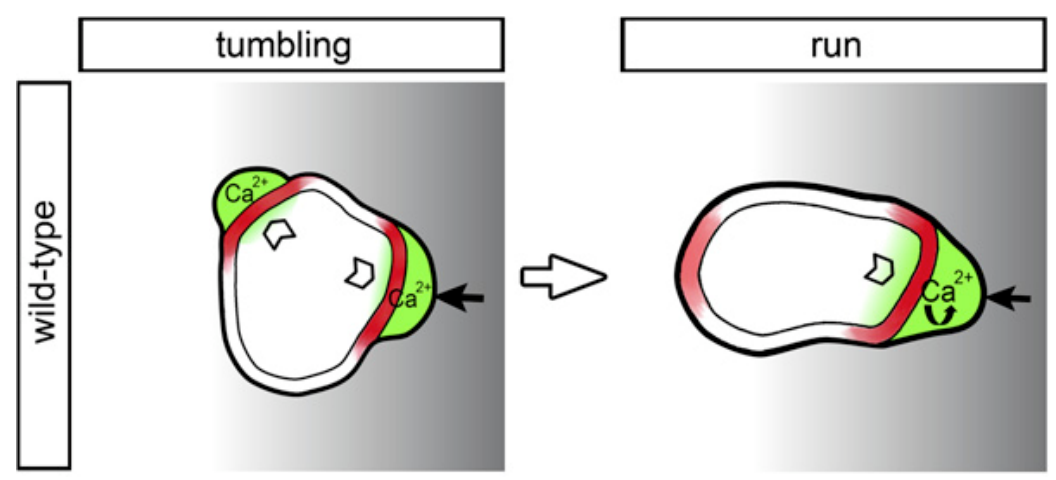

Figure 1.13 PGC migration is governed by blebbing

Mechanism of bleb formation during PGC migration. During tumbling phase stochastic local increase in calcium (green) at various regions at the cell periphery induces acto-myosin contraction at cortex resulting in bleb formation. The gradient of SDF-1a (grey) is responsible for enhanced signalling on one side of the cell (black arrows), thereby amplifying calcium influx that stabilizes a specific protrusion that becomes the leading edge (Adapted from [34]).

\subsection{The aim of the present work}

The aim of this study was to investigate the role of Rho GTPases in regulating actin cytoskeleton during primordial germ cell migration in Zebrafish.

In the course of this work I studied the role of Rho GTPases in controlling actin cytoskeleton dynamics during PGC migration. Mutants for Rac, Cdc42 and RhoA were utilized to study the role of respective Rho GTPases in actin cytoskeleton 
remodeling. To monitor the activation of Rho GTPases in real time, ratio imaging in PGCs using FRET biosensors for Rho GTPases was for the first time established. 


\section{MATERIALS AND METHODS}

\subsection{Materials}

\subsubsection{Zebrafish strains}

Zebrafish (Danio rerio) of the $A B$ or $A B \times T L$ genetic background were used for injections with mRNA or morpholino antisense oligonucleoties. For actin visualization, the kop-EGFP-actin-nos1-3'UTR transgenic fish line was used ([68] and ReichmanFried $\mathrm{M}$, unpublished).

\subsubsection{Bacteria for plasmid propagation}

E. Coli Top 10F' electro competent cells were purchased from Invitrogen and used to propagate plasmid DNA for mini and midi preparation.

\subsubsection{Kits}

\begin{tabular}{|l|l|l|}
\hline \multicolumn{1}{|c|}{ Name of the kit } & \multicolumn{1}{|c|}{ Purpose } & \multicolumn{1}{c|}{ Company } \\
\hline QIAfilter Plasmid Mini Kit & Plasmid mini preparation & Quiagen \\
\hline $\begin{array}{l}\text { QIAfilter Plasmid } \\
\text { Midi/Maxi Kit }\end{array}$ & Plasmid midi preparation & Quiagen \\
\hline $\begin{array}{l}\text { QIAquick Gel/PCR } \\
\text { extraction Kit }\end{array}$ & $\begin{array}{l}\text { DNA isolation from the gel, PCR } \\
\text { purification, Linearized DNA } \\
\text { purification }\end{array}$ & Quiagen \\
\hline Topo-TA Cloning Kit & $\begin{array}{l}\text { DNA fragments subcloning into } \\
\text { pTOPO shuttle vector }\end{array}$ & Invitrogen \\
\hline mMesage mMachine Kit & Capped mRNA in vitro synthesis & Ambion, UK \\
\hline OmniScript RT Kit & cDNA synthesis & Quiagen \\
\hline
\end{tabular}




\subsubsection{Chemicals}

All the chemicals unless indicated otherwise, were purchased from the following companies: Applichem, Calbiochem, Merck, Roth, and Sigma.

\subsubsection{Molecular biology reagents}

All the restriction enzymes were from New England Biolabs (NEB) or Fermentas. For the PCR amplification, high fidelity DNA polymerase Phusion ${ }^{\mathrm{TM}}$ was from FINNZYMES. T4 DNA polymerase, Antarctic phosphatase, T4 DNA ligase, T4 Polynucleotyde kinase and Tag DNA polymerase were from Invitrogen.

\subsubsection{List of the constructs used in this study}

Nos1 3' UTR is used to drive the protein expression in PGCs, $\beta$-Globin 3' UTR is used to drive the protein expression globally in the somatic cells and in PGCs

Original constructs from the lab:

\begin{tabular}{|l|l|l|c|}
\hline \multicolumn{1}{|c|}{ No. } & \multicolumn{1}{|c|}{ Name } & \multicolumn{1}{|c|}{ Description } & $\begin{array}{c}\text { Amount } \\
\text { injected } \\
\text { (pg) }\end{array}$ \\
\hline 481 & Rac1V12-nos1-3'UTR & Constitutively active Rac mutant & $\mathbf{1 5 0}$ \\
\hline 432 & ROCK C'-nos1-3'UTR & Dominant-negative ROK mutant & $\mathbf{1 5 0}$ \\
\hline A316 & $\begin{array}{l}\text { spDSRedMutStim1- } \\
\text { nos1-3'UTR }\end{array}$ & $\begin{array}{l}\text { Dominant Stim1 mutant mutated for } \\
\text { the EF hand }\end{array}$ & $\mathbf{4 5 0}$ \\
\hline 393 & $\begin{array}{l}\text { RN3 EGFP-F nos1- } \\
\text { 3'UTR }\end{array}$ & Membrane EGFP marker & $\mathbf{9 0}$ \\
\hline A709 & mCherry-F-Globin & Membrane mCherry marker & $\mathbf{9 0}$ \\
\hline A264 & $\begin{array}{l}\text { pSP64-MLCK-fip-nos1- } \\
\text { 3'UTR }\end{array}$ & $\begin{array}{l}\text { FRET MLCK biosensor, used to } \\
\text { visualize MLCK localization in PGCs }\end{array}$ & $\mathbf{3 0 0}$ \\
\hline
\end{tabular}

Constructs generated during the present work: 


\begin{tabular}{|c|c|c|c|}
\hline No. & Name & Description & $\begin{array}{l}\text { Amount } \\
\text { injected } \\
\text { (pg) }\end{array}$ \\
\hline 858 & $\begin{array}{l}\text { EGFP-Rac1-nos1- } \\
\text { 3'UTR }\end{array}$ & $\begin{array}{l}\text { EGFP fusion of zebrafish Rac1. Shows } \\
\text { localization of Rac1 in PGCs }\end{array}$ & 300 \\
\hline 859 & $\begin{array}{l}\text { EGFP-Cdc42-nos1- } \\
\text { 3'UTR }\end{array}$ & $\begin{array}{l}\text { EGFP fusion of zebrafish Cdc42. } \\
\text { Shows localization of Cdc42 in PGCs }\end{array}$ & 300 \\
\hline 860 & $\begin{array}{l}\text { EGFP- RhoA-nos1- } \\
\text { 3'UTR }\end{array}$ & $\begin{array}{l}\text { EGFP fusion of zebrafish RhoA Shows } \\
\text { localization of RhoA in PGCs }\end{array}$ & 300 \\
\hline e122 & $\begin{array}{l}\text { RhoA-V14-nos1- } \\
\text { 3'UTR }\end{array}$ & Constitutively active RhoA mutant & 150 \\
\hline A820 & $\begin{array}{l}\text { hCRIB-RasCT-nos1- } \\
\text { 3'UTR }\end{array}$ & Rac/Cdc42 loss of function mutant & 600 \\
\hline A994 & $\begin{array}{l}\text { hPKN-EYFP-RasCT- } \\
\text { nos1-3'UTR }\end{array}$ & $\begin{array}{l}\text { EYFP fusion of RhoA loss of function } \\
\text { mutant }\end{array}$ & 600 \\
\hline B006 & $\begin{array}{l}\text { Abp140-GFP-nos1- } \\
\text { 3'UTR }\end{array}$ & $\begin{array}{l}\text { EGFP fusion of the actin binding } \\
\text { fragment from yeast ABP140. Marker } \\
\text { for G- and F-Actin in PGCs }\end{array}$ & 150 \\
\hline B007 & $\begin{array}{l}\text { Abp140-Ruby-nos1- } \\
\text { 3'UTR }\end{array}$ & $\begin{array}{l}\text { Red fusion of the actin binding fragment } \\
\text { from yeast ABP140. Marker for G- and } \\
\text { F-Actin in PGCs }\end{array}$ & 150 \\
\hline 735 & SECFP-nos1-3'UTR & $\begin{array}{l}\text { Used as a negative control for FRET } \\
\text { measurements in combination with } \\
\text { Venus or Ypet }\end{array}$ & 150 \\
\hline 637 & Venus-nos1-3'UTR & $\begin{array}{l}\text { Used as a negative control for FRET } \\
\text { measurements in combination with } \\
\text { SECFP }\end{array}$ & 150 \\
\hline E82 & Ypet-nos1-3'UTR & $\begin{array}{l}\text { Used as a negative control for FRET } \\
\text { measurements in combination with } \\
\text { SECFP }\end{array}$ & 150 \\
\hline 636 & $\begin{array}{l}\text { SECFP-10aa-Venus- } \\
\text { nos1-3'UTR }\end{array}$ & $\begin{array}{l}\text { FRET tandem. SECFP and Venus } \\
\text { serve as donor and acceptor } \\
\text { respectively }\end{array}$ & 360 \\
\hline
\end{tabular}


Constructs generated during the present work (continued):

\begin{tabular}{|c|c|c|c|}
\hline No. & Name & Description & $\begin{array}{l}\text { Amount } \\
\text { injected } \\
\text { (pg) }\end{array}$ \\
\hline A615 & $\begin{array}{l}\text { SECFP-10aa-Ypet- } \\
\text { nos1-3'UTR }\end{array}$ & $\begin{array}{l}\text { FRET tandem. SECFP and Ypet serve } \\
\text { as donor and acceptor respectively }\end{array}$ & 360 \\
\hline 517 & $\begin{array}{l}\text { RacFRET-RacCT- } \\
\text { nos1-3'UTR }\end{array}$ & $\begin{array}{l}\text { Rac-FRET biosensor [57] SECFP and } \\
\text { Venus serve as donor and acceptor } \\
\text { respectively }\end{array}$ & 360 \\
\hline 519 & $\begin{array}{l}\text { RacFRET-RhoACT- } \\
\text { nos1-3'UTR }\end{array}$ & $\begin{array}{l}\text { Original RhoA-FRET biosensor [69]. } \\
\text { SECFP and Venus serve as donor and } \\
\text { acceptor respectively }\end{array}$ & 360 \\
\hline A563 & $\begin{array}{l}\text { RacFRET-noNLS- } \\
\text { RacCT-nos1-3'UTR }\end{array}$ & $\begin{array}{l}\text { Rac-FRET biosensor with the Rac C- } \\
\text { terminal domain without NLS as a } \\
\text { targeting sequence. SECFP and Venus } \\
\text { serve as donor and acceptor } \\
\text { respectively }\end{array}$ & 360 \\
\hline A247 & $\begin{array}{l}\text { RacFRET-noCT- } \\
\text { nos1-3'UTR }\end{array}$ & $\begin{array}{l}\text { Rac-FRET biosensor without C-terminal } \\
\text { targeting sequence. SECFP and Venus } \\
\text { serve as donor and acceptor } \\
\text { respectively }\end{array}$ & 360 \\
\hline 801 & $\begin{array}{l}\text { RacV12FRET-noCT- } \\
\text { nos1-3'UTR }\end{array}$ & $\begin{array}{l}\text { Positive control for the Rac-FRET } \\
\text { biosensor without C-terminal targeting } \\
\text { sequence. SECFP and Venus serve as } \\
\text { donor and acceptor respectively }\end{array}$ & 360 \\
\hline A422 & $\begin{array}{l}\text { RacFRET-Ypet-noCT- } \\
\text { nos1-3'UTR }\end{array}$ & $\begin{array}{l}\text { Rac-FRET biosensor without C-terminal } \\
\text { targeting sequence. SECFP and Ypet } \\
\text { serve as donor and acceptor } \\
\text { respectively }\end{array}$ & 360 \\
\hline A569 & $\begin{array}{l}\text { RacV12FRET-Ypet- } \\
\text { noCT-nos1-3'UTR }\end{array}$ & $\begin{array}{l}\text { Positive control for Rac-FRET } \\
\text { biosensor without C-terminal targeting } \\
\text { sequence. SECFP and Ypet serve as } \\
\text { donor and acceptor respectively }\end{array}$ & 360 \\
\hline
\end{tabular}


Constructs generated during the present work (continued):

\begin{tabular}{|c|c|c|c|}
\hline No. & Name & Description & $\begin{array}{l}\text { Amount } \\
\text { injected } \\
(p g)\end{array}$ \\
\hline A777 & $\begin{array}{l}\text { Cdc42FRET- } \\
\text { Cdc42CTnos1-3'UTR }\end{array}$ & $\begin{array}{l}\text { Cdc42-FRET biosensor with Cdc42 C- } \\
\text { terminal targeting sequence. SECFP } \\
\text { and Ypet serve as donor and acceptor } \\
\text { respectively }\end{array}$ & 360 \\
\hline A676 & $\begin{array}{l}\text { RhoAFRETnoCT- } \\
\text { nos1-3'UTR }\end{array}$ & $\begin{array}{l}\text { RhoA-FRET biosensor without C- } \\
\text { terminal targeting sequence. SECFP } \\
\text { and Ypet serve as donor and acceptor } \\
\text { respectively }\end{array}$ & 360 \\
\hline A021 & $\begin{array}{l}\text { DH-PH(Tiam1)nos1- } \\
\text { 3'UTR }\end{array}$ & $\mathrm{DH}-\mathrm{PH}$ domain of the Tiam1 & 600 \\
\hline A823 & $\begin{array}{l}\text { Rac1V12C40-nos1- } \\
\text { 3'UTR }\end{array}$ & $\begin{array}{l}\text { Double mutant for CA Rac1 that lacks } \\
\text { the ability to interact with PAK }\end{array}$ & 150 \\
\hline A832 & Rac1C40-nos1-3'UTR & $\begin{array}{l}\text { Rac1 mutant that lacks the ability to } \\
\text { interact with PAK }\end{array}$ & 150 \\
\hline A833 & $\begin{array}{l}\text { Rac1V12L37-nos1- } \\
\text { 3'UTR }\end{array}$ & $\begin{array}{l}\text { Double mutant for CA Rac1 that lacks } \\
\text { the ability to interact with POR } 1\end{array}$ & 150 \\
\hline A851 & Rac1L37-nos1-3'UTR & $\begin{array}{l}\text { Rac1 mutant that lacks the ability to } \\
\text { interact with POR1 }\end{array}$ & 150 \\
\hline A857 & $\begin{array}{l}\text { Rac1V12E186-nos1- } \\
\text { 3'UTR }\end{array}$ & $\begin{array}{l}\text { Double mutant for CA Rac1 that is } \\
\text { defective in inducing PI-5K }\end{array}$ & 150 \\
\hline A877 & $\begin{array}{l}\text { Rac1E186-nos1- } \\
\text { 3'UTR }\end{array}$ & $\begin{array}{l}\text { Rac1 mutant that is defective in } \\
\text { inducing } \mathrm{PI}-5 \mathrm{~K}\end{array}$ & 150 \\
\hline A900 & $\begin{array}{l}\text { Rac1V12L37C40- } \\
\text { nos1-3'UTR }\end{array}$ & $\begin{array}{l}\text { Triple mutant for CA Rac1 that lacks } \\
\text { the ability to interact with POR } 1 \text { and } \\
\text { PAK }\end{array}$ & 150 \\
\hline
\end{tabular}




\subsubsection{List of the oligos used in this work}

\begin{tabular}{|c|c|c|}
\hline No. & Sequence & Purpose \\
\hline B190 & GAAGATCTATGCAGGCCATAAAGTGTGT & Rac1 amplification, Fw \\
\hline B191 & CCGCTCGAGATATCTCACAGAAGGAGACA & Rac1 amplification, rev \\
\hline B192 & GAAGATCTATGCAGACGATCAAGTGCGT & Cdc42 amplification, Fw \\
\hline A858 & AATCTCGAGTCATAGCAGCACACAT & Cdc42 amplification, Rev \\
\hline A870 & AATCTCGAGGGCATGGCAGCAATTCGCAA & RhoA amplification, Fw \\
\hline A871 & AATCTCGAGTCACAGCAGACAGCATTTGTT & RhoA amplification, Rev \\
\hline A981 & GTGGGAGACGTAGCTGTAGGT & Rac G12V substitution, Fw \\
\hline A982 & ACCTACAGCTACGTCTCCCAC & $\begin{array}{l}\text { Rac G12V substitution, } \\
\text { Rev }\end{array}$ \\
\hline A985 & GTGGGCGATGTTGCTGTTGGT & $\begin{array}{l}\text { Cdc42 G12V substitution, } \\
\text { Fw }\end{array}$ \\
\hline A986 & ACCAACAGCAACATCGCCCAC & $\begin{array}{l}\text { Cdc42 G12V substitution, } \\
\text { Rev }\end{array}$ \\
\hline B700 & CAGAGAAAATGCCTGCTGTTGTAA & $\begin{array}{l}\text { RacCT-noNLS } \\
\text { R185G/K186Q Fw }\end{array}$ \\
\hline B701 & CCCCTTCTCCACGGGAGGCGGGCA & $\begin{array}{l}\text { RacCT-noNLS } \\
\text { R185G/K186Q Rev }\end{array}$ \\
\hline B304 & $\begin{array}{l}\text { TCGAGTCCGGAGGTGGAACCGGTGGTGGA } \\
\text { CGC }\end{array}$ & $\begin{array}{l}\text { For linker in the FRET } \\
\text { tandem, Fw }\end{array}$ \\
\hline B305 & $\begin{array}{l}\text { GGCCGCGTCCACCACCGGTTCCACCTCCG } \\
\text { GAC }\end{array}$ & $\begin{array}{l}\text { For linker in the FRET } \\
\text { tandem, Rev }\end{array}$ \\
\hline B862 & TAGCATGCGGGAAAACATGT & $\begin{array}{l}\text { RhoA G14V substitution, } \\
\text { Fw }\end{array}$ \\
\hline B863 & CATCTCCTACAATCACCAGC & $\begin{array}{l}\text { RhoA G14V substitution, } \\
\text { Rev }\end{array}$ \\
\hline $\mathrm{C047}$ & ATATGCATACCATGAAACTCCGCAAAGTCA & $\begin{array}{l}\text { DH-PH module of Tiam1 } \\
\text { amplification, Fw }\end{array}$ \\
\hline $\mathrm{C} 048$ & TACTCGAGTCAACGCCGCTGTTTATCT & $\begin{array}{l}\text { DH-PH module of Tiam1 } \\
\text { amplification, Rev }\end{array}$ \\
\hline
\end{tabular}

List of the oligos used in this work (continued): 


\begin{tabular}{|c|c|c|}
\hline No. & Sequence & Purpose \\
\hline C079 & TTCTGCAAATGTGATGGTCGAT & Rac1 Y40, Fw \\
\hline $\mathrm{C080}$ & CAATTATCAAACACAGTGGGAA & $\begin{array}{l}\text { Rac1 C40, Rev } \\
\text { Contains Y40C } \\
\text { substitution in the coding } \\
\text { region of Rac1 }\end{array}$ \\
\hline C094 & GGATAATTATTCTGCAAATGTGAT & $\begin{array}{l}\text { Rac1 L37, Fw } \\
\text { Contains F37L substitution } \\
\text { in the coding region of } \\
\text { Rac1 }\end{array}$ \\
\hline C095 & AACACAGTGGGAATGTATTCCCCA & Rac1 F37, Rev \\
\hline C115 & AAAGATGTCTCCTTCTGTGAGA & $\begin{array}{l}\text { Rac1 E186, Fw } \\
\text { Contains the R186E } \\
\text { substitution in the coding } \\
\text { region of Rac1 }\end{array}$ \\
\hline C116 & СССТССТССТСTTCACCGGAGG & Rac1 R186, Rev \\
\hline
\end{tabular}

\subsubsection{Morpholino antisense oligonucleotides used in this study}

\begin{tabular}{|l|l|c|}
\hline $\begin{array}{l}\text { Targeting } \\
\text { specificity }\end{array}$ & Sequence & $\begin{array}{l}\text { Working } \\
\text { concentration }\end{array}$ \\
\hline Control & 5'-CCTCTTACCTCAGTTACAATTTATA-3' & $\begin{array}{c}\text { According to the } \\
\text { experiment }\end{array}$ \\
\hline CXCR4b & 5'-AAATGATGCTATCGTAAAATTCCAT-3 & $200 \mu \mathrm{M}$ \\
\hline SDF-1a & 5'-TTGAGATCCATGTTTGCAGTGTGAA-3 & $200 \mu \mathrm{M}$ \\
\hline E-Cadherin & 5'-ATCCCACAGTTGTTACACAAGCCAT-3 & $100 \mu \mathrm{M}$ \\
\hline
\end{tabular}




\subsubsection{Technical Equipment}

HARDWARE

\begin{tabular}{|c|c|c|}
\hline Device & Purpose & Specifications \\
\hline Needle puller & Preparing glass needles for injection & $\begin{array}{l}\text { PN-30 Microelectrode } \\
\text { puller, Science } \\
\text { products }\end{array}$ \\
\hline Injector & $\begin{array}{l}\text { Used to fix the needle and provide } \\
\text { pressure during injection into the } \\
\text { embryo }\end{array}$ & $\begin{array}{l}\text { PV830 Pneumatic } \\
\text { PicoPump, World } \\
\text { precision instruments }\end{array}$ \\
\hline Cameras & $\begin{array}{l}\text { Recording the intensity information } \\
\text { during imaging }\end{array}$ & $\begin{array}{l}\text { RT slider spot, } \\
\text { Diagnostic instruments }\end{array}$ \\
\hline Zeiss Axioplan2, & Fluorescence and bright field imaging & Zeiss Axioplan2, Zeiss \\
\hline $\begin{array}{l}\text { Confocal } \\
\text { microscope }\end{array}$ & Confocal microscopy & TCS SL2, Leica \\
\hline Dual View & $\begin{array}{l}\text { Separates two emission signals during } \\
\text { ratio imaging }\end{array}$ & $\begin{array}{l}\text { Photometric Germany, } \\
\text { Visitron }\end{array}$ \\
\hline PCR machines & PCR amplification & $\begin{array}{l}\text { Master Cycler } \\
\text { Personal, Eppendorf; } \\
\text { PCR machine My } \\
\text { Cycler, Biorad }\end{array}$ \\
\hline Cooling block & $\begin{array}{l}\text { Block for temperature control for } \\
\text { various purposes }\end{array}$ & $\begin{array}{l}\text { Thermomixer comfort, } \\
\text { Eppendorf }\end{array}$ \\
\hline Gel chambers & $\begin{array}{l}\text { DNA fragment separation during } \\
\text { electrophoresis }\end{array}$ & $\begin{array}{l}\text { Gel chambers } \\
\text { ComPhor L Mini, Midi }\end{array}$ \\
\hline Power Supply & $\begin{array}{l}\text { Generates Electric field during } \\
\text { electrophoresis }\end{array}$ & $\begin{array}{l}\text { E-C Apparatus } \\
\text { Corporation }\end{array}$ \\
\hline $\begin{array}{l}\text { Electroporation } \\
\text { MicroPulser }\end{array}$ & $\begin{array}{l}\text { Bacterial electroporation for plasmid } \\
\text { transformation }\end{array}$ & BioRad \\
\hline Spectrophotometer & Measuring OD & $\begin{array}{l}\text { Eppendorf 6131, } \\
\text { Eppendorf }\end{array}$ \\
\hline Centrifuges & $\begin{array}{l}\text { Spinning down material for various } \\
\text { purposes }\end{array}$ & $\begin{array}{l}\text { Eppendorf 5415D, } \\
\text { Eppendorf; Centrifuge } \\
\text { Biofuge primo R, } \\
\text { Heraeus }\end{array}$ \\
\hline PH-Meter MP220 & Measuring $\mathrm{PH}$ in the solutions & Mettler Toledo \\
\hline
\end{tabular}


SOFTWARE

\begin{tabular}{|l|l|l|}
\hline \multicolumn{1}{|c|}{ Program } & \multicolumn{1}{|c|}{ Purpose } & \multicolumn{1}{c|}{ Specifications } \\
\hline Vector NTI & $\begin{array}{l}\text { Sequence analysis tool for all Molecular } \\
\text { Biology purposes }\end{array}$ & Invitrogen \\
\hline Sequencer & Tool for sequence alignment & $\begin{array}{l}\text { Gene codes } \\
\text { corporation }\end{array}$ \\
\hline ImageJ & Image processing and analysis & http://rsbweb.nih.gov/ij/ \\
\hline $\begin{array}{l}\text { Adobe } \\
\text { Illustrator CS2/3 }\end{array}$ & $\begin{array}{l}\text { Graphics for various purposes, such as } \\
\text { final figure maker and scheme drawing }\end{array}$ & Adobe Systems \\
\hline Word & Writing documents & Microsoft \\
\hline Excell & $\begin{array}{l}\text { Data documentation, Statistical analysis, } \\
\text { graphs generation }\end{array}$ & Microsoft \\
\hline Endnote & Citation manager & Thomson \\
\hline Paper & Pdf files organizer & Mekentosj.com \\
\hline Filemaker & Data organizer for various purposes & FileMaker Inc. \\
\hline
\end{tabular}




\subsection{Methods}

\section{FISH WORK}

\subsubsection{Fish maintenance and embryo staging}

Fish maintenance and embryo collection was carried out as described [70] [71]. For injection and subsequent incubation embryos were maintained in the 0.3 Danieau's solution.

\subsubsection{Transgenic fish generation}

The kop-EGFP-actin-nos1-3'UTR transgenic fish line was created with the kopEGFP-actin-nos1-3'UTR cloned into the pTol2000 vector (Tol2 transposase vector) [72]. The purified plasmid DNA was coinjected with sense RNA encoding for the Tol2 transposase into one-cell stage fish embryos (Reichman-Fried $\mathrm{M}$, unpublished). The transgene directs EGFP-actin expression in PGCs.

\subsubsection{Targeting protein expression in PGCs}

To target specific protein expression in PGCs, the coding sequence for the respective gene or a fusion construct was fused to the 3' UTR of nanos-1 (nos1) gene. 3' nanos UTR contains regulatory sequence that stabilize the mRNA specifically in PGC, while degrading in the somatic cells as well as ensuring efficient protein translation from the transcript in PGCs [73].

\subsubsection{Knocking down protein expression in PGCs}

To inhibit protein translation in the embryo, morpholino antisense oligonucleotides were injected into the one-cell stage embryos (Gene Tools, http://www.gene-tools.com/). 


\subsubsection{Solutions and materials for the injection}

\section{0x Danieau's pH 7.6 Stock solution}

$1.74 \mathrm{M} \mathrm{NaCl}$

$21 \mathrm{mM} \mathrm{KCl}$

$12 \mathrm{mM} \mathrm{MgSO}_{4}\left[7 \mathrm{H}_{2} \mathrm{O}\right]$

$18 \mathrm{mM} \mathrm{Ca}\left(\mathrm{NO}_{3}\right) 2\left[4 \mathrm{H}_{2} \mathrm{O}\right]$

150 mM HEPES

$\mathrm{pH}$ is adjusted with $\mathrm{NaOH} 5 \mathrm{mM}$

The working concentration for Danieau's: 0.3X

\section{Hepes 500 mM, pH 7.4 Stock Solution}

Working concentration for RNA/DNA/Morpholino injections: 10mM HEPES, pH 7.4

\section{Agarose ramps for embryo immobilization during injection or during imaging}

Agarose ramps were prepared by melting $1.5 \%$ agarose in 0.3 Danieau's buffer. The slots in the agarose were made with the help of plastic grids that were positioned on top of the liquid agarose and letting the agarose to solidify. $10 \mathrm{~cm}$ Petri dishes were used for the injection ramps and $6 \mathrm{~cm}$ Petri dishes were used for making imaging ramps. Agarose ramps can be stored at $4^{\circ}$ up to one week.

\section{Injection needles}

Glass capillaries were pulled with the needle puller and the tips of the needles were cut open with the sharp scalpel under the stereomicroscope.

\section{Injection procedure}

The RNA with the required concentration for the injection (typical range was $10 \mathrm{ng} / \mu \mathrm{l}-300 \mathrm{ng} / \mu \mathrm{l}$ ) was kept on ice during the injection procedure. For the morpholino injection, the stock morpholino solution was preheated at $65^{\circ} \mathrm{C}$ for 10 min prior the injection. After heating up, the morpholino solution was centrifuged at maximum speed for 5-10 min and then diluted with HEPES or RNase-free water to the desired concentration or mixed with the mRNA to be injected. Morpholino and mRNA mixes were injected directly into the yolk according to the Figure 2.1. For generationg the transgene, the DNA was injected directly into the cell. After the injection, embryos were kept at $28^{\circ} \mathrm{C}$ in the Danieau's buffer. Prior microscopy, the chorion surrounding 
the embryo was removed with the forceps and embryos were oriented with the help of a hair within the clots of the imaging agarose ramp.

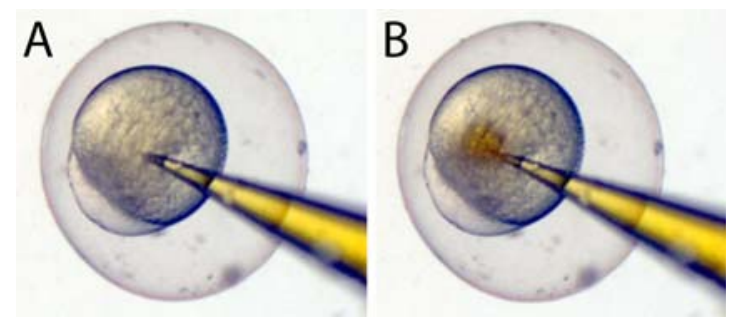

Figure 2.1 Injection into one-cell stage zebrafish embryos

A. The needle with injection material is introduced into the yolk. B. The appropriate amount of the injection material is seen in brown/red being released during the injection. 


\section{MOLECULAR BIOLOGY}

\subsubsection{RNA extraction from zebrafish embryos:}

About 50 embryos were grown to a certain stage of development, transferred into $200 \mu \mathrm{l}$ Trizol reagent (Gibco BRL-Life Technologies) and homogenized with a glassteflon pistil. Following homogenization, $800 \mu \mathrm{l}$ Trizol reagent were added then the cell suspension was centrifuged $\left(12 \mathrm{~min}, 12000 \mathrm{rpm}, 4^{\circ} \mathrm{C}\right.$ ) to further process the liquid phase and to discard the pellet. Next, the liquid phase was incubated at RT for about 5 min to dissociate associated proteins on the RNA. $200 \mu \mathrm{l}$ of chloroform was added, shacked and incubated for about 2 min at RT followed by spinning (15 min, $12000 \mathrm{rpm}, 4^{\circ} \mathrm{C}$ ). The upper (aqueous phase including the RNA) was transferred into a new Eppendorf-tube and $500 \mu \mathrm{l}$ iso-propyl alcohol was added before shacking and spinning (10 $\mathrm{min}, 12000 \mathrm{rpm}, 4^{\circ} \mathrm{C}$ ). The supernatant was discarded and the residual RNA pellet was washed with $1 \mathrm{ml} 75 \%$ ethanol/water before spinning again (5 min, $\left.7000 \mathrm{rpm}, 4^{\circ} \mathrm{C}\right)$. The ethanol was removed, the pellet got air-dried and finally the RNA was dissolved in $20 \mu$ l HEPES solution (10mM, pH 7.4).

\subsection{7. cDNA synthesis protocol:}

1. Thaw RNA on ice.

2. Thaw the primer stocks, 10x Buffer RT, dNTP Mix, and RNase-free water at room temperature

3. Prepare a fresh master mix on ice as follows:

- 10x RT buffer $2 \mu l$

- dNTP mix (5mM each dNTP) $2 \mu \mathrm{l}$

- Oligo-dT primer (10mM0 $2 \mu l$

- RNase inhibitor (10 units/ $\mu$ l) $1 \mu l$

- Omniscript reverse transcriptase $1 \mu l$

- Template RNA + RNase free water up to $20 \mu \mathrm{l}$

4. Add template RNA to the individual tubes containing the master mix.

5. Incubate for $60 \mathrm{~min}$ at $37^{\circ} \mathrm{C}$.

6. Store the cDNA at $-20^{\circ} \mathrm{C}$ (can be used directly for amplifications by PCR) 


\subsubsection{Cloning procedures}

Individual cloning steps required for plasmid were carried out as it is outlined below.

\section{PCR amplification}

For high fidelity DNA amplification the Phusion Polymerase from FINNZYMES was used with according to the manufacturer instructions. The template used for amplification was either cDNA from the desired embryonic stage $(0.5 \mu \mathrm{l}$ per reaction) or plasmid containing the target sequence (10-50ng/ $\mu$ l per reaction). Primers used for PCR amplification were from MWG (Ebersberg, Germany). The stock concentration of primers used was 10pM. To add TA overhangs to the PCR product for the TA cloning, Taq polymerase from invitrogene was added during the last step of final 20 min elongation at $72^{\circ} \mathrm{C}$.

\section{5'/3' Blunting wit T4 Polymerase (Fermentas)}

The purpose of blunting is to create blunt ends on DNA template after the restriction with the enzyme that generates protruding 3' or 5' ends.

\section{Blunting Protocol:}

$\begin{array}{ll}\text { Buffer } 5 \mathrm{x} & 4 \mu \mathrm{l} \\ \text { DNA } & 1 \mu \mathrm{g} \\ \text { dNTP mix (2mM each) } & 0.4 \mathrm{mM} \\ \text { T4 polymerase } & 0.2 \mu \mathrm{l} \\ \text { Final volume adjusted with water } & 20 \mu \mathrm{l}\end{array}$

Incubate 5 min at room temperature

Incubate $10 \mathrm{~min}$ at $70^{\circ} \mathrm{C}$ to heat inactivate

Store on ice for short term at $-20^{\circ} \mathrm{C}$ for long term

\section{Dephosphorylation with Antarctic phosphatase form NEB}

The purpose of dephosphorylation is to prevent the self-ligation of the vector. Used to dephosphorylate the vector DNA template that will be used for the ligation after digestion with the single restriction enzyme or with the combination of restriction enzymes that generate compatible restriction sites.

\section{Dephosphorylation Protocol:}


Buffer 10x

DNA (purified after the digest)

Antarctic phosphatase

Final volume

30 min at $37^{\circ} \mathrm{C}$

5 min at $65^{\circ} \mathrm{C}$

Use for ligation directly

Store on ice for short term at $-20^{\circ} \mathrm{C}$ for long term
$4 \mu l$

$35 \mu l$

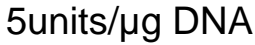

$40 \mu \mathrm{l}$

\section{Phosphorylation with T4 Polynucleotyde kinase (T4 PNK) (NEB)}

The purpose of phosphorylation is to introduce the phosphate groups to the 5'-hydroxyl terminus of polynucleotides (double and single stranded DNA and RNA ) Most typical use of the T4 PNK during cloning is phosphorylation the PCR products, oligo dubplexes, with the subsequent use for the ligation.

\section{Phosphorylation Protocol:}

Ligase buffer $5 \mathrm{x} \quad 8 \mu \mathrm{l}$

DNA (PCR product, purified) $\quad 30 \mu \mathrm{l}$

T4 PNK (NEB) $\quad 1.5 \mu \mathrm{l}$

$30 \min 37^{\circ} \mathrm{C}$

Directly proceed for the ligation by adding ligase to the reaction mix

\subsubsection{Electroporation of a plasmid DNA into bacteria}

- Add 10-100 pg of plasmid DNA or of a ligation reaction to $50 \mu$ of electrocompetent bacteria

- Incubate on ice for 1-2 min

- Chill the electroporation cuvette on ice for 1-2 min

- Transfer cells into the cuvette and transform the cells by using the MicroPulser (Program EC2)

- Add $300 \mu \mathrm{l}$ of LB medium to the cells with the glass Paster pipette and transfer the cells into the $1,5 \mathrm{ml}$ eppendorf tube

- Incubate the transformed cells $40-60$ min at $37^{\circ} \mathrm{C}$ to allow $2-3$ generation times

- Plate the desired amount (100-200 $\mu \mathrm{l})$ on LB agar plate with the appropriate antibiotic resistance 


\subsubsection{0. mRNA synthesis}

Before RNA synthesis, DNA template was prepared as follows. The stock DNA of 1-2 $\mu \mathrm{g} / \mu \mathrm{l}$ was used for linearization reaction with the appropriate restricion enzyme. $10 \mu \mathrm{g}$ of DNA was used in the total volume of $100 \mu \mathrm{l}$ using 5-10 units of the restriction enzyme. THe linearization wa allowed to proceed for $2 \mathrm{~h}$ ar over night at the optimal temerature for the restriction enzyme. The complete linearization was checked on a gel. The linearized DNA was purified with PCR clean up kit from Quiagen and eluted in the RNAse free water. The concentration was measured and the typical range was $200-600 \mathrm{ng} / \mu \mathrm{l}$. Linearized DNA template was stored at $-20^{\circ} \mathrm{C}$. mRNA in vitro transcription was performed using mMessage mMachine kit (Ambion, UK) according to the manufacturer instructions. For the routine tests half reaction was done as follows. $500 \mu \mathrm{g}$ of linearized, purified DNA was used as a template for transcription. The final volume was adjusted with water to $3.2 \mu l .1 \mu l$ of the reaction buffer, $5 \mu \mathrm{l}$ of the $2 x d N T P$ mix and $0.8 \mu$ l of the enzyme were added to the DNA, mixed well and the tube was incubated at $37^{\circ} \mathrm{C}$ for two hours. After the synthesis the DNA template was removed by a 30 min DNase I treatment. The mRNA was purified with Phenol/Chlorophorm and precipitated with $\mathrm{NH}_{4} \mathrm{Ac}$. mRNA pellet was dissolved in $10 \mathrm{mM}$ HEPES and stored at $-80 \mathrm{C}^{\circ}$. The concentration of the mRNA was measured and the usual parameters for quality control were as follows:

Concentration range $\quad 500-1000 \mathrm{ng} / \mu \mathrm{l}$

260/280 ratio $\quad 1.8-2$

\subsubsection{Plasmid isolation: Mini and Midi purification}

Mini and Midi plasmid isolation was carried out according to the manufacturer instructions within the kit used. 


\section{MICROSCOPY}

\subsubsection{Confocal Microscopy}

Images of migrating PGCs were obtained using a Leica TCS Confocal microscope controlled by the internal Leica software. To study the subcellular localization of the Rho GTPases and their respective FRET biosensors in PGCs, high magnification images or time-lapse movie of migrating PGCs were recorded using 40x water objective immersion with numerical aperture 0.8 .

\subsubsection{Wide field Microscopy}

High magnification images or time-lapse movie of migrating PGCs were obtained using a Zeiss Axioplan2 upright microscope controlled by the Metamorph software (Universal Imaging). The objective used was 40x with numerical aperture 0.8. During time-lapse imaging, the time intervals between capturing subsequent frames ranged between 5 to 30 seconds.

\subsubsection{FRET ratio imaging}

FRET ratio imaging was done with the Zeiss Axioplan2 upright microscope. Imaging was done according to the Phogemon instruction (http://www.path1.med.kyoto-u.ac.jp/mm/e-phogemon/phomane.htm) and to the [57]. For each experiment at least 50 cells were recorded in at least three different days using the same settings for the image acquisition. To measure FRET, two emission images for donor and acceptor upon donor excitation were acquired. 440AF21 (XF1071) was used for the donor excitation, 455DRLP for the dichroic mirror. The emissions were filtered with 480AF30 (XF3075) for the donor and 535AF26 (XF3079) for the acceptor. The filters and dichroics were obtained from the Omega Optical. To avoid bleaching, the 6\% ND filter was fitted before the UV pass. CFP and FRET images were acquired either sequentially using the switching wheel (Figures: 3.9, 3.11 through 3.15) or simultaneously with the Dual-View (Figures 3.17 and 3.19). In a case of the switching wheel, to avoid possible artifacts, the experiment was always done in duplicate: recording first FRET channel, then CFP channel and than in the reverse order to verify the reliability of the data obtained. 


\subsubsection{Image processing}

All image processing and analysis was performed using ImageJ software http://rsbweb.nih.gov/ij/).

\section{FRET/CFP ratio image processing and analysis}

To generate FRET/CFP ratio image from raw data, the following algorithm was used. Whenever possible, a macro was recorded to automate the processing.

\section{Ratio image generation algorithm}

1. Open raw data images, FRET and CFP channels

2. Select region of interest (ROI) $100 \times 100$ pixels and crop both images

3. Subtract the background caused by uneven illumination using rolling ball algorithm, rolling ball radius 200

4. Register the FRET image using CFP image as a target with Turboreg plugin, implementing the rigid transformation

5. Threshold the FRET image and set the background values to NaN (mask generation)

6. Run smooth filter on both images

7. Generate FRET/CFP ratio image with the Ratio Plus plugin

8. Set the relevant intensity values according to the controls

9. Run lookup table for the color code (here Blue_Green_Red.lut was used)

\section{Macros used for the ratio image generation:}

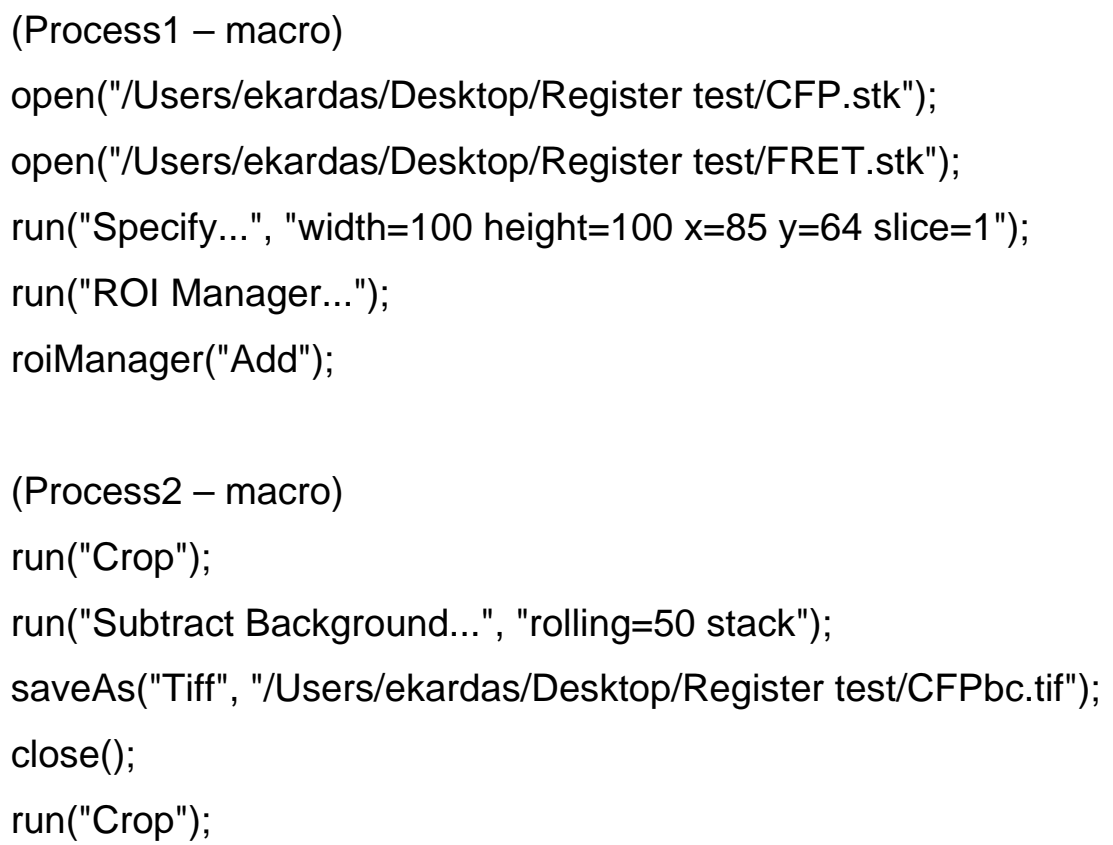


run("Subtract Background...", "rolling=50 stack");

saveAs("Tiff", "/Users/ekardas/Desktop/Register test/FRETbc.tif");

close();

(Register macro)

open("/Users/ekardas/Desktop/Register test/C/c1.tif");

open("/Users/ekardas/Desktop/Register test/F/f1.tif");

run("TurboReg ");

(Ratio Macro)

open("/Users/ekardas/Desktop/Register test/F/registered/f1.tif");

run("Smooth");

setAutoThreshold();

//run("Threshold...");

setAutoThreshold();

run("NaN Background");

open("/Users/ekardas/Desktop/Register test/C/c1.tif");

run("32-bit");

run("Smooth");

run("Ratio Plus", "image1=f1.tif image2=c1.tif background1=0

clipping_value1=0 background2=0 clipping_value2=0 multiplication=1");

run("Save", "save=[/Users/ekardas/Desktop/Register test/Ratio/R1.tif]");

close();

close();

close();

\section{FRET/CFP ratio image analysis}

The mean ratio value for the entire cell was obtained with the $<$ Analyse/measure> command and used to calculate the mean ratio values for a number of cells when comparing different stages or various treatments.

To intensity profile along the line in the ratio image was generated with the $<$ Analyse/Plot Profile $>$ command. 


\section{RESULTS}

\subsection{Rho GTPases control actin cytoskeleton dynamics during PGC migration}

Most of the knowledge regarding actin remodeling during cell migration is derived from experiments performed in $2 \mathrm{D}$ environments. However, in cells observed in $3 \mathrm{D}$ environment actin organization differs dramatically, which is reflected by the lack of stress fibers and a more complex arrangement of the actin at the front of the cell [8]. It is of great importance to gain knowledge on the actin regulation in cells migrating in 3D situation, however imaging migrating cells in their native environment is technically challenging. Here, I took advantage of PGC migration in Zebrafish, which is an excellent model system to study cell migration processes in the noninvasive fashion within the living organism.

\subsubsection{Actin behaviour during PGC migration, wild type situation}

Recent findings from our lab have demonstrated that actin accumulates at the front of the migrating PGC forming a dense network. The bleb at the front of the cell progressed past the actin network indicating that actin polymerization did not contribute in generating the protrusion by pushing the membrane as it does in certain cell types. Conversely, during the tumbling phase, the dense actin network was no longer observed [34]. It is not clear as to the function of actin accumulation at the front of the migrating PGC. To study the function of actin during PGC migration, I followed actin dynamics during run and tumbling phases using time-lapse microscopy. To visualize actin in PGCs, I employed either transgenic fish expressing EGFP-actin-nos1-3'UTR under the control of the askopos promoter [68] or labeled actin in PGCs by injecting mRNA for the Abp140-17aa-EGFP-nos1-3'UTR or Abp140-17aa-Ruby-nos1-3'UTR [74]. In all running cells, actin appeared at the front of the cell forming a dense network resembling brushes, from hereafter referred to as actin brushes (Figure 3.1). 


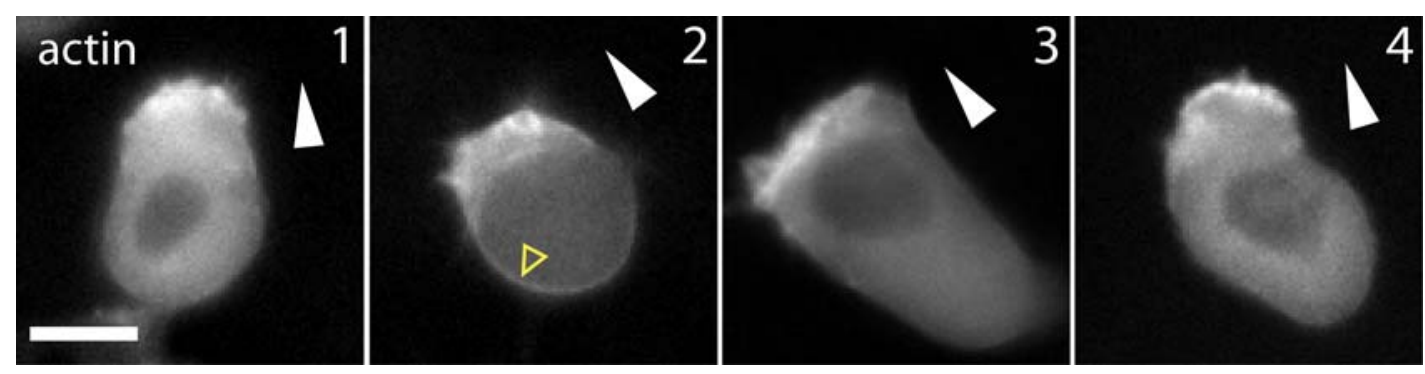

Figure 3.1 Actin cytoskeleton in migrating PGCs

Snapshots of four different PGCs during run phase are shown. Actin in PGCs was visualized with the transgene kop-EGFP-actin-nos1-3'UTR (cells 1, 3, and 4) labeled by injection with mRNA for Abp140-17aa-Ruby-nos1-3'UTR into one-cell stage embryo. White arrows indicate direction of a migration. Yellow arrow points at the cortex. Scale bar: $10 \mu \mathrm{m}$

Time lapse imaging of actin cytoskeleton dynamics revealed that actin brushes moved backward relative to the forming bleb (Figure $3.2 \mathrm{~A}$ and $\mathrm{C}$, time 20"; supplemental movie S1), and subsequently disassembled (Figure 3.2A, time 40" and supplemental movie S1). The new actin then accumulated underneath the plasma membrane (Figure 3.2A and C, time 60" and supplemental movie S1). The cycle of actin accumulation, bleb formation and the re-accumulation of new actin takes about 60 seconds (Figure 3.2A and supplemental movie S1). The estimates speed of actin backward flow varies from cell to cell, and ranges between $3.6 \mu \mathrm{m} / \mathrm{min}$ to $6.8 \mu \mathrm{m} / \mathrm{min}$. During the tumbling phase, no brushes were detected (Figure 3.2B and supplemental movie S2).

\subsubsection{Effect of SDF-1a/CXCR4b signalling on actin cytoskeleton}

PGCs are guided towards their target by the chemokine SDF-1a, which signals through its receptor CXCR4b. In the absence of functional SDF-1a/CXCR4b signalling, PGCs are motile, albeit non-directional and are unable to reach the target [66]. To test, whether actin dynamics observed during PGC migration depend on SDF-1a/CXCR4b signalling I knocked down CXCR4b expression with a morpholino antisense oligonucleotide and monitored actin in non-directionally migrating PGCs. Actin dynamics at the leading edge of PGCs migrating without functional SDF1a/CXCR4b signalling appeared similar to that observed in the non manipulated cells migrating in wild type environment (Figure 3.2D and supplemental movie S3). Actin followed the same cycle of accumulating at the front forming brushes and flowing backwards, while the bleb was advancing. From these results I conclude that the dynamic behaviour of actin observed at the front of PGCs is important for general motility of the cell rather than directionality. 


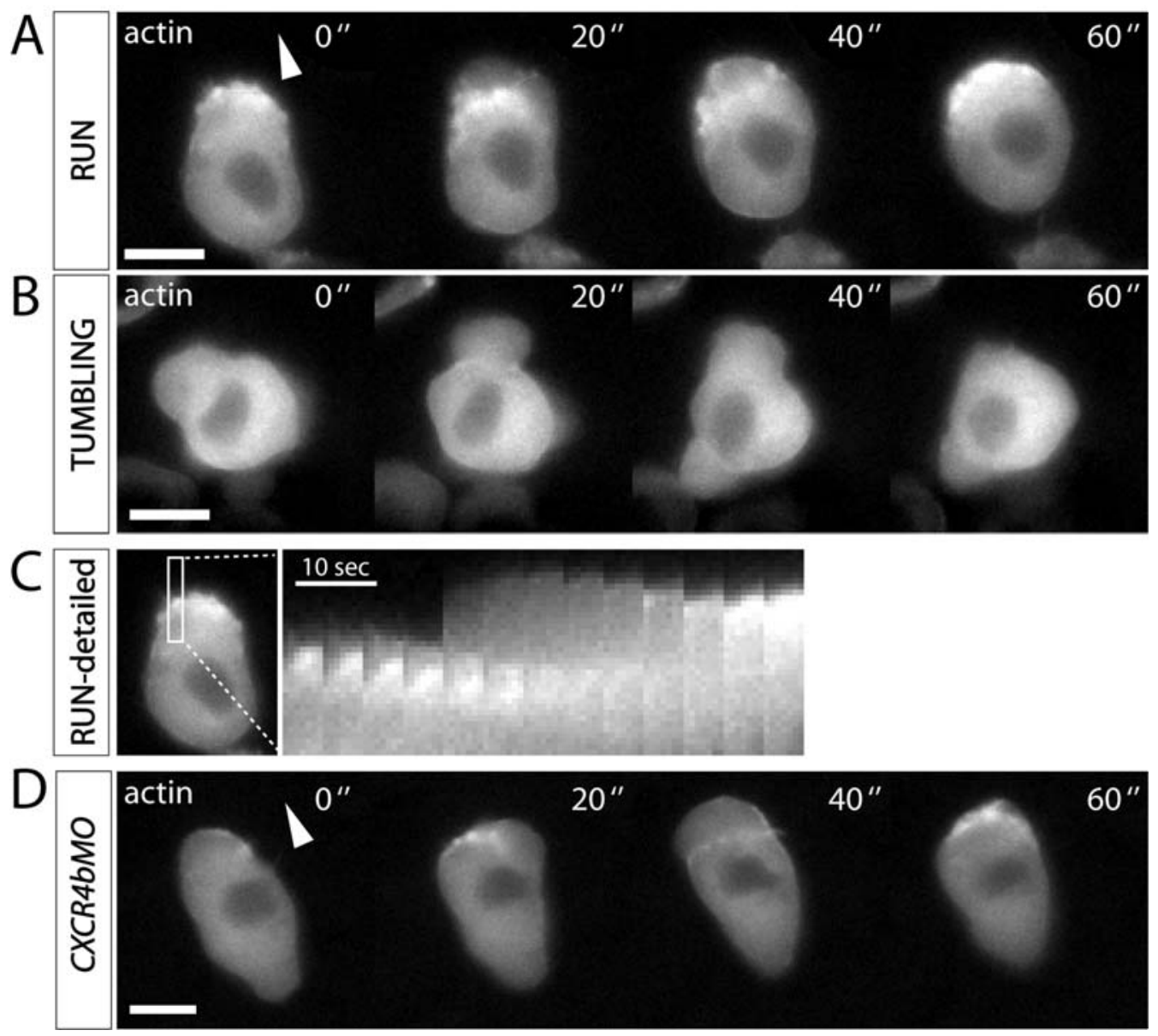

Figure 3.2 Actin citoskeleton dynamics in migrating PGCs

A.,B. Actin cytoskeleton was visualized in migrating PGC during run (A) and tumbling (B) phases ( $A$ and $B$ show the same PGC at different phases). C. The kymograph presents actin backward flow at the front of the PGC in run phase during bleb formation (derived from the running cell shown in A, 5 seconds intervals) $D$. Actin dynamics in PGC migrating without functional SDF-1a/CXCR4b signalling. Arrows indicate the direction of a migration. Actin in PGCs was visualized with the transgene kop-EGFP-actin-nos1-3'UTR. Scale bar: 10 $\mu \mathrm{m}$

\subsubsection{Interfering with the function of endogenous Rho GTPases affects actin cytoskeleton and PGC migration}

Rac, Cdc42, and RhoA are the best studied Rho GTPases and they were shown to play a major role in regulating cytoskeleton dynamics. Therefore I decided to focus my attention on the effect of these three Rho GTPases on actin cytoskeleton in migrating PGCs. Dominant-negative (DN) mutants for Rho GTPases have been widely used as a tool for studying their function. DN Rho GTPase mutants potentially bind and titrate off the large number of GEFs thus often resulting in artefacts for example by blocking GEFs that might be shared with another Rho GTPase [37, 48]. Indeed, in the null mutants for Rac, cellular phenotypes varied dramatically from those observed in the dominant-negative mutants [49]. Therefore, I sought a more specific approach to interfere with the function of these proteins in PGCs. The 
established method of measuring the activity of Rho GTPases is based on the use of GST fusions of the Rho GTPase binding domain (RBD) of the effector protein for a particular Rho GTPase in pull down experiments and subsequent detection of Rho GTPases on a Western blot. Since only the GTP-bound form interacts with the RBD of the effector protein, only the GTP-bound form of the Rho GTPase is expected to be detected on a Western blot [53]. Based on this information, I reasoned, that expression of the RBD domain of the specific target for a particular Rho GTPase in PGCs should act as a loss of function mutant by binding the active form of the Rho GTPase in cells. Upon activation through GDP to GTP exchange, Rho GTPases are believed to translocate to the plasma membrane, where they function in regulating actin cytoskeleton remodelling [75]. Therefore, in the loss of function mutant for Rho GTPases, the RBD was tagged with the farnesylation signal from the C-terminal domain of Ras [76]. Active Rac and Cdc42 interact specifically with the CRIB domain (Cdc42/Rac Interactive binding protein), which is located within the N-terminal region of P21-activated kinase (PAK) [77]. I fused the CRIB domain of PAK to the farnesylation signal from C-terminal domain of Ras in order to target it to the membrane. The resulting construct: CRIB-RasCT should bind active forms of Rac and Cdc42 that are found at the membrane resulting in a phenotype that should reflect Rac/Cdc42 loss of function.

Interfering with the function of endogenous Rac and Cdc42 affect actin cytoskeleton dynamics in PGCs. PGCs expressing the CRIB-RasCT fusion appeared non-polarized and were forming blebs in random directions (Figure 3.3A and supplemental movie S4). Actin brushes were no longer detected in cells without functional Rac/Cdc42, however actin cortex seemed to form properly when the bleb retracted (Figure 3.3A and supplemental movie S4). These data suggest that Rac and/or Cdc42 might play a role in actin assembly into the brushes observed at the front of the cell. Constitutively-active (CA) mutants for Rho GTPases are conventionally used to study their cellular functions. In the next series of experiments, I studied the effects of CA mutants for Rac1 and Cdc42 on actin cytoskeleton during PGC migration. Rac activity has previously been shown to induce the formation of membrane ruffles and lamellipodia in macrophages [45]. 


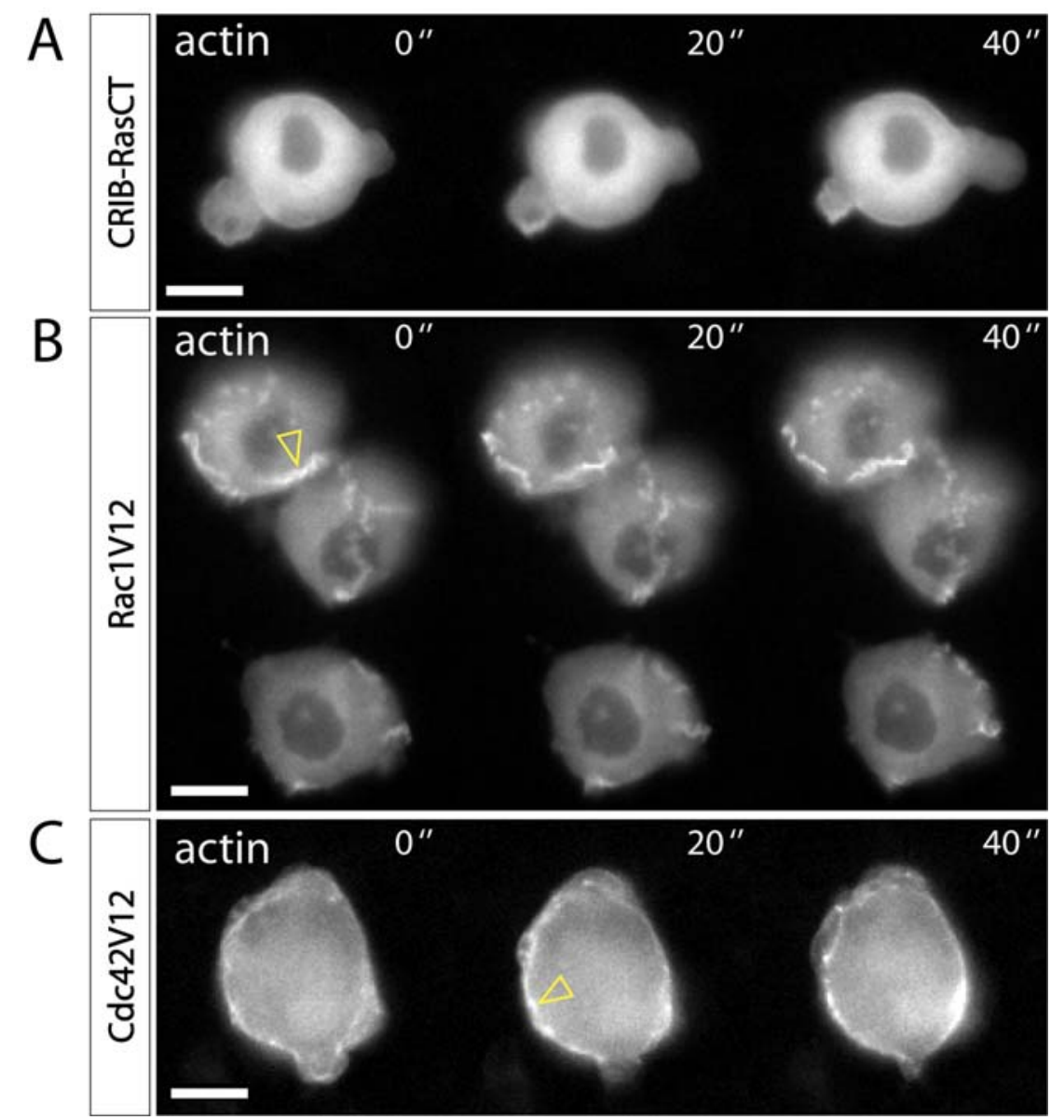

Figure 3.3 Interfering with the function of endogenous Rac and Cdc42 affects actin cytoskeleton dynamics in PGCs

A. Actin in PGCs without functional Rac/Cdc42. B. Actin in PGCs expressing constitutively active Rac1 $\mathrm{V} 12^{2}$ mutant. Arrow points at the actin-dense structure. C. Actin in PGCs expressing $\mathrm{CA} C \mathrm{Cdc} 42^{\mathrm{V} 12}$ mutant. Arrow points at the cortical region. One cell stage embryos were injected with 750pg of mRNA for CRIB-RasCT-nos1-3'UTR (A), $150 \mathrm{pg}$ of mRNA for Rac1V12-nos1-3'UTR, (B), and 150pg of mRNA for Cdc42V12-nos1-3'UTR (C). Actin in PGCs was visualized with the transgene kop-EGFP-actin-nos1-3'UTR in A and B or by injecting the $150 \mathrm{pg}$ of mRNA for Abp140-17aa-Ruby-nos1-3'UTR in C. Scale bar 10 $\mu \mathrm{m}$

In PGCs expressing CA Rac1V12 mutant, actin formed several dense structures (Figure 3.3B). These actin-rich structures induced by the Rac1 $\mathrm{V} 12$ mutant were slightly motile and did not disassemble (Figure 3.3B and supplemental movie S5). There was no detectable cortex visible and also there were no blebs formed in PGCs expressing the CA Rac1 $\mathrm{V} 12$ mutant. Additionally, PGCs expressin the CA Rac1 ${ }^{\mathrm{V} 12}$ mutant failed to polarize or to migrate (Figure 3.3B and supplemental movie S5). Cdc42 activity was reported to induce filopodia formation in fibroblasts [45, 52]. In endothelial cells, Cdc42 activity was reported to form lamellipodia and thick actin bundles [47]. Expression of the CA Cdc42V12 mutant in PGCs resulted in unpolarized cells. There were no actin brushes detected in these cells but there was 
residual blebbing activity (Figure $3.3 \mathrm{C}$ and supplemental movie S6). The blebs formed in PGCs overexpressing CA Cdc42 $\mathrm{V} 12$ mutant appeared much shallower compared to the blebs in the wild type cell (this blebbing phenotype was not quantified here). The actin signal corresponding to the cortex appeared stronger compared to the wild type cell (Figure 3.3C). The morphological changes induced by the function of CA Cdc42 ${ }^{\mathrm{V} 12}$ mutant in PGCs are very different from those usually observed in other cell types described, where its function is most often associated with induction of filopodia [52]. These results indicate that Rac and Cdc42 activities might induce distinct signalling pathways in PGCs. The CA Rac1 12 mutant activity resulted in actin polymerization at several locations within the cell while the CA Cdc42 V12 mutant did not result in actin polymerization into brushes or filopodia, but rather affected blebbing ability in PGCs, resulting in the formation of shallow blebs. Although, signal corresponding to the cortex appeared stronger in the presence of the CA Cdc42V12 mutant, the signal for the cortical actin was still visible in PGCs without Rac/Cdc42 activity (Figure 3.3A). These results suggest, that Rac activity is important for actin polymerization into the brushes in PGCs. Based on the Cdc42 mutant's phenotype it is not clear what is the exact function of Cdc42 in PGCs.

RhoA mutants affect actin cytoskeleton dynamics in PGCs. The most prominent structures induced by the RhoA activity in cell culture are stress fibres and focal adhesions [47, 52]. However, cells migrating in a 3D environment are usually devoid of stress fibres [8]. RhoA function is also implicated in the regulation of contractility via activation of Rho kinase (ROK), which can phosphorylate myosin or myosin light chain phosphatase (MLCP) thus resulting to acto-myosin contraction [7, 51]. I asked how interfering with RhoA function would affect actin cytoskeleton in PGCs. To block specifically RhoA function I fused the Rho binding domain from protein kinase $\mathrm{N}$, which is one of the downstream targets of activated RhoA [78], to the farnesylation signal of the Ras C-terminus (PKN-RasCT). Such a mutant is expected to block the active form of RhoA at the membrane thus compromising RhoA function in PGCs. PGCs expressing the PKN-RasCT mutant exhibited a non-polarized, rounded morphology (Figure 3.4A). There was still actin accumulation underneath the plasma membrane visible and this actin formation appeared at a distinct location of the cell. However, actin did not exhibit the backward flow without functional RhoA and in addition PGCs appeared round and did not form blebs (Figure 3.4A and supplemental movie S7). This observation is consistent with the similar cell morphology and actin behaviour in the presence of the dominant negative mutant of ROK, the downstream effector of activated RhoA ([34], Figure 3.4B and 
supplemental movie S8). When the CA RhoAV14 mutant was expressed in PGCs, cells appeared polarized with two different poles (Figure $3.4 \mathrm{C}$ and $\mathrm{C}^{\prime}$.). Actin accumulated at one pole, while the other pole was wider and devoid of actin.
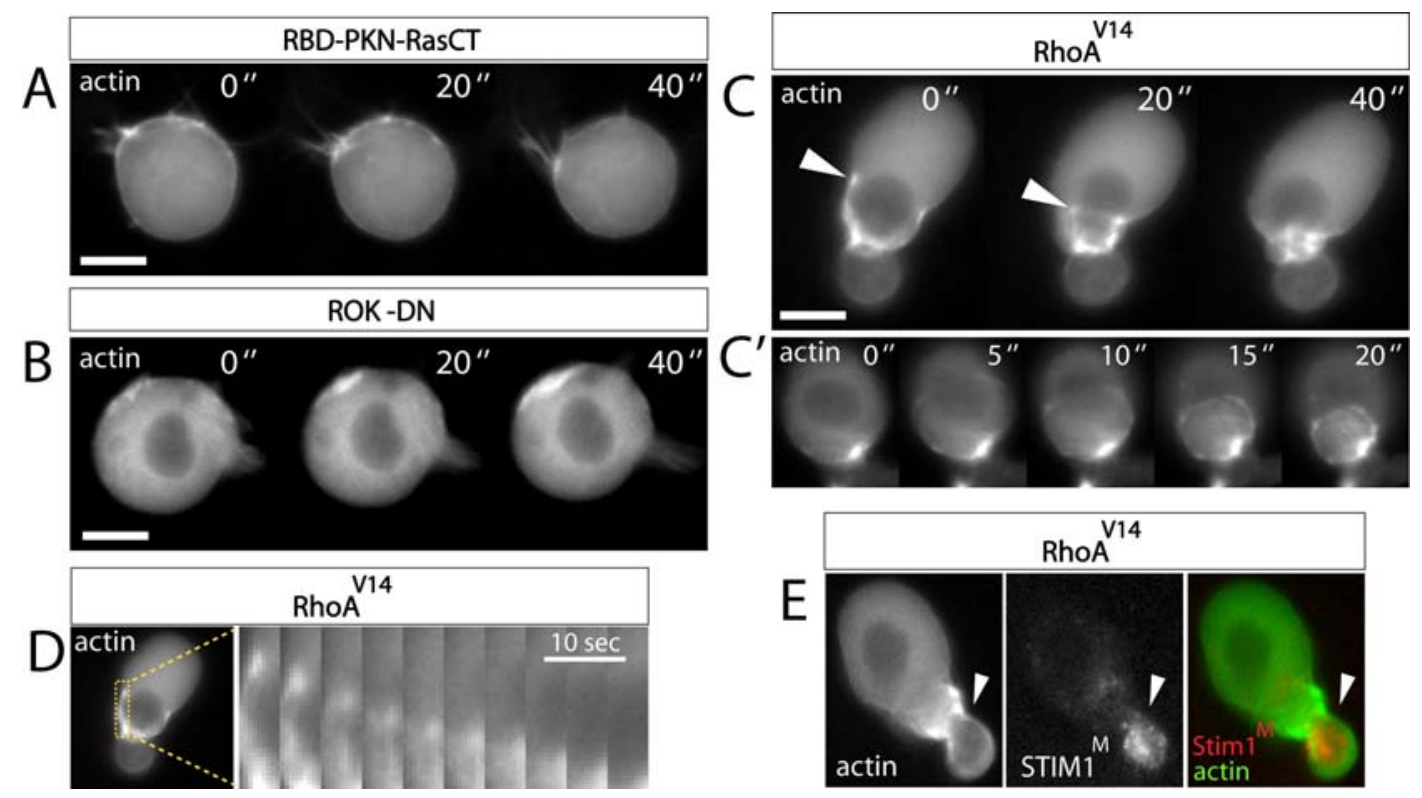

Figure 3.4 Interfering with the function of endogenous RhoA affects actin cytoskeleton dynamics in PGCs

A. Actin in PGCs without functional RhoA. B. Actin in PGCs without functional ROK C., C'. Two representative PGCs expressing CA RhoA ${ }^{\mathrm{V} 14}$ mutant are shown. Arrow in $\mathrm{C}$ points to the actin, which is recruited to one pole of the cell $D$. The kymograph is derived from the cell in $\mathrm{C}$ and shows actin backward flow in. the presence of CA RhoA $\mathrm{V} 14$ mutant. E. Dominant mutant Stim $1^{\mathrm{M}}$, which is used as a backness marker colocalizes with actin. Arrow points at the back of the PGC as defined with $S$ tim $1 \mathrm{M}$. One cell stage embryos were injected with the mix of 150pg of mRNA for the RBD-PKN-RasCT-nos1-3'UTR and $150 \mathrm{pg}$ of mRNA for the Abp140-17aa-Ruby-nos1-3'UTR (A); 300 pg of mRNA for the ROK-DN-nos1-3'UTR (B); 150pg of mRNA for RhoAV14-nos1-3'UTR (C, C', and D); mix of $450 \mathrm{pg}$ mRNA for dsRedMutStim1-nos1-3'UTR and 150 pg of mRNA for the Abp140-17aa-Ruby-nos1-3'UTR. Actin in PGCs was visualized with the transgene kop-EGFP-actin-nos1-3'UTR in B, C, C' and E. Scale bar: $10 \mu \mathrm{m}$

The actin was constantly flowing in the direction of the actin-rich pole induced by what appeared like the contractile forces (Figure 3.4 C and ' ' and supplemental movies S9 and S10). The contraction forces seemed to be initiated at the pole of the cell with the low actin density and during the contraction actin appeared to be recruited towards the other pole (Figure 3.4C, C', and D and supplemental movies S9 and S10). These data are in agreement with previous reports concerning RhoA function in inducing contractility $[45,79,80]$. To ask, whether PGCs expressing RhoA $\mathrm{V} 14$ mutant posses a defined back and front similar to wild type cells, dominant mutant Stim1 ${ }^{\mathrm{M}}$, which is known to localize at the back of PGCs [68] was employed 
here as a backness marker. Stim $1^{\mathrm{M}}$ mutant localized at the pole exhibiting high actin density, suggesting that actin was recruited towards the back of the cell by RhoA activity (Figure $3.4 \mathrm{E}$ ). The actin backward flow appeared to be enhanced in the presence of the CA RhoA ${ }^{\mathrm{V} 14}$ mutant, with a calculated speed for actin backward flow ranging between the $15.5 \mu \mathrm{m} / \mathrm{min}$ and $20 \mu \mathrm{m} / \mathrm{min}$.

Based on the observed actin recruitment towards the back of the cell by the action of RhoA V14 mutant, one may suggest that RhoA function in PGCs generates forces required for contractility and actin backward flow, which is also observed at the front of the non-manipulated PGCs during run phase (Figure 3.2A and $\mathrm{C}$, and supplemental movie S1).

\subsubsection{Correct balance between Rac and RhoA activities is important for PGC migration}

Rac and RhoA are believed to act in a mutually exclusive fashion antagonizing each other functions [81-83]. Rac is normally believed to act at the front of the migrationg cell, while RhoA activity is associated with the back of migrating cells [84]. There are various models proposing how Rac and RhoA could counteract each other's activities. For example, in HEK293 cell stimulated with thrombin, Rac function prevents stress fibres formation by inhibiting RhoA function via activation of PAK that in turn inhibits the DH-PH domain of the P115RhoGEF - the RhoA specific GEF [85]). Another report recently suggested a mechanism by which Rac-mediated protrusive activity may be suppressed by Rho activity through the recruitment of RacGAP through Rho function [86]. In the presence of the CA Rac1V12 mutant, there were no blebs formed (Figure 3.3 B), suggesting that Rac activity could suppress the RhoA function, which otherwise would have led to the contraction and bleb formation. If the latter assumption is true, CA RhoA V14 mutant should rescue the CA Rac1 V12 mutant-induced non-blebbing phenotype. To elucidate, whether Rac operates upstream of RhoA, I combined both of the CA mutants for Rac and RhoA by expressing the equal amounts of CA RhoA V14 and the CA Rac1V12 mutants in PGCs and followed actin dynamics. Intriguingly, when the two mutants where combined the proper motile behaviour of PGCs appeared to be restored (Figure 3.5 and supplemental movies S11 and S12). Although, it is still unclear whether there is a direct regulation among the two molecules, these experimental data suggest that 
the right balance between Rac and RhoA activities is crucial in dictating proper PGC migration.
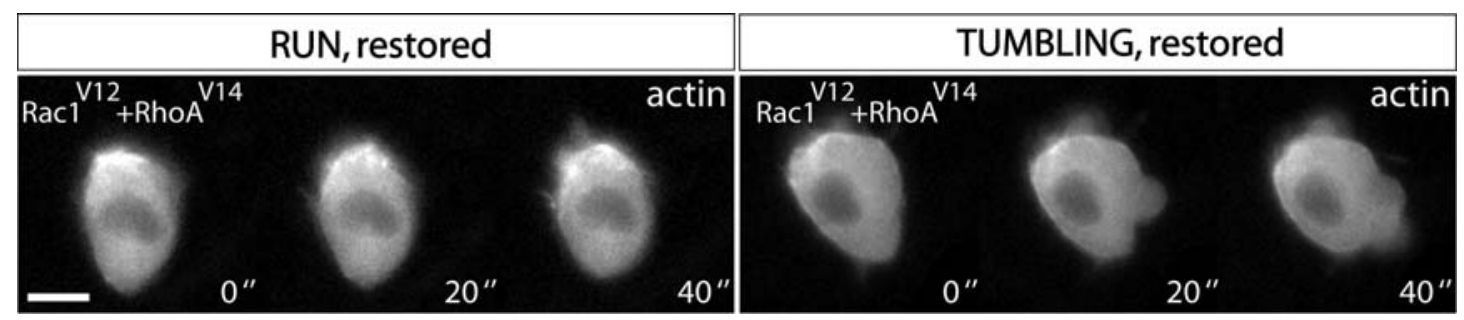

Figure 3.5 Correct balance for Rac1 and RhoA activities in PGCs

One-cell stage embryos were injected with equal amounts of mRNA for constitutively active mutants of the CA RacV12 and CA RhoAV14 mutants. Representative cells displaying run (left panel) and tumbling (right panel) behaviors are shown. One cell stage embryos were injected with the mix of 150pg of mRNA for RacV12 -nos1-3'UTR and 150pg of mRNA for RhoAV14_ nos1-3'UTR. Actin in PGCs was visualized with the transgene kop-EGFP-actin-nos1-3'UTR. Scale bar: $10 \mu \mathrm{m}$

\subsubsection{Actin brushes are part of the contractile machinery in PGCs}

Actin brushes at the front of the PGC do not participate in pushing the membrane forward ([34], Figure 3.2A and supplemental movie S1). Instead, one may suggest that by acting in concert with contractile machinery actin brushes could play a role in generating forces that expel the bleb at the front. Blebbing in PGCs is thought to be induced by the free calcium ions that stimulate myosin light chain kinase (MLCK) activation that in turn leads to acto-myosin contraction [34]. Previous findings from our lab have demonstrated that MLCK, whose activity is calcium dependent, localizes to the front of the migrating PGC, in a pattern similar to that of actin ([34] and Figure 3.6A) MLCK localization reflects either the localization of myosin and/or localization of myosin light chain phosphorylation events, thus reporting where the regions of active contraction in the cell are found. To gain inside into the function of actin brushes, I studied MLCK dynamics during bleb formation and observed that similarly to actin, MLCK has the tendency of flowing backwards (Figure 3.6B and supplemental movie S13). Furthermore, constitutively active RhoA $\mathrm{V} 14$ mutant resulted in MLCK recruitment towards the back of the cell, where it colocalized with actin. (Figure 3.6C). 


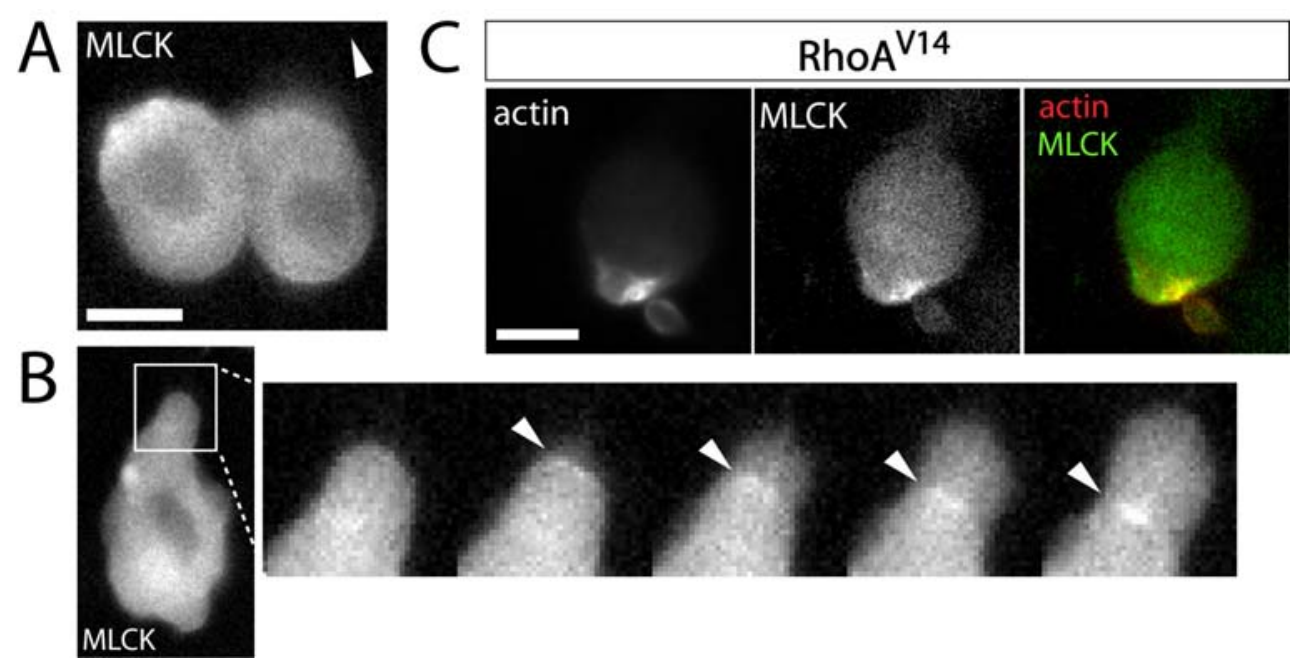

Figure 3.6 MLCK is localized to the front in migrating PGCs

A. Localization of MLCK in PGCs during run phase. Left cell shows MLCK localization at the front of the cell. B. An example of MLCK backward movement during bleb formation at the front of the cell. Frames are taken every $5 \mathrm{sec}$. C. Actin and MLCK are both found at the back of the cell in the presence of CA RhoA $\mathrm{V} 14$ mutant. Arrow in $\mathrm{A}$ indicates the direction of a migration, and in $B$ MLCK backward movements. One cell stage embryos were injected with the $300 \mathrm{pg}$ of mRNA for MLCK (A and B); the mix of $300 \mathrm{pg}$ of mRNA for MLCK and 150pg of mRNA for Abp140-17aa-Ruby-nos1-3'UTR and 150pg of mRNA for RhoAV14-nos1-3'UTR (C). Scale bar: $10 \mu \mathrm{m}$

These results further support the assumption that actin brushes at the front of the PGC are part of the contractile machinery that takes part in mediating bleb formation.

\subsubsection{Role of cell-cell adhesion during PGC migration}

Actin retrograde flow observed in focal adhesions of the cells crawling in 2D environment has been implicated in generating the traction force required for cell migration [26]. One may therefore suggest that actin backward flow observed in PGCs could play a role in generating traction forces. However, PGCs do not appear to form focal adhesions (unpublished observations). Instead, during their migration, PGCs appear to be closely associated with the surrounding somatic cells. Actin retrograde flow in migrating cells is often seen to flow back relative to the neighbouring cell adjacent to PGC (Figure 3.7A, B; and supplemental movies S14). I hypothesized that actin in PGCs might be linked to the E-cadherins that connect two cells via adherent junctions and by flowing back to push against the adjacent cell thereby generating an additional force required for efficient PGC locomotion. 


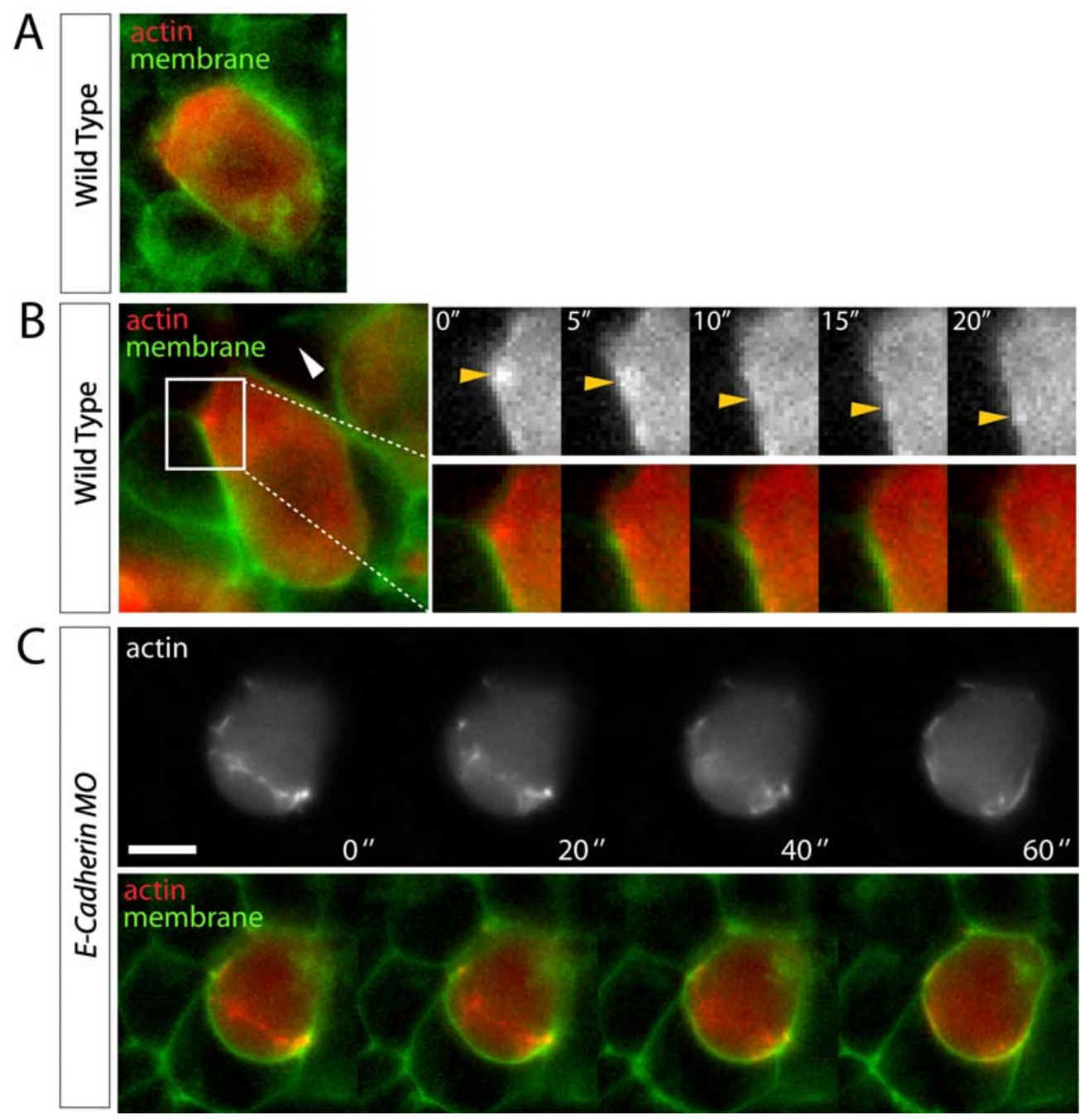

Figure 3.7 PGCs migrate in close association with the somatic tissue

A. Migrating PGC and surrounding somatic cells are shown. Actin in PGC is labeled in green and the membrane in PGC and somatic cells is labeled with red. B. PGC, in which actin is seen to flow backward relative to the somatic cell. Inset shows the front of the cell, where actin backward flow is visible. White arrow indicates direction of a migration. Yellow arrow is pointing at actin that appears to flow back relative to the somatic cell adjacent to PGC. C. Effect of E-Cadherin knock-down on actin organization in PGCs and their migration. One cell stage embryos were injected with 120pg of mRNA for Abp140-17aa-Ruby-nos1-3'UTR to visualize actin and 90pg of mRNA for mCherry-F-Globin-3'UTR to visualize the membrane in all cells. $0.2 \mathrm{pmol}$ of the control morpholino (A and $\mathrm{B}$ ) or E-Cadherin morpholino (in $\mathrm{C}$ ) was co injected with the mRNA. Scale Bar: $10 \mu \mathrm{m}$

The requirement for correct E-cadherin levels for PGC migration was demonstrated by the finding that E-cadherin levels are reduced (but present) when PGCs acquire motile behaviour [68]. I asked, whether cell-cell adhesion plays a role in PGC migration. To this end I inhibited E-cadherin translation using a morpholino antisense oligonucleotyde. In the E-cadherin morphants, PGCs were no longer migratory and their blebbing ability was impaired (Figure 3.7C and supplemental movies S15 and S16). The actin organization in PGCs without functional E-cadherin appeared 
disrupted (Figure 3.7C). Based on these initial E-cadherin knockdown experiments, I conclude that functional E-Cadherin is required for proper actin organization in PGCs (both brushes and cortex) and probably for blebbing as well. 


\subsection{Activation of Rho GTPases during PGC migration}

RhoGTPases act as molecular switches alternating between the active, GTPbound and inactive, GDP-bound forms. In their active GTP-bound form, Rho GTPases interact with their downstream partners inducing signalling cascades that lead to a variety of cellular effects, such as cytoskeleton remodelling [36]. It is important to have the information regarding spatial-temporal activation pattern of Rho GTPases in order to understand the mechanism of their function. Here, to study the activation of Rac, Cdc42, and RhoA in migrating PGCs, recently developed FRET biosensors for Rho GTPases were employed [57, 69]. These FRET biosensors for Rho GTPases were reported to be insensitive to RhoGDIs, reporting therefore the local balance between the GEF and GAP activities in the cell [60]. The GDP/GTP loading of the biosensor is reflected in the energy transfer, which is low in the GDPbound form and high in the GTP-bound form. During the experiment with FRET biosensors two images are acquired: FRET channel (CFP excitation, YFP emission) and CFP channel (CFP excitation, CFP emission). Then the ratio image FRET/CFP is generated (See the Methods). In the ratio image every pixel represents the value for the FRET/CFP ratio, which reports on the activation state of the molecule and hence the activity of Rho GTPase. Most of the measurements for Rho GTPases activition during cell migration using FRET biosensors was performed in cell culture $[57,69,87]$, and only two papers were published, where Rho GTPases activity was measured with FRET in the living organism $[88,89]$.

\subsubsection{FRET imaging setup in migrating PGCs}

There was no established routine for ratio imaging procedure such as image acquisition and analysis in our lab; therefore I first developed the procedure for FRET ratio imaging in zebrafish embryo. To set up the ratio imaging in PGCs I first established the acquisition conditions in PGCs using basic controls with the donor and acceptor only. In the original FRET probes for Rho GTPases SECFP (a variant of the cyan fluorescent protein) and Venus (a variant of the YFP, which gives brighter signal) served as a donor and acceptor respectively during the energy transfer [59]. Due to the spectral properties of CFP and YFP chromophores, there is a non-specific signal in the FRET channel, which results from a combination of the acceptor spectral bleed through (ASBT) and the donor spectral bleed through (DSBT) (Figure3.8). 


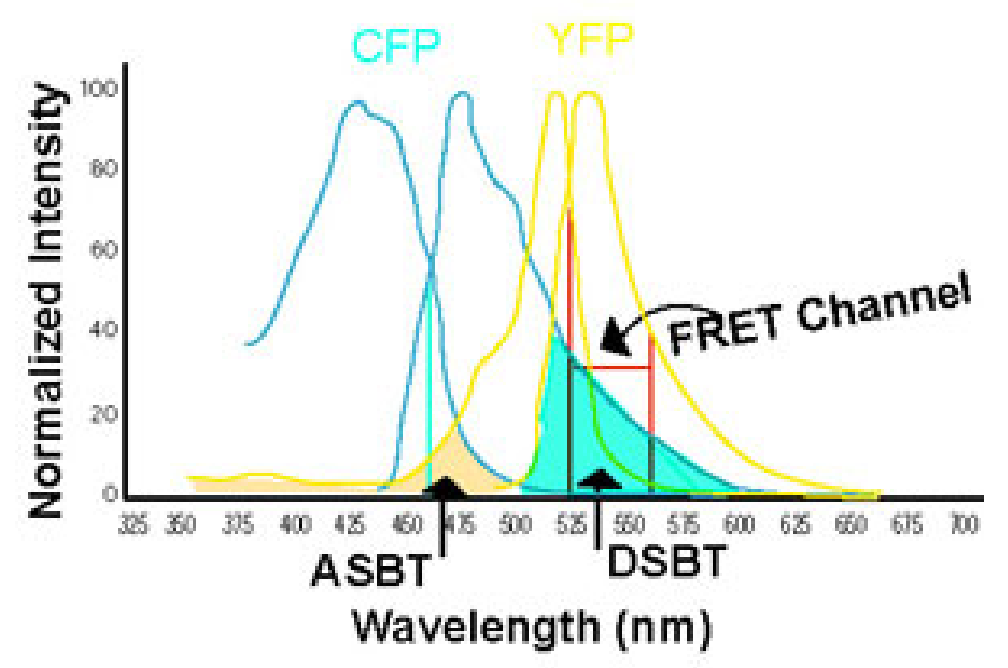

Figure 3.8 Excitation and emission spectra for CFP and YFP

ASBT - Acceptor spectral bleed-through. DSBT - Donor spectral bleed-through

To measure the ratio in the absence of the energy transfer between the CFP and YFP chromophores, I co-injected equal amounts of mRNAs for SECFP-nos1-3'UTR and Venus-nos1-3'UTR. The FRET/CFP ratio image for such combination should give the lowest value possible, which would reflect the background signal in the absence energy transfer. For a positive control I created a SECFP-Venus tandem construct in which SECFP and Venus were linked with 10 amino acids [90]. During FRET imaging two images are acquired: the CFP channel - measuring CFP emission upon CFP excitation and the FRET channel - measuring YFP emission upon CFP excitation. The ratio image of FRET/CFP represents the efficiency in energy transfer and therefore the activation state of the biosensor. The color hue in the ratio image is associated with the ratio value thus representing the activation state of the biosensor. Basic setup for ratio imaging is shown at Figure 3.9A. I tested two different combinations of the donor and acceptor: SECFP-Venus (the original combination in Raichu FRET biosensors) and SECFP-Ypet, where Ypet is a variant of YFP exhibiting a higher energy transfer in combination with SECFP [91]. 
A

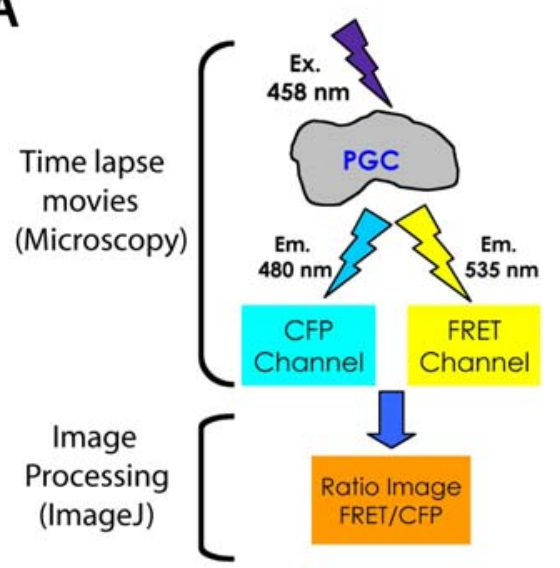

B

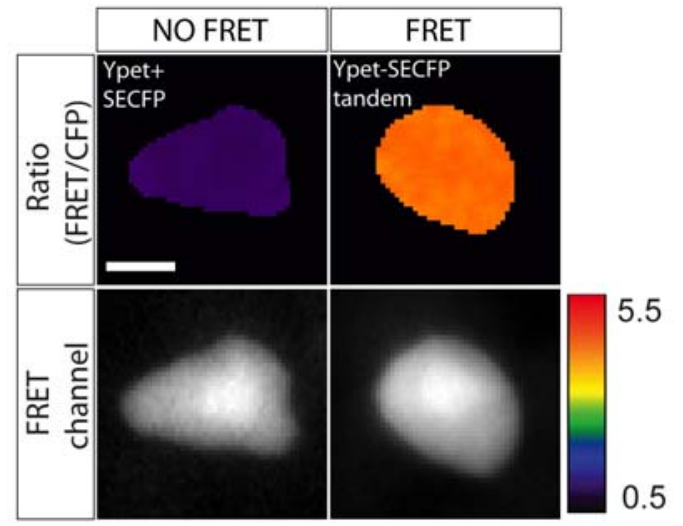

C

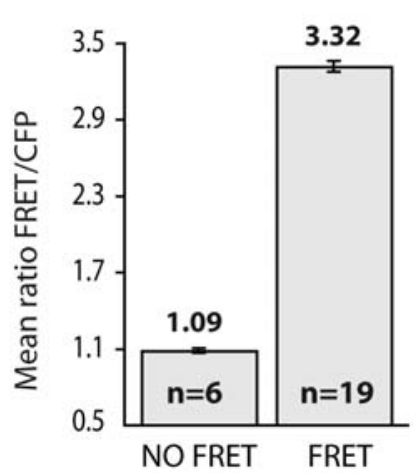

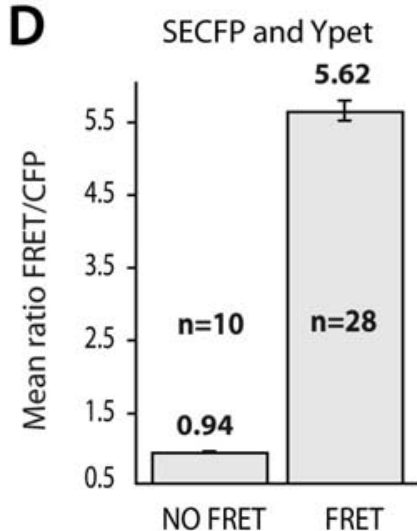

$\mathbf{E}$ SECFP-Ypet tandem

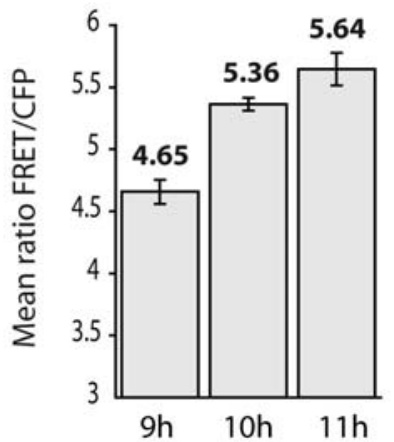

Figure 3.9 Ratio imaging setup in PGCs

A. The acquisition setup during ratio imaging. B. FRET channel and Ratio FRET/CFP images for negative and positive controls for the donor (SECFP) and acceptor (Ypet) are shown. C. Graph showing the mean ratio FRET/CFP values images for the negative and positive controls for Venus and SECFP combination. D. Graph showing the ratio values images for negative and positive controls for Ypet and SECFP combination. E. Increase in FRET/CFP ratio within the SESCFP-Ypet tandem with time. One-cell stage embryos were injected with the mix of $150 \mathrm{pg}$ of mRNA for the Ypet-nos1-3'UTR and $150 \mathrm{pg}$ of mRNA for the SECFPnos1-3'UTR (B, cell at the left); 200 pg of mRNA for Ypet-SECFP-nos1-3'UTR (B, cell at the right) Scale bar: $10 \mu \mathrm{m}$

\subsubsection{Comparison between two different Donor and Acceptor pairs}

The original combination of donor and acceptor pair gave the ratio values 1.1 for no-energy transfer situation and 3.3 for the strong energy transfer in the SECFPVenus tandem construct (Figure 3.9C). As expected, the SECFP-Ypet tandem exhibited stronger energy transfer, which resulted in ratios 0.94 for no energy transfer and 5.62 for strong energy transfer (Figure 3.9B and D). The sensitivity of the FRET biosensor is reflected in its dynamic range that shows the maximum of difference between the active and inactive states of the FRET biosensor. To improve the dynamic range of the original FRET biosensors, Venus was replaced with Ypet. PGC migration takes several hours during development. This means, that during ratio 
imaging, the information might be acquired at different developmental stages. To test how consistent the results obtained during ratio imaging at different developmental stages are, FRET measurements were performed at various times along development. An increase in the energy transfer measured with the Ypet-SECFP tandem is observed with time (Figure 3.9E). Although, the reasons for the increase in FRET ratio during time are unclear, this observation emphasizes the importance of comparing between the same developmental stages, when performing measurements with FRET biosensors involving different treatments.

\subsubsection{Targeting Rac-FRET biosensor expression in PGCs}

The imaging conditions were first optimized for the Rac-FRET bbiosensor. The next chapters show the targeting of the Rac-FRET biosensor expression in PGCs and the controls necessary for distinguishing between the active and inactive states of the biosensor. The same principle applies for the biosensors for Cdc42 and RhoA as well.

There are several important conditions for the optimal FRET biosensor [60]. First, FRET biosensor should be neutral, meaning it should not interfere with the signalling pathways within the cell. Therefore I checked whether PGCs expressing Rac-FRET biosensor migrated properly and arrived at the right position within the embryo at the 24 hour stage. Indeed, this criterion was fulfilled as shown in Figure 3.10B, right. (24 hpf). The other condition requires target specificity of the FRET biosensor, meaning it must localize at the cellular compartments, where the endogenous protein is normally found. Usually, subcellular targeting of FRET biosensors is achieved by fusing the Cterminal region of the respective Rho GTPase to the C-terminus of the biosensor, following the CFP variant [57], thus the original FRET biosensor for Rac contains 22 amino acids from the C-terminal tail of Rac (Figure 3.10C). The localization of the Rac-FRET biosensor was compared with the localization of Rac as visualized with its EGFP fusions (Figure 3.10A and B). As visualized with EGFP tagging, Rac was localized throughout the cell showing dynamic localization to the membrane, cytosol and/or to the nucleus (Figure 3.10A, cells at 8-10 hpf). Overexpression of EGFP fusions of Rac seem not to interfere with normal PGC migration as PGCs exhibited normal morphology during their migration and arrived at their proper positions after 24 hours (Figure 3.10A, embryo at $24 \mathrm{hpf}$ ). When the original Rac-FRET biosensor was expressed in PGCs, it localized strongly to the nucleus and faintly to the membrane (Figure 3.10B), something that differs dramatically from the localization of Rac, when fused to EGFP tag (Figure 3.10A, cells at 8-10hpf). As mentioned above, 
the localization of Rac-FRET biosensor is regulated by the C-terminal region, which is the Rac C-terminal domain. A closer look at this region of Rac revealed the presence of a canonical nuclear localization signal: K-K/R-X-K/R (Fig 3.10C, highlighted in blue). Indeed, nuclear localization signal was previously noticed at the C-terminal polybasic region of several Rho GTPases, including Rac and Cdc42. It has also been reported that Rho GTPases containing the nuclear localization signal translocate to the nucleus in a tissue-specific manner [92, 93]. Although Rac has the tendency to localize to the nucleus in PGCs (Figure 3.10A, upper panel), this nuclear localization appears to be a transient event. The permanent nuclear accumulation of the Rac-FRET biosensor most likely is an artefact of that specific fusion behaviour in PGCs. The localization of the original Rac-FRET biosensor did not match the localization of the Rac1 in PGCs, and addition compromised the signal at the membrane and in the cytosol renderring the measurements impossible to perform. Two new probes were generated, where different modifications were introduced to the C-terminal domain of the original Rac-FRET biosensor in an effort to match their localization with that of Rac. In the first one, the NLS in the Rac C-terminal tail was destroyed by mutagenesis (Figure $3.10 \mathrm{C}$ ), resulting in noNLS-RacCT, while in the second the entire Rac C-terminal tail that follows the SECFP was removed, generating the no-CT or the cytosolic probe (Figure 3.10C and D). Both C-terminally modified biosensors gave similar readout in FRET measurements. The localization of the cytosolic biosensor was more uniform within the cell, provided stronger signal to noise ratio and was more homogeneously expressed among different cells. Therefore most of the measurements for Rac activation in PGCs were performed using the cytosolic FRET biosensor. 

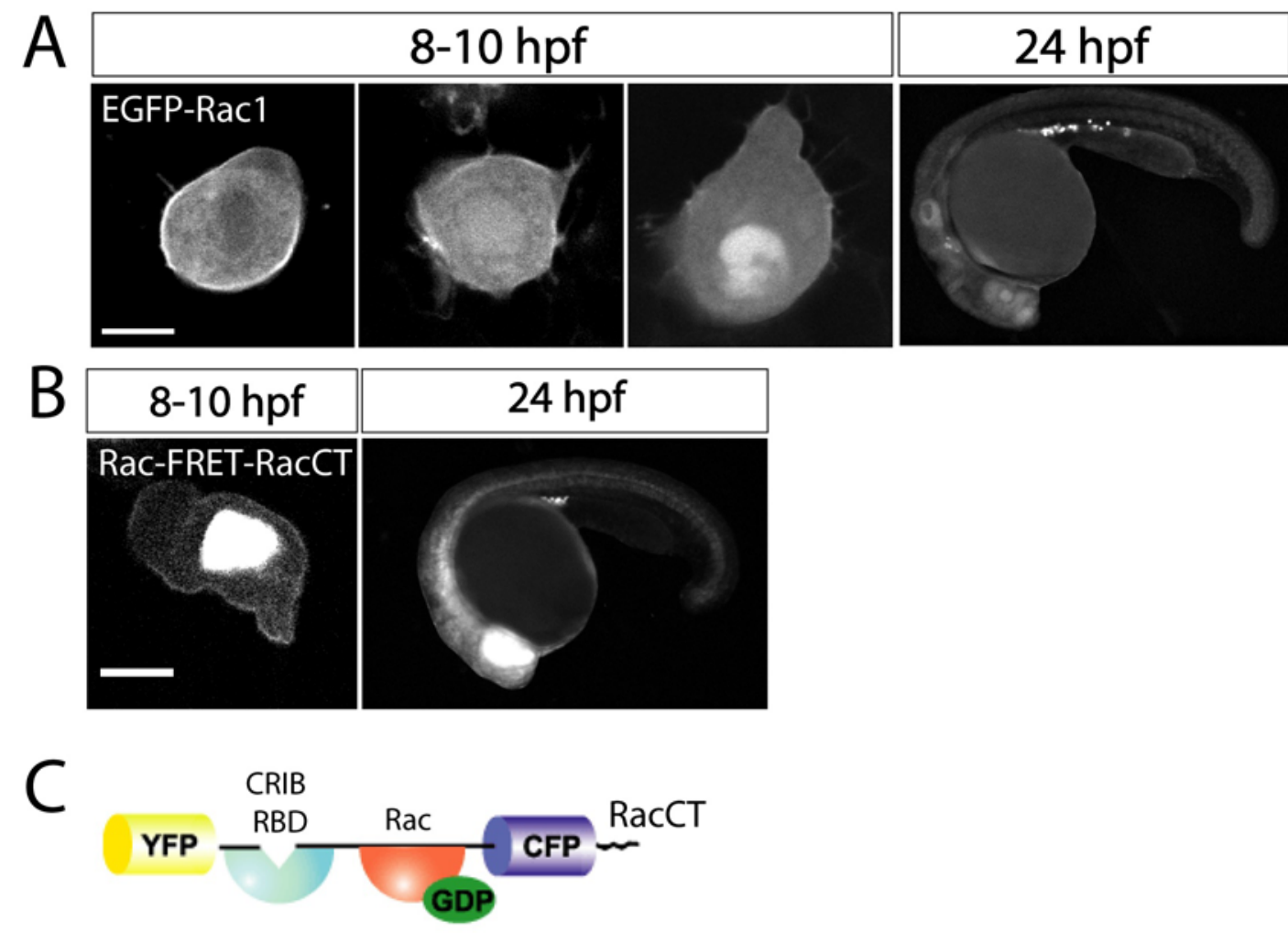

RacCT: VAIRA V L CPPPVEKRKRKCLLL noNLS-RacCT: R185G/K186Q
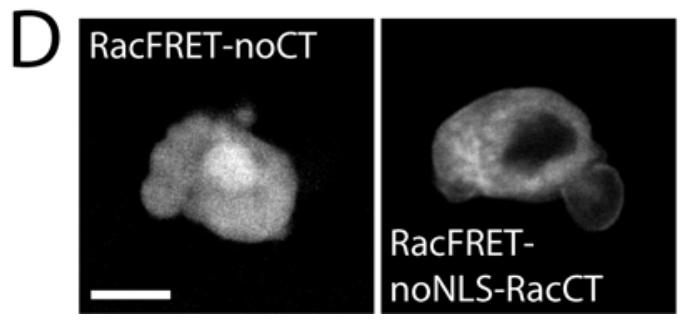

Figure 3.10 Targeting Rac-FRET biosensor expression in PGCs

A. Localization of Rac, was visualized with EGFP fusions. Three representative PGCs expressing Rac1-EGFP during migratory stages are shown at the left. Representative embryo at $24 \mathrm{hpf}$ is shown at the right B. Representative PGC expressing original Rac-FRET biosensor is shown at the left and the embryo at $24 \mathrm{hpf}$ is shown at the right. $\mathbf{C}$. The most $\mathrm{C}$ terminal sequence from the original Rac-FRET biosensor is shown. The canonical nuclear localization signal (NLS) is highlighted in blue. The substitutions that destroy the nuclear localization signal in the C-terminal domain of the original Rac-FRET biosensor are shown below. The amino acid substitutions that destroy the NLS in the Rac C-terminal tail are shown below. The numbers correspond to the amino acid number within the Rac1 C-terminal domain D. Representative PGCs expressing Rac-FRET biosensors with modified C-terminal domain are shown. One-cell stage embryos were injected with $300 \mathrm{pg}$ of mRNA for the EGFP-Rac1nos1-3'UTR (A); 360pg of mRNA for the RacFRET-RacCT-nos1-3'UTR (B); 360 pg of mRNA for RacFRET-noCT-nos1-3'UTR (D, cell at the left) and $360 \mathrm{pg}$ of mRNA for RacFRETnoNLS-RacCT-nos1-3'UTR (D, cell at the right). hpf -hours post fertilization. Scale bar: 10 $\mu \mathrm{m}$ 


\subsubsection{Scale setup for measuring Rac activity}

In the next step, the measurements with the two new C-terminally modified RaFRET biosensors were performed. In order to interpret correctly the ratio information obtained with FRET biosensors, the range between its active and inactive states has to be established. To date there is no published protocol introducing an accurate and reliable method fordistinguishing between the active and inactive states of the FRET biosensor within a cell. Controls necessary for establishing the range with Rac-FRET biosensor are presented below. Note that a similar principle applies to any other biosensor as well. To define the ratio values corresponding to the inactive, GDPloaded state of the Rac-FRET biosensor, Rac-FRET biosensor was coexpressed with Rac1N17 dominant-negative mutant. Rac1N17 is believed to result in Rac inactivation by competing with endogenous GEFs for Rac activation [48]. Therefore the Rac-FRET is expected to be found in the GDP-bound, inactive state and give a low FRET/CFP ratio when coexpressed with Rac1N17. Indeed, Rac-FRET biosensor exhibits a dose-response to the inactivation by the Rac1 N17 (Figure 3.11A and B). To define the ratio values corresponding to the active, GTP-loaded state, I introduced the G12V substitution in the Rac coding region of Rac-FRET. The G12V substitution inactivates Rac ability to hydrolyse GTP to GDP resulting in the constant association of Rac with the CRIB domain of the probe predicted to give the highest possible ratio value for the given sensor [50] (Figure 3.11A). Both C-terminally modified Rac-FRET biosensors responded similarly to the inactivation by the DN Rac1 $N 17$, suggesting that the new biosensors must be sensitive to the activation by endogenous GEFs (only the data for the cytosolic biosensor are shown). In addition, the activation patterns obtained with both biosensors were similar (Figure 3.11C). However, the localization of the cytosolic Rac-FRET biosensor was more uniform, resembling the subcellular localization of Rac and in addition provided a better signal intensity, which is essential for the accurate ratio imaging. Therefore, I proceeded by using the cytosolic biosensor. As in the case for the SECFP-Ypet tandem, I observe an increase in the FRET/CFP ratio with time (Figure 3.12). 
A
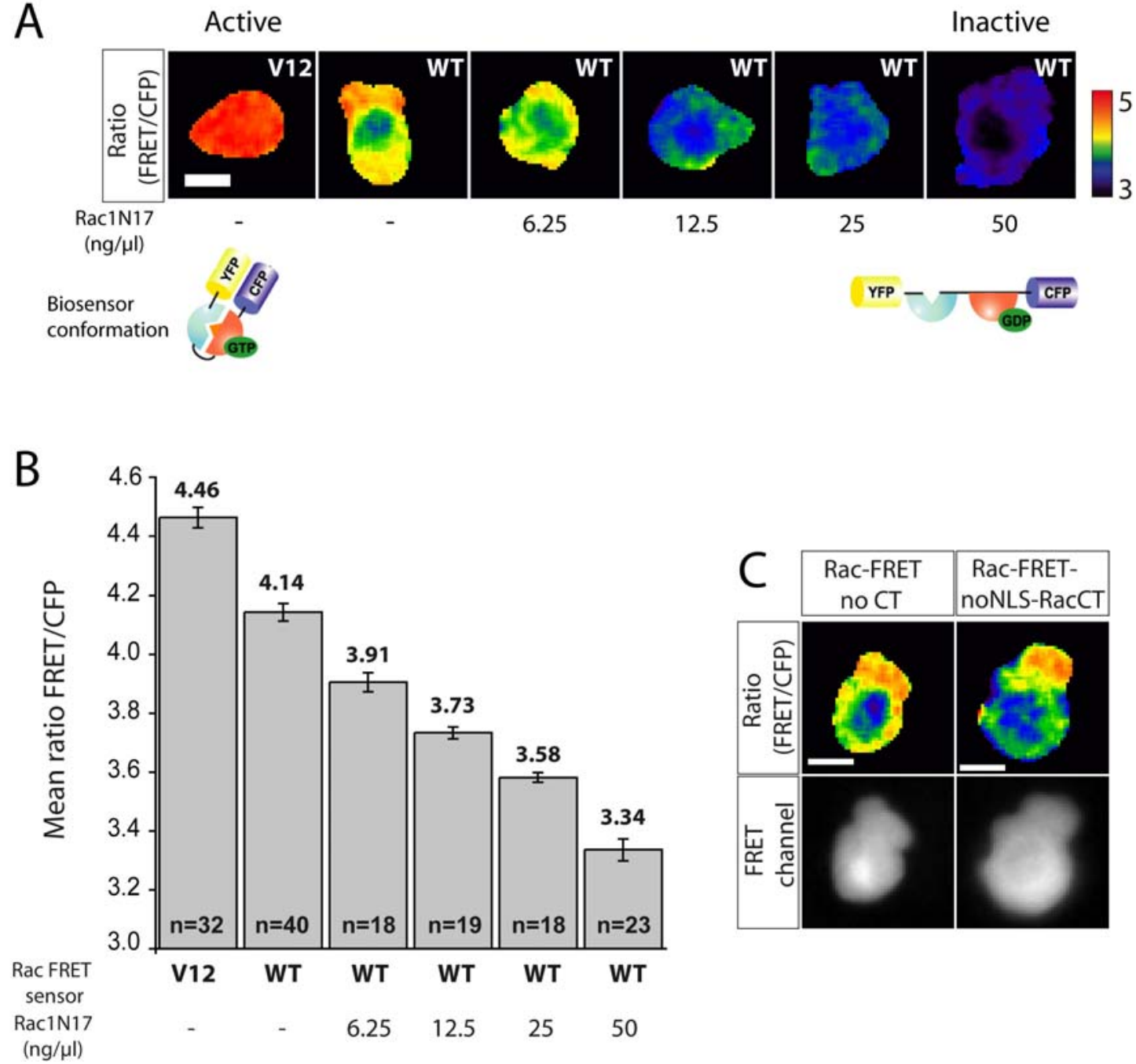

Figure 3.11 Calibration for the Rac-FRET biosensor

A. Representative ratio images displaying a range of activation states for Rac-FRET biosensor are shown. V12 mutation was introduced in the coding region of Rac within the biosensor rending a positive control. Different concentrations of Rac1 ${ }^{\mathrm{N} 17}$ dominant-negative mutant were coinjected with Rac-FRET biosensor to achieve the range of activation levels. $B$. Graph is showing mean ratio FRET/CFP values corresponding to the cells presented in A. C. Comparison between Rac-FRET biosensors with two different C-terminal modifications. Onecell stage embryos were injected with $360 \mathrm{pg}$ of mRNA for the RacV12-FRET-noCT-nos13'UTR (A, cell at the left) and mixes of 360pg of mRNA for the RacFRET-RacCT-nos1-3'UTR together with the indicated amounts of mRNA for Rac1N17-nos1-3'UTR (A, all cells except for the cell at the left); $360 \mathrm{pg}$ of mRNA for RacFRET-noCT-nos1-3'UTR (C, cell at the left) and $360 \mathrm{pg}$ of mRNA for RacFRET-noNLS-RacCT-nos1-3'UTR (C, cell at the right). Scale bar: $10 \mu \mathrm{m}$ 


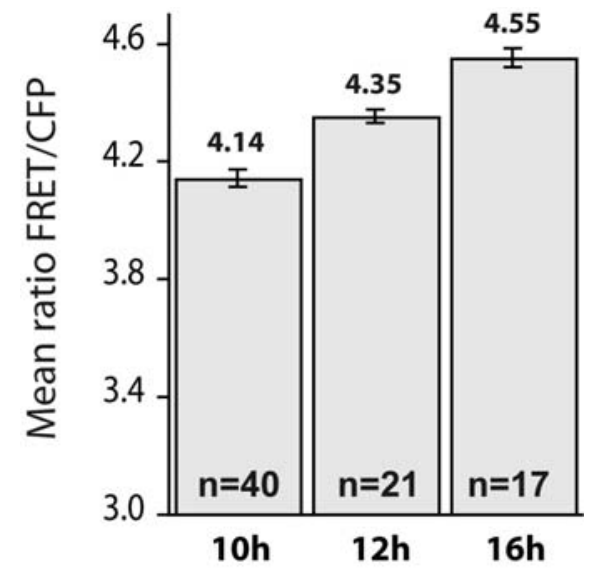

Figure 3.12 Increase in FRET of the Rac-FRET biosensor with time.

One cell stage embryos were injected with the $300 \mathrm{pg}$ of mRNA for the Ypet-SESFP-nos13'UTR and the FRET measurements were performed at different stages.

To further validate, that RacFRET biosensor responds to activation by GEFs, I tested the Rac-specific GEF: T-Cell lymphoma invasion and metastasis 1 (Tiam1). Tiam1 was shown to activate Rac in response to LPA stimulation and it is possible that Tiam1 might be activated by CXCR4 in response to SDF [94]. Tiam1 belongs to Dbl homology $(\mathrm{DH})$ domain family of GEFs. The $\mathrm{DH}-\mathrm{PH}$ module represents the functional domain in the Dbl-homology family of GEFs and is sufficient to activate Rac [42]. When the DH-PH domain of Tiam1 was coexpressed together with the Rac-FRET an increased level of Rac activation was observed in PGCs (Figure 3.13A and B), which as expected appeared to adversely affect PGCs migration resulting in $42 \%$ of ectopic cells at $24 \mathrm{hpf}$.

A

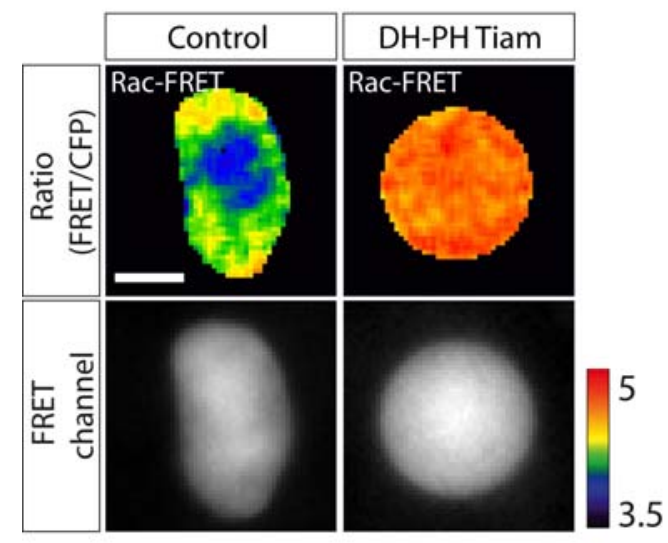

B

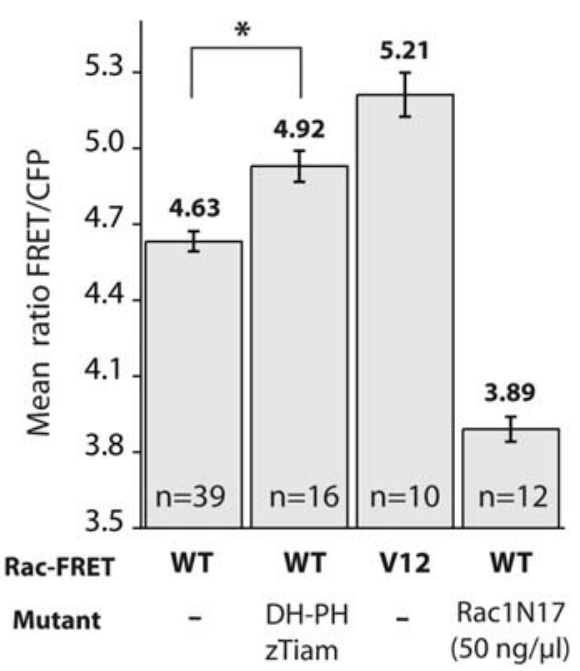

Figure 3.13 DH-PH domain of Tiam1 activates Rac in PGCs

A. Representative images of PGCs expressing the Rac-FRET biosensor together with the control protein (left cell) or DH-PH domain of Tiam1 (right cell). Images of PGCs for the 
positive and negative controls are not shown here B. Graph comparing the mean emission ratios FRET/CFP for Rac-FRET sensors in the presence of control or DH-PH domain. * $p<0.005$. One cell stage embryos were injected with the mixes of $360 \mathrm{pg}$ of mRNA for the RacFRET-noCT-nos1-3'UTR together with $600 \mathrm{pg}$ of the control mRNA (A, cell at the left) or with the $400 \mathrm{pg}$ of mRNA for the DH-PH(Tiam1)-nos1-3'UTR (A, cell at the right) Scale bar: $10 \mu \mathrm{m}$

These results indicate that the Rac-FRET biosensor faithfully reflects the activation state of Rac in PGCs and responds specifically to activation by exogenously introduced GEFs.

\subsubsection{Rac activation during PGC migration revealed with FRET}

FRET biosensors were previously used before to demonstrate the activation pattern for Rho GTPases in cells migrating in 2D environment. For example, Rac activity was detected in membrane ruffles in response to EGF stimulation [58]. However, little is known regarding Rho GTPases activation pattern in the cells migrating in 3D environment. I measured Rac activity in migrating PGCs during both run and tumbling phases. During the run phase Rac activity localized to the front and to the back of a migrating cell, yet the level of activation at the front was higher than the one at the back (17 cells out of 22) (Figure 3.14A and B and supplemental movie S17). The central area of the cell exhibiting low Rac activity corresponds to the nucleus, which was confirmed during the measurements with the original Rac-FRET biosensor, which localized to the nucleus of PGCs (Data not shown here). During the tumbling phase, Rac activity was detected at the cell periphery and in blebs (Figure 3.14C and supplemental movie S18). Due to the acquisition conditions it was not possible to resolve the correlation between the Rac activity and bleb formation. 


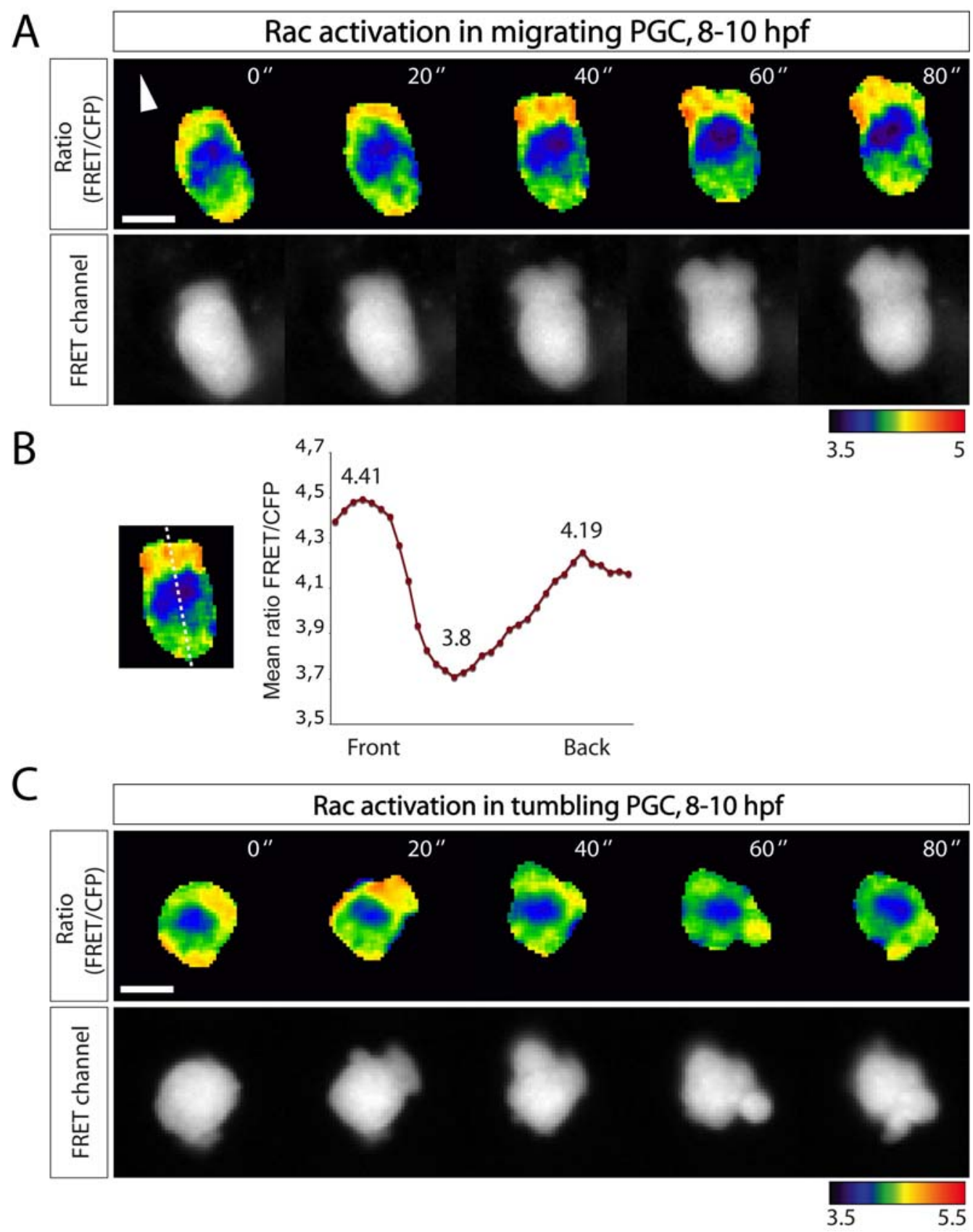

Figure 3.14 Rac activation during PGC migration

A., C. Representative images of migrating PGCs run (A) and tumbling (C) phases are shown. Upper panel shows the FRET/CFP ratio image and the lower panel shows the FRET channel. B. Intensity profile of Rac activation along the line in the cell at 40 " from (A) is plotted. Onecell stage embryos were injected with $360 \mathrm{pg}$ of mRNA for the RacFRET-noCT-nos1-3'UTR. Arrow indicates the direction of a migration. Scale bar: $10 \mu \mathrm{m}$

Previous reports have suggested, that activated GPCRs could lead to stimulation of Rho GTPases by directly activating specific GEFs [95]. To test, whether Rac activity depends on SDF-1a/CXCR4b signalling in PGCs, I measured Rac activity in PGCs laching functional SDF-1a/CXCR4b signalling. For this I knocked down CXCR4b or SDF-1a expression with morpholino antisense 
oligonucleotides. There was no detectable difference in the Rac activation pattern in PGCs migrating non-directionally without functional SDF-1a/CXCR4b signalling (Figure 3.15A). Additionally, the level of Rac activation was unaffected by the knockdown of either SDF-1a or CXCR4b (Figure 3.15B).
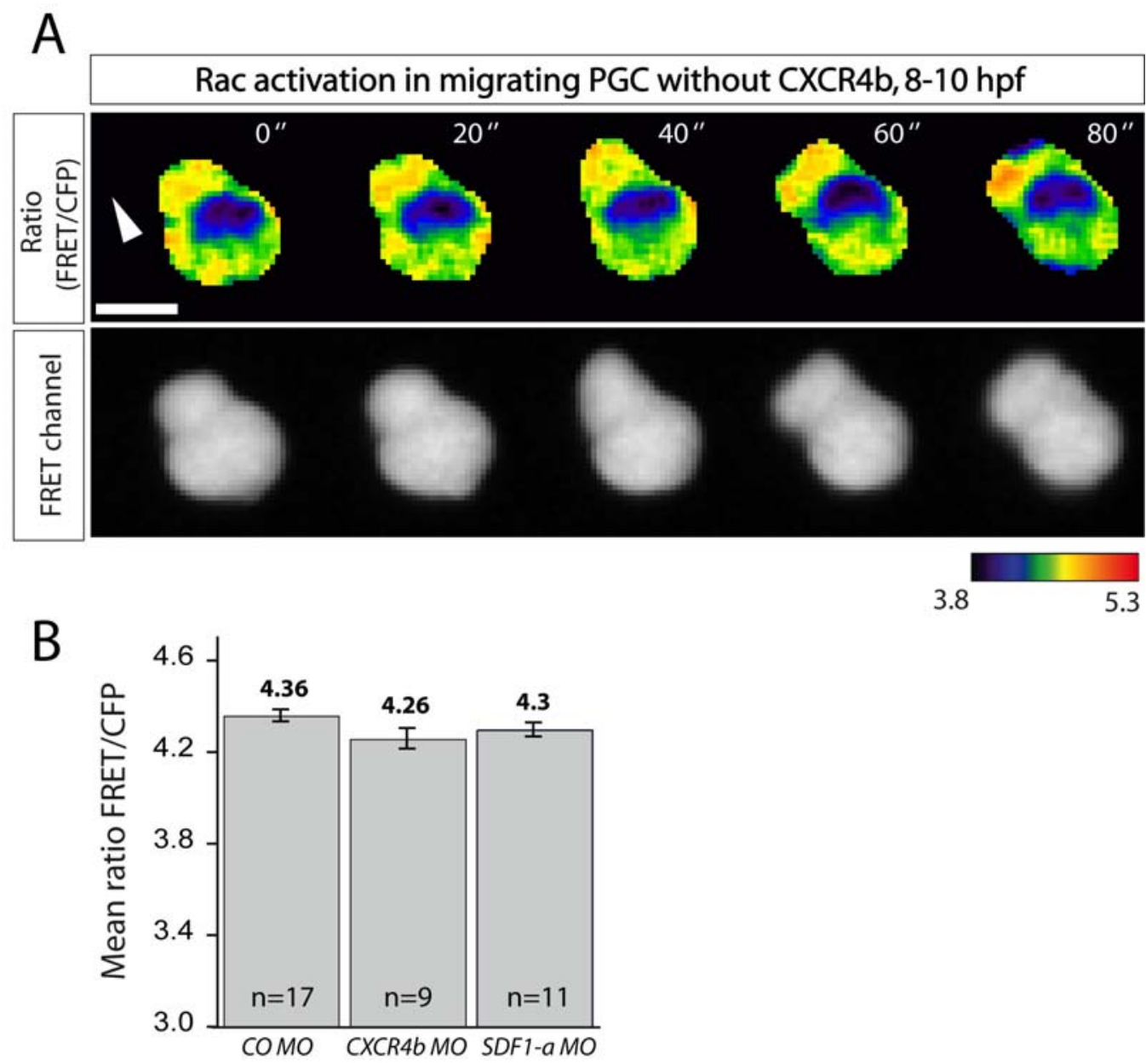

Figure 3.15 Rac activation in PGCs migrating without functional SDF-1a/CXCR4b signalling

A. Representative PGC migrating without functional CXCR4b. Upper panel shows the FRET/CFP ratio image and the lower panel shows the FRET channel. One-cell stage embryos were injected with $360 \mathrm{pg}$ of mRNA for the RacFRET-noCT-nos1-3'UTR together with 0.6 pmol of morpholino against CXCR4b (A) or with the 0.6 pmol of control morpholino, ,CXCR4b morpholino, or SDF-1a morpholino (B). Arrow indicates the direction of a migration. B. Graph shows the comparison between Rac activation levels in PGCs in the wild type situation versus SDF-1a or CXCR4b knockdown. Scale bar: $10 \mu \mathrm{m}$

The Rac activation pattern revealed by FRET is in agreement with previous reports in other cell types, where Rac was shown to be active at the front of the cell. Activation of Rac at the front of the cell could account for actin polymerization into brushes (Figure 3.1 and 3.2A). The Rac activation pattern in the absence of the 
functional SDF-1a/CXCR4b signalling strongly suggests that Rac activity is most likely needed for the general motility of PGCs rather than their directional migration.

\subsubsection{Cdc42 activation revealed with FRET in PGCs}

The localization of the Cdc42-FRET biosensor was compared with the localization of Cdc42 as visualized with its EGFP fusion (Figure 3.16A and B). Similarly to Rac, Cdc42 was localized throughout the cell exhibiting a dynamic localization to the membrane, cytosol and/or to the nucleus (Figure 3.16A, cells at 8 to $10 \mathrm{hpf}$ ). Overexpression of EGFP fusion for Cdc42 seemed not to interfere with the normal PGC migration as PGCs exhibited normal morphology during their migration and arrived at their proper positions at 24 hours (Figure 3.16A, embryo at $24 \mathrm{hpf}$ ). Localization of Cdc42-FRET was comparable with the localization pattern exhibited by Cdc42, matching the cells, in which it was localized to the cytosol and nucleus (Figure 3.9A and B, middle panels). Localization of the Cdc42-FRET biosensor showed no variations among different cells. Since the localization of Cdc42-FRET and Cdc42 matched in many PGCs and due to its uniform expression within cells, no further modifications were made to this biosensor.

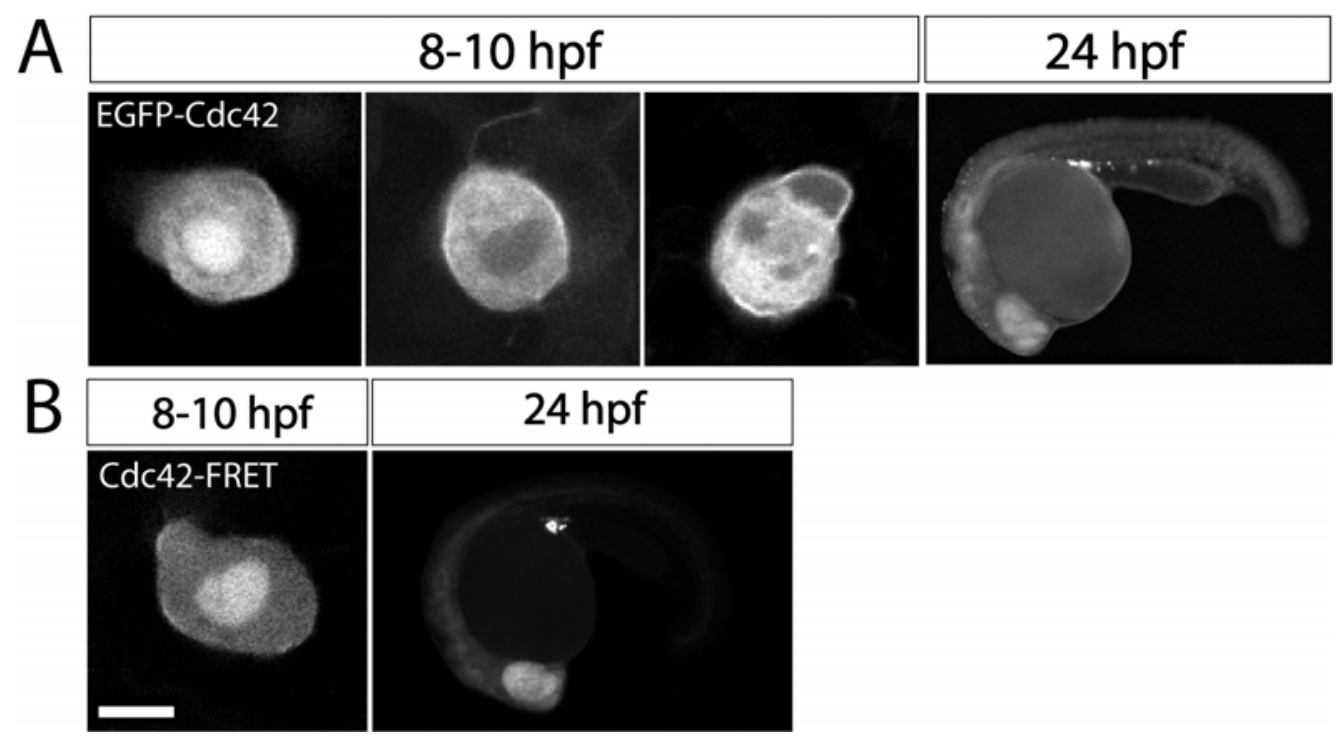

Figure 3.16 Targeting Cdc42-FRET biosensor expression in PGCs

A. Localization of Cdc42 was visualized with EGFP fusion. Three representative cells are shown at the left. Representative embryo at $24 \mathrm{hpf}$ is shown at the right $\mathbf{B}$. Representative PGC expressing original Rac-FRET biosensor is shown at the lefft and the embryo at $24 \mathrm{hpf}$ is shown at the right. One-cell stage embryos were injected with $300 \mathrm{pg}$ of mRNA for the EGFP-Cdc42-nos1-3'UTR (A); 360pg of mRNA for the Cdc42FRET-Cdc42CT-nos1-3'UTR (B); hpf - hours post fertilization. Scale bar $10 \mu \mathrm{m}$ 
Measurements with FRET biosensors previously revealed that in fibroblasts Cdc42 activity localizes to the leading upon EGF stimulation [58]. Surprisingly, when measured in PGCs, the activation pattern of Cdc42 was reciprocal to that of Rac, low in the cytoplasm and high in the nucleus (Figure 3.17). Slight reduction in Cdc42 activation was observed in the frontal protrusion (Figure 3.17. 20" and 40" and supplemental movie S20). These findings are surprising, given that Cdc42 in PGCs is not active at sites of cytoskeleton rearrangements within cells.

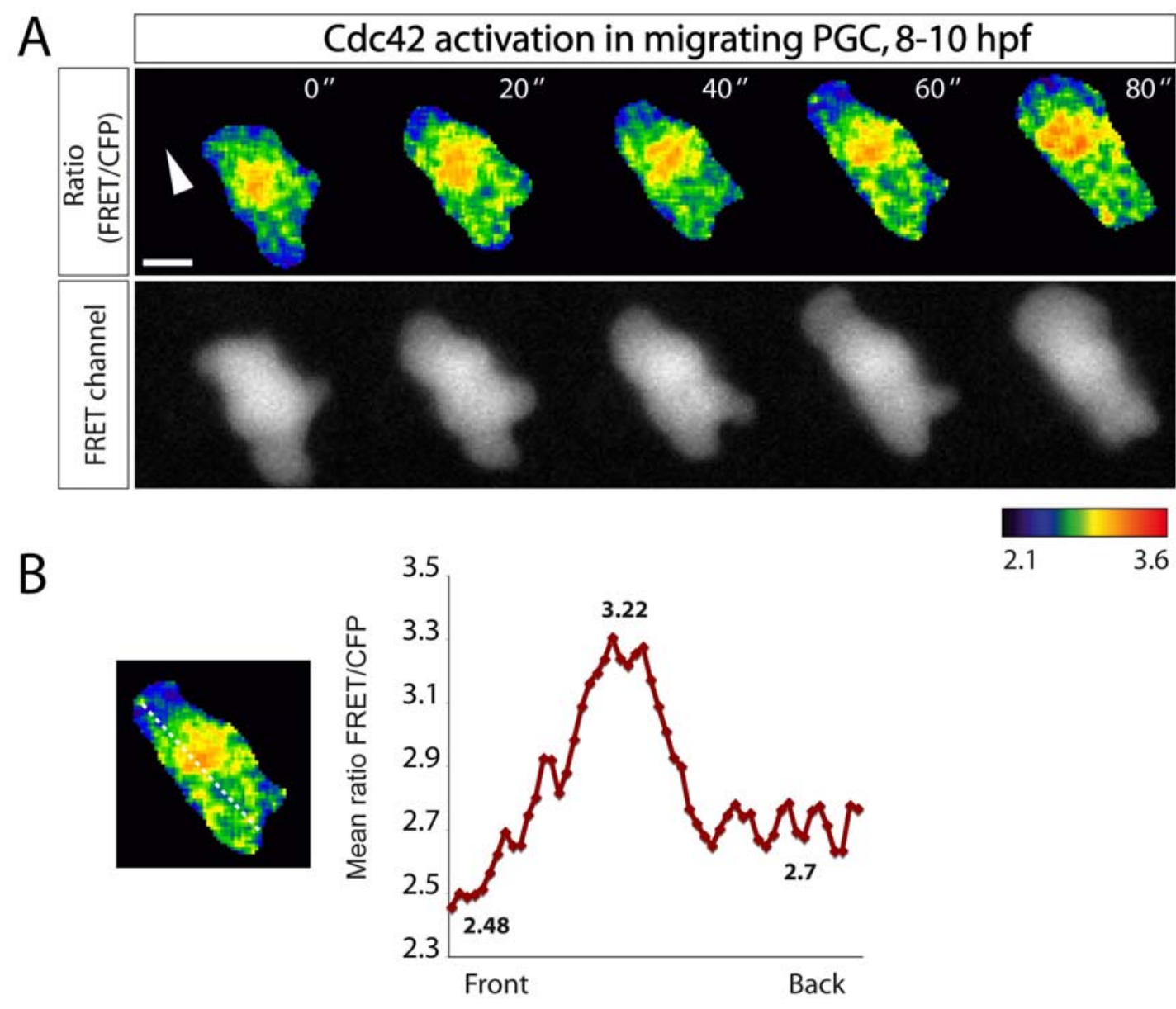

Figure 3.17 Cdc42 activation during PGC migration

A. Representative image of PGC expressing Cdc42 FRET biosensor is shown. Upper panel shows the FRET/CFP ratio image and the lower panel shows the FRET channel. B. Intensity profile of Cdc42 activation along the line in the cell at 60 " from (A) is plotted. Arrow indicates the direction of a migration. One-cell stage embryos were injected with 360pg of mRNA for 360pg of mRNA for the Cdc42FRET-Cdc42CT-nos1-3'UTR. Scale bar: $10 \mu \mathrm{m}$ 


\subsubsection{RhoA activation revealed with FRET in PGCs}

To study the RhoA activation in PGCs, first the localization of the RhoA-FRET biosensor was compared with the localization of RhoA as visualized through EGFP fusion (Figure 3.18A and B). RhoA was localized uniformly throughout the cell and was excluded form the nucleus (Figure 3.18A, cells at 8 to $10 \mathrm{hpf}$ ). Overexpression of EGFP fusion for RhoA seemed not to interfere with the normal PGC migration as PGCs exhibited normal morphology during their migration and arrived at their proper positions after 24 hours (Figure 3.18A, embryo at $24 \mathrm{hpf}$ ). RhoA-FRET localized to the membrane in PGCs, which differs from the localization of EGFP-RhoA (Figure 3.18A and B, cells at 8-10 hfp). The biosensor for RhoA provided a limited amount of signal available for measurements to be taken, which made experiments with the original RhoA-FRET technically impossible to perform. Measurements with Cterminally-modified Rac-FRET biosensors suggested that the cytosolic biosensor is fully functional in reporting Rac activation in PGCs (Figure 3.11C). I assumed, that similarly to Rac-FRET, cytosolic RhoA-FRET should be a valid tool for measuring RhoA activation in PGCs. Therefore, measurements for RhoA were also performed with the cytosolic RhoA-FRET biosensor.

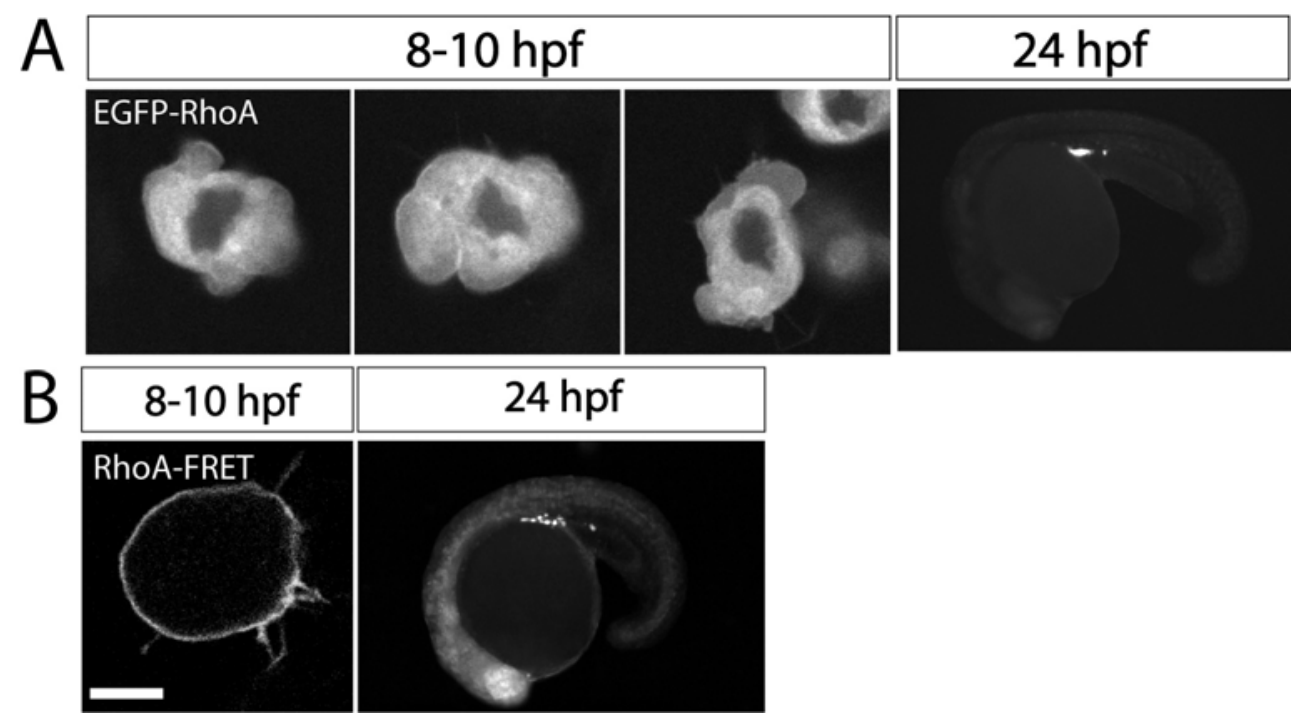

Figure 3.18 Targeting RhoA-FRET biosensor expression in PGCs

A. Localization of Rac, was visualized with EGFP fusions. Three representative cells are shown at the left. Representative embryo at $24 \mathrm{hpf}$ is shown at the right $\mathbf{B}$. Representative PGC expressing original RhoA-FRET biosensor is shown at the lefft and the embryo at $24 \mathrm{hpf}$ is shown at the right. One-cell stage embryos were injected with $300 \mathrm{pg}$ of mRNA for the EGFP-RhoA-nos1-3'UTR (A); 360pg of mRNA for the RhoA-FRET-RhoA-CT-nos1-3'UTR (B); hpf - hours post fertilization. Scale bar $10 \mu \mathrm{m}$ 
RhoA activity is believed to associate with the back of the cell, where it regulates acto-myosin contraction during rear retraction [84]. It has been demonstrated through a FRET approach that RhoA activity localizs to the back of the polarized neutrophils [96]. However, several recent reports utilizing FRET biosensors have shown that in certain cell types, such as HeLa cells stimulated with EGF, RhoA activity can also detected at the front of migrating cells [87].
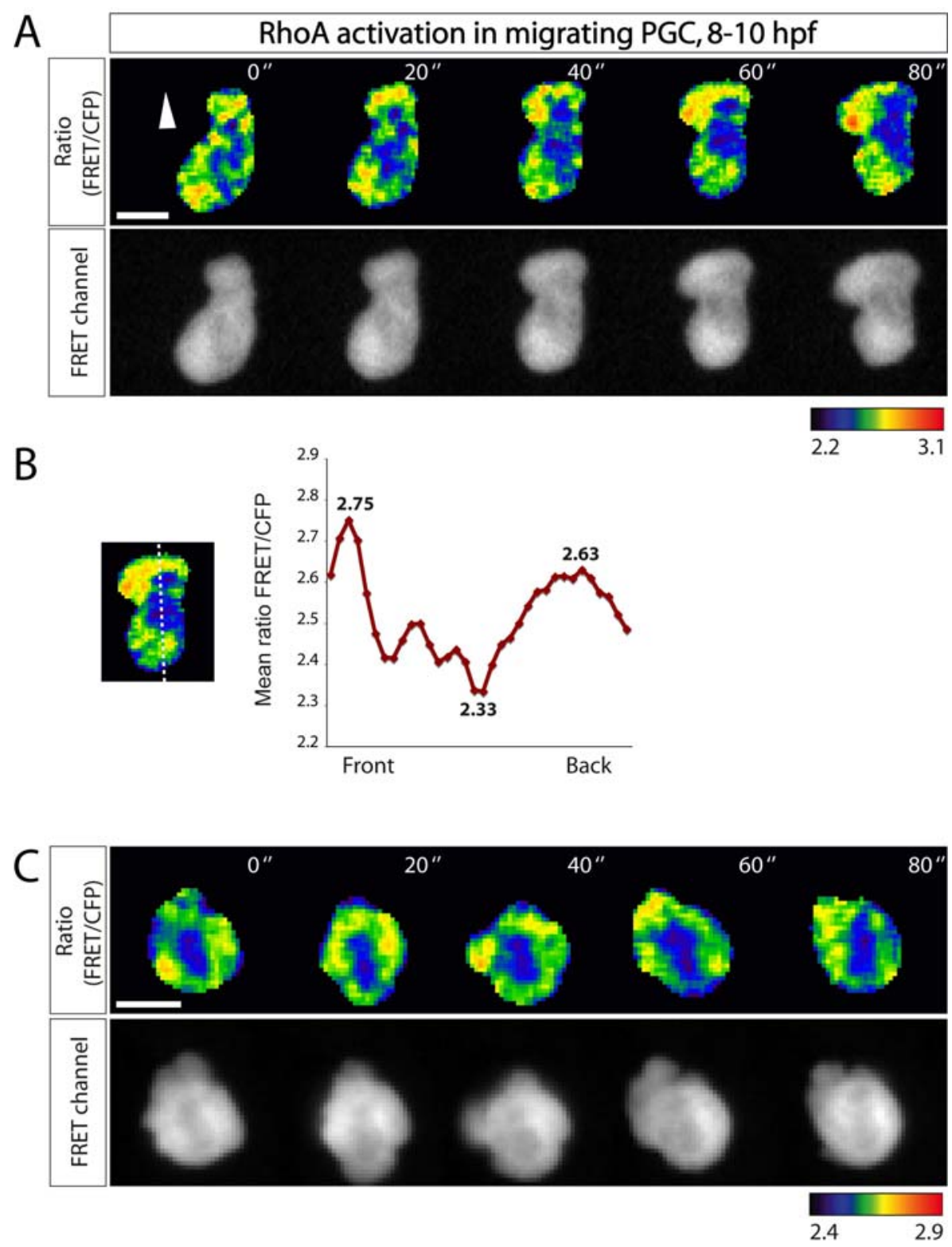

Figure 3.19 RhoA activation during PGCs migration

A. Representative PGCs expressing RhoA FRET biosensor during run (A) and during tumbling (C) phases are shown. Upper panel shows the FRET/CFP ratio image and the lower panel shows the FRET channel. B. Intensity profile of RhoA activation along the line in the cell at 60 " from $(A)$ is plotted. One-cell stage embryos were injected with 360pg of mRNA for the RhoA-FRET-noCT-nos1-3'UTR. Arrow indicates the direction of a migration. Scale bar: $10 \mu \mathrm{m}$ 
FRET imaging in PGCs, detected RhoA activity at the front and at the back of the migrating PGC in a pattern similar to that of Rac, while the front exhibited higher levels of activation. Also, similar to Rac activation the activity of RhoA was reduced at the central region of the cell, which corresponds to the nucleus (Figure 3.19A and $B$ and supplemental movie S21). During tumbling, RhoA activity was detected at the cell periphery and in the blebs resembling the activation pattern of Rac (Figure 3.19C).

\subsection{Signalling events during PGC migration}

\subsubsection{Calcium influx at ectopic locations is not sufficient to trigger actin polymerization}

In order to migrate, cells have to polarize by generating the leading edge with the protrusive activity and the retracting back [32]. Cells can polarize in response to a signal or spontaneously [97]; [98]. Due to their ability to migrate in the absence of SDF-1a/CXCR4b signalling, PGCs represent one of the examples of spontaneous cell polarization [66]. PGCs ability to polarize spontaneously is reflected by the actin brushes formation at the leading edge when PGCs are migrating non-directionally in the absence of SDF-1a/CXCR4b signalling (Figure 3.2D). It has been proposed that during normal physiological processes, the signals inducing polarization could contain two elements: one that activates spontaneous asymmetry amplification process, and another one that provides spatial bias directing the polarization in the relevant orientation [97]. One may therefore suggest that calcium signalling downstream of the activated receptor could provide such bias in migrating PGCs. Previous studies from our lab have demonstrated that during directional migration of PGCs to their targets, there is an elevated level of calcium at the front, which presumably results in MLCK activation and therefore bleb formation [34]. I wondered, whether calcium rise could trigger the assembly of actin brushes in PGCs. 


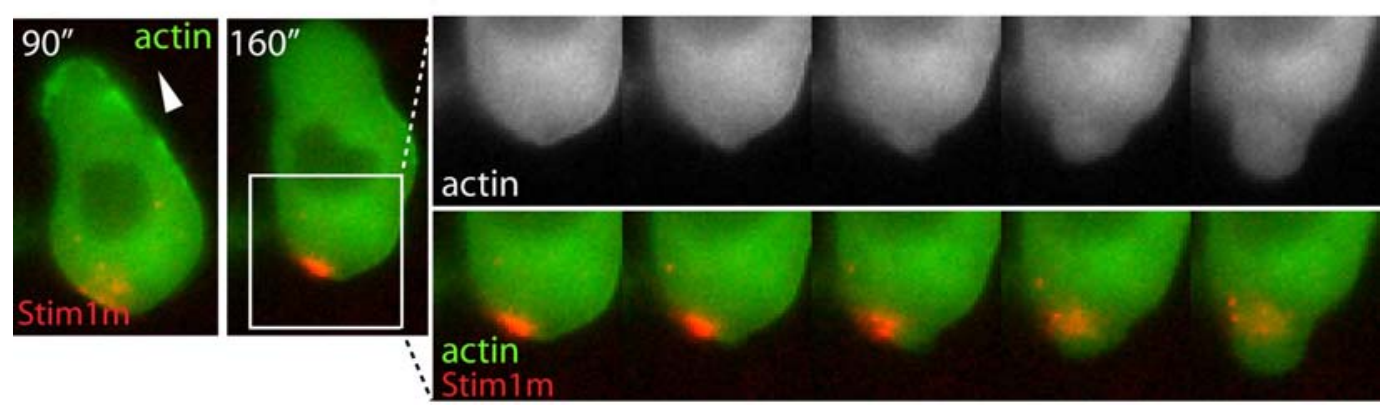

Figure 3.20 Calcium influx at ectopic location does not lead to actin brushes formation PGCs

Representative PGC expressing Stim $1^{\mathrm{M}}$ mutant (red) and the actin-EGFP (green) in the run phase is shown. Panel shows Individual snapshots corresponding to $160-220 \mathrm{sec}$ interval from the supplemental movie S22, where bleb formation induced by Stim $1 \mathrm{M}$ at the back of the cell is observed. Time interval between the frames is 5 sec. $450 \mathrm{pg}$ of mRNA for dsRedMutStim1-nos1-3'UTR. Actin in PGCs was visualized with the transgene kop-EGFPactin-nos1-3'UTR. Arrow indicates the direction of a migration.

To test this hypothesis, the Stim $1^{\mathrm{M}}$ mutant was used to induce calcium influx at the back of the cell, where actin brushes do not usually form [34]. Stim1 functions in regulating calcium influx in the cell. Stim1 normally resides in the ER and upon calcium depletion from internal stores translocates to the plasma membrane, where it regulates calcium channels, such as Orai1 [99]. In the presence of the Stim ${ }^{\mathrm{M}}$ mutant, PGCs could polarize and the actin brushes were detected at the front of the cell (Figure 3.20, snapshot of a cell at 90" and supplemental movie S22). Stim1 ${ }^{\mathrm{M}}$ induced bleb formation at the back of the cell as previously reported ([34] and Figure 3.20), however actin brushes were not formed at the back of the cell where calcium was increased by the action of Stim1 $1^{\mathrm{M}}$ (Figure 3.20). These results suggest, that Calcium rise alone is not sufficient to initiate actin polymerization resulting in the functional leading edge.

\subsubsection{Signalling downstream to activated Rac}

Activated Rac is able to induce a number of signalling cascades by binding to its effectors [100]. To understand how Rac activity manifests itself to a specific cellular behaviour, it is important to know the particular pathway operating downstream of Rac at that given situation. The next series of experiments was aimed at dissecting downstream signalling cascades induced by activated Rac in migrating PGCs. Specific residues within the effector recognition domain of RhoGTPases responsible for binding to a particular partner have been already determined [101]. 
To define, which effectors are activated downstream of Rac in migrating PGCs, double mutants of Rac defective in binding to a particular effector or effectors were generated. In these mutants, a second mutation known to affect the interaction of activated Rac with its specific partner was introduced in addition to the G12V substitution. Rac1 $\mathrm{V} 12$ mutant expressed in PGCs signals aberrantly resulting in a high percentage of ectopic cells at $24 \mathrm{hpf}(82.4 \%)$. The second mutation that prevents binding of the activated Rac to a particular downstream partner should rescue the migration PGC phenotype caused by the G12V substitution only if the downstream pathway operates through that partner in PGCs. The mRNA produced using cDNA templates of these double mutants was co injected with a marker that allows visualization of PGCs and ectopic cells were counted after 24hours.

$\mathrm{P} 21$-activated kinase (PAK) is often implicated in regulating actin dynamics downstream to activated Rac/Cdc42. Upon activation, PAK phosphorylates LIM kinase, which in turn phosphorylates and inhibits cofilin, an actin-severing molecule [102]. The Y40 residue in Rac is important for the binding to, and activating p21activated kinase (PAK). Rac1 $12 \mathrm{C} 40$ double mutant led to a less severe phenotype as compared to the Rac1 $\mathrm{V} 12$ mutant, however Rac1 $\mathrm{V} 12 \mathrm{C} 40$ still affected PGC migration resulting in $61.8 \%$ of ectopic cells at $24 \mathrm{hpf}$ as compared to $82.4 \%$ of cells induced by Rac1 V12 mutant (Figure 3.21, $p<0.0005$ ). These data suggest that in addition to inducing PAK signalling, Rac might induce other signalling events in PGCs.

The F37 residue of Rac is important for inducing membrane ruffles via interaction with POR1, a partner of activated Rac1 [103]. Rac1V12L37 double mutant also resulted in reduced germ cell phenotype at $24 \mathrm{hpf}$ (63.5\% ectopic cells) as compared to the Rac1 $\mathrm{V} 12$ single mutant (Figure 3.21, $\mathrm{p}<0.0005$ ). These results suggest that in PGCs, activated Rac could operate through at least two different pathways - such as PAK and POR1. To test this supposition, a triple mutant was designed, in which both pathways were affected. Indeed, the triple Rac1V12L37C40 mutant failed to induce strong migration phenotype in PGCs resulting only in $18 \%$ of ectopic cells at 24hpf (Figure 3.21, p<0.00005).

Another mechanism employed by an activated Rac to induce actin polymerization might be mediated via stimulation of the type I phosphatidylinositol-4phosphate 5-kinase (PIP5-kinase) [104]. Activated PIP5- kinase is responsible for generating PIP2 pools that regulate actin polymerization by uncapping existing actin filaments [105]. K186 residue in C-terminal tail of Rac is important for inducing the PIP5-kinase activity. Rac1V12E186 did not lead to a reduction in the percentage of 
ectopic PGCs at $24 \mathrm{hpf}$ resulting in $87.2 \%$ of ectopic cells (Figure 3.21). These data led led me to conclude that at least two signalling pathways are likely to operate in PGCs downstream to activated Rac, one operating through PAK and another one through POR1 stimulation. Moreover, the PIP5-kinase signalling pathway appears not to play a role in PGC migration downstream of activated Rac.

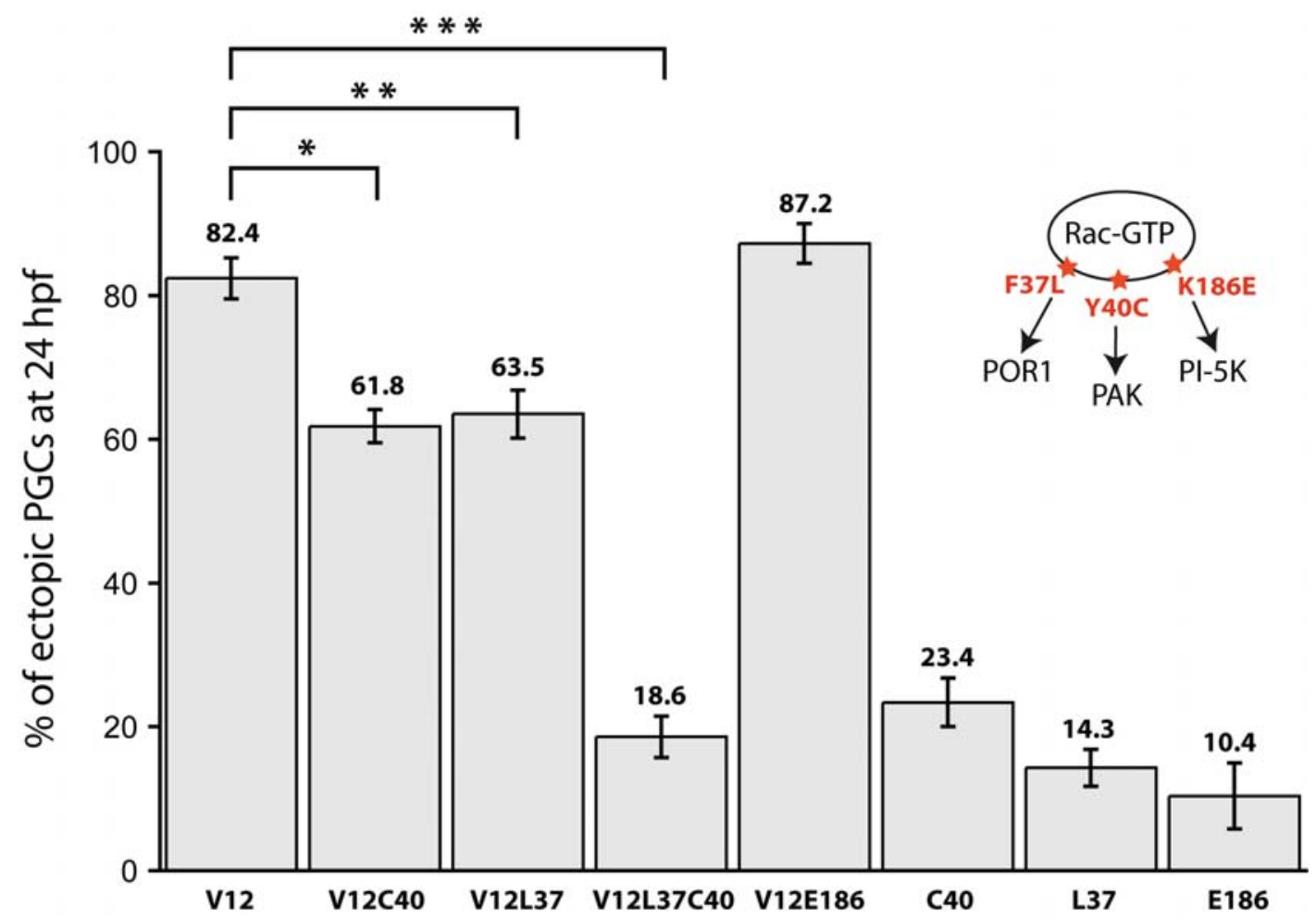

Figure 3.21 Dissecting signalling pathways downstream to activated Rac1 in PGCs

One-cell stage zebrafish embryos were injected with the mix of 150pg of mRNA for Rac1 mutants together with 90pg of mRNA for Venus-nos1-3'UTRCs. Ectopic PGCs were counted at 24 hours. A drawing depicts individual mutations (in red) affecting Rac1 binding to its effector proteins. POR1 - partner of activated Rac1, PAK- P21 activated kinase, PI-5K Phosphatidyl-Inositol 5 Kinase. ${ }^{*} p<0.00005,{ }^{* *} p<0.00005,{ }^{* * *} p<0.00005$ 


\section{DISCUSSION}

In the present study I used in vivo imaging to investigate the role of Rho GTPases in regulating actin cytoskeleton dynamics during PGC migration in zebrafish embryos. Results arising from this work show for the first time that Rac and RhoA are both active at the front of migrating PGCs and their activity exerts distinct effects on actin dynamics. Data presented here demonstrate, that Rac functions by regulating actin assembly into brushes at the leading edge of migrating cell, while RhoA activity results in actin backward flow and contraction. The possible mechanisms by which Rac and RhoA exert their effects on the actin cytoskeleton thereby promoting PGC motility are discussed. In addition, the technical aspects concerning the use of FRET-based biosensors in the in vivo situation are discussed.

\subsection{Rac and RhoA exert distinct effects on actin dynamics}

\subsubsection{Rac and RhoA are active at the front of migrating PGCs}

Most of the information regarding the spatial-temporal activation of Rho GTPases and actin cytoskeleton dynamics was obtained in culture cells migrating in a 2D environment. However, experiments performed in models for cell migration that are closer to the physiological environment, such as 3D Matrigel, suggested that the organization and dynamics of the actin cytoskeleton in cells within the living organism differ dramatically from that of cultured cells. In contrast to the cells situated in a 2D environment that form lamellipodia, membrane ruffles, stress fibers and focal adhesions, cells migrating in a 3D situation exhibit a more complex organization of actin at the front of the cell, refrain from forming stress fibers and focal adhesions [7, 8]. It is thus crucial to study the molecular mechanisms that govern cell migration in a physiological setting. The FRET method is the only available technique to study the activation pattern of Rho GTPases in living cells. Thus far, there were two reports that studied the activation pattern of Rho GTPases by utilizing FRET biosensors in the living organism. One such study presented the spatial-temporal activation pattern for RhoA, which was done in the lateral hypoblast cells in Zebrafish where it was shown that STAT3 signalling is required for RhoA activation and the establishement of cell polarization during convergence and extension [88]. In the other report, Rac and RhoA activation was measured with FRET biosensors in neural crest cells in 
Zebrafish and Xenopus [89]. However, in this latter study, the measurements were performed in fixed samples, which do not allow monitoring the dynamics of protein activity. The present thesis represents the first detailed study of Rho GTPases activation pattern in living cells migrating in the developing embryo performed with the FRET technique. Results presented here show that both Rac and RhoA are active at the front and at the back of migrating PGCs (Figure 3.14 A and B, and 3.19 $A$ and $B$ ), while Cdc42 is active in the nucleus (Figure 3.17). Cdc42 activity was reduced at the front of the cell during the protrusion formation (Figure 3.17A, 60 "). The Cdc42 activation pattern is strikingly different from that reported for other migrating cells, where FRET measurements showed that Cdc42 activity was restricted to the leading edge $[57,58]$. Additionally, in contrast to the established function of $\mathrm{Cdc} 42$ in inducing filopodia formation [45], the CA Cdc42V12 did not generate filopodia when expressed in PGCs. Instead, PGCs expressing Cdc42V12 formed shallow blebs (Figure 3.3C). Although it is presently unclear as to the exact function of Cdc42 activity in PGCs, its activation pattern suggests that Cdc42 is not the likely candidate to play a role in PGC migration. The cell-type specific nuclear localization for certain Rho GTPases including Rac and Cdc42 was previously reported [92]. Although there was no report demonstrating that Cdc42 is active in the nucleus of other cell types, it has been suggested that nuclear translocation of Rho GTPses might be implicated in the regulation of signalling programs inside the nucleus [93]. Cdc42 could also be involved in other aspects of PGC physiology like cell cycle regulation [37]. My data represent the first ever demonstration for Cdc42 activity in the nucleus of PGCs as determined by FRET. Further experiments would be necessary to validate the biological relevance for the presented Cdc42 activation pattern. Since the main focus of the present investigation was aimed at the role of Rho GTPases in actin cytoskeleton remodeling during PGC migration, further studies were focused solely at the function of Rac and RhoA alone in migrating PGCs.

The activation levels of both Rac and RhoA are higher at the front of migrating PGCs (Figure 3.14 A and B, and 3.19 A and B). The data obtained after measuring the Rac activation pattern in migrating PGCs are in line with previously published results, where Rac activation was measured with FRET in cells migrating in a 2D environment. For example, Rac activity was shown to localize ar the front of motile epithelial cells, behind the leading edge [57]. In another work, active Rac was detected at the front and also at the rear of neutrophils during chemotaxis [106]. Rac activity at the rear of the cell was suggested to play a role in the tail retraction as cells expressing the DN Rac mutant were unable to detach their rear from the substrate 
[106]. Rac function is well established in regulating actin polymerization. To promote actin polymerization activated Rac normally stimulates a nucleation promoting factor, such as WAVE, that in turn associates with the Arp2/3 complex to stimulate actin polymerization [107]. Most of the current knowledge regarding Rac function is based on in vitro studies performed in fibroblasts and epithelial cells, where its function is believed to result in localized actin polymerization that pushes the membrane at the leading edge $[6,108]$. In all PGCs analyzed, actin dense networks or actin brushes were detected at the front during the run phase [34] and Figure 3.1 and 3.2A). When Rac function was abolished using the CRIB domain of PAK targeted to the membrane in PGCs, actin brushes no longer formed (Figure 3.3A). Conversely, overexpression of the CA Rac1 $\mathrm{V} 12$ mutant resulted in actin polymerization at several locations within the cell and in the weaker actin signal at the cortical region (Figure 3.3 B). The apparent reduction of cortical actin in PGCs expressing Rac1V12 mutant could be explained by a competition between the signalling pathways controlling cortex formation and those regulating acting brushes assembly. Thus in Rac1 V12 expressing PGCs, the balance tipped towards brushes formation thus compromising the available actin for cortex formation. Based on these results I conclude that Rac function at the front of the PGCs during the run phase results in actin brushes formation. Due to the lack of sufficient experimental data, I will not be discussiong Rac function at the back of migrating PGCs. FRET measurements of Rac activity revealed that Rac activation pattern does not depend on SDF-1a/CXCR4b signalling (Figure 3.15). Together with the observation of the actin brushes formation at the front of a non-directionally migrating PGC without functional CXCR4b (Figure 3.2D), these data suggest that Rac activity promoting actin polymerization is important for the general motility of the PGC rather than directionality.

RhoA activity is normally associated with the rear of the cell; where it is believed to regulate acto-myosin contraction during tail retraction $[45,109,110]$. A recent report utilizing FRET biosensors provided evidence that RhoA is active at the leading edge of MDCK cells migrating as a monolayer sheet, where it was proposed to cooperate with Rac inducing membrane ruffles [87]. Results obtained here with FRET imaging in PGCs demonstrate that RhoA is active at the front and back of migrating PGCs, yet the activation level is higher at the front. RhoA function in inducing acto-myosin contraction is well established [45]. Actin backward flow observed at the front of the PGCs (Figure 3.2A and supplemental movie S1) is reminiscent of actin retrograde flow described for other cell types [111, 112]. The speed of actin backward flow in PGCs ranged from $3.6 \mu \mathrm{m} / \mathrm{min}$ to $6.8 \mu \mathrm{m} / \mathrm{min}$, which 
is comparable to that reported for the actin retrograde flow observed at the leading edge of spreading cells [113]. Myosin II function has been implicated in actin retrograde flow in yeast [114], in neuronal growth cones [115], and in mouse embryonic fibroblast cells [116]. One may therefore suggest, that RhoA activity detected with FRET at the front of PGCs is needed for regulating acto-myosin contraction therefore contributing to the actin backward flow. Indeed, when the CA RhoAV14 mutant was used, actin backward flow was enhanced, achieving speeds ranging from $15.5 \mu \mathrm{m} / \mathrm{min}$ to $20 \mu \mathrm{m} / \mathrm{min}$ (Figure 3D and supplemental movies S9 and S10). The enhanced actin backward flow in the presence of the CA RhoAV14 mutant resulted in actin accumulation at the back of the cell (Figure 3.4C, C1 and E). RhoA function might also contribute to the bleb formation in PGCs during tumbling, since without functional RhoA, PGCs appear round and do not form blebs in the absence of a functional RhoA (Figure 3.3A and supplemental movie S7). ROK, the downstream effector of activated RhoA that was previously suggested to function in PGCs [34], is a likely candidate for inducing the contractility as dominant-negative ROK results in a very similar phenotype to that of loss of function for RhoA (Figure 3.4B and supplemental movie S8).

Taken together, results obtained with measuring Rac and RhoA activity and studies of actin cytoskeleton dynamics in migrating PGCs suggest that Rac results in actin polymerization at the front of the PGC, while RhoA mediates acto-myosin contraction leading to the actin backward flow.

\subsubsection{Coordinated actions of Rac and RhoA at the front result in cell locomotion}

Actin brushes at the front of the migrating PGC do not generate protrusive force necessary for pushing the membrane forward [34] as polymerized actin does in cells migrating in 2D environment [6] since the blebs devoid of actin brushes at the cell front progress beyond them ([34]; Figure 3.2A and supplemental movie S1). Conversely, actin brushes are pulled backwards of the cell by forces resulting from RhoA activity (Figure 3.4C and C' and supplemental movies S9 and S10). Thus, actin brushes at the front of PGCs could contribute to the generation of contractile forces. MLCK is also present at the front of the migrating PGC, where it is believed to promote acto-myosin contraction necessary for bleb formation ([34] and Figure 3.6A). MLCK flows backward during bleb formation in a manner similar to that of actin (Figure 3.6B and supplemental movie S13.). Moreover, in the presence of the CA RhoA $\mathrm{V} 14$ mutant, whose action results in actin recruitment towards the back of the 
PGC (Figure 3.4C, C', and E), MLCK also colocalizes with actin at the back of the cell (Figure 3.6C). These results suggest that actin brushes might recruit the contractile machinery that consists of MLCK and active RhoA to the front of migrating PGCs. Accumulation of the contractile machinery at the front of the cell and depletion from other locations could promote the localized frontal blebbing at the front and at the same time suppress blebbing activity at the back and at the side of the cell thus maintaining the leading edge. The actin backward flow could contribute to the forces that result in cortex detachment from the membrane at the front thus contributing to bleb formation. For a more convincing proof as to the role of actin of brushes in localizing the contractile machinery to the front of PGCs, it would be necessary to demonstrate that other essential components of the contractile machinery, such as myosin, are also colocalized with the actin brushes at the front of migrating PGC.

Actin backward flow could also in addition play a role in PGC locomotion. The actin backward flow observed at the front of PGCs resembles retrograde actin flow reported for other migrating cell types. For example, actin retrograde movement was previously observed in focal adhesions, where it is believed to function by generating traction forces during cell locomotion $[111,114]$. However, preliminary experiments performed with focal adhesion markers suggest that PGCs do not form focal adhesions during migration (unpublished data). Instead, PGCs migrate in close association with the somatic cells (Figure 3.7A and B). In many PGCs analyzed actin appears to flow backwards, relative to the somatic cells that neighbor PGC (Figure 3.7B, inset and supplemental movie S14). Cell-cell adhesion is mediated through homophilic interactions between surface adhesion molecules, among others transmembrane receptors of the cadherin family [24]. Cadherins are linked with the actin cytoskeleton through a complex of adaptor proteins, such as catenins and vinculin [24]. Fine-tuned regulation of E-cadherin-based cell-cell adhesion is essential for proper embryogenesis [117], and for cell migration during development and epithelial-mesenchymal transition [24, 118]. An interesting question arises, of whether cell-cell adhesion could play a role in PGC migration. E-Cadherin levels are reduced in PGCs undergoing the transition from non-motile to motile behavior [68]. However, there is a possibility that remaining E-Cadherin mediates cell-cell adhesion. When E-Cadherin function was knocked down in PGCs, actin appeared disorganized and cells were not migratory (Figure 3.7C and supplemental movies S15 and S16). Thus, one could hypothesize that actin backward flow could also provide an additional force for PGC locomotion by pushing against the neighboring cells utilizing the E-cadherin based interactions. Future experiments aimed to determine E- 
cadherin dynamics during PGC migration are necessary to conclusevly support the latter hypothesis.

Based on these results, the proposed function for actin brushes at the front of the cell could be providing the physical platform that is instrumental in generating contractile forces necessary for cell locomotion (Figure 4.1).

A

TUMBLING

RUN
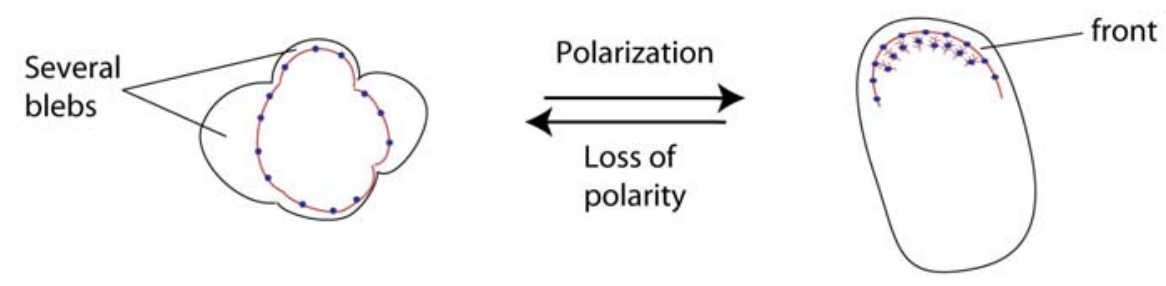

B
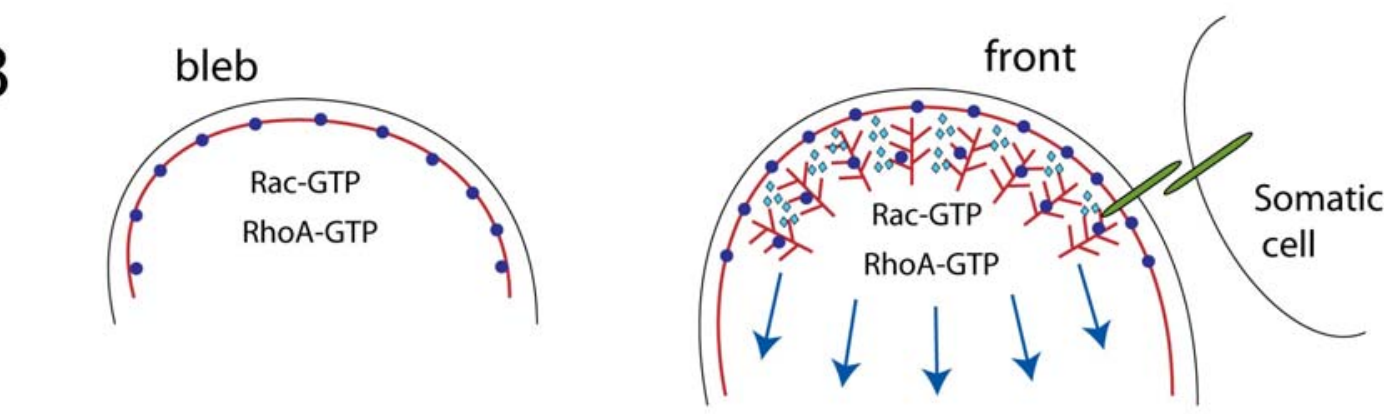

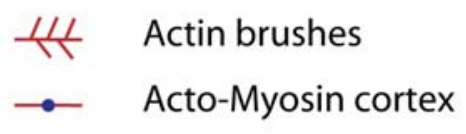

- Myosin

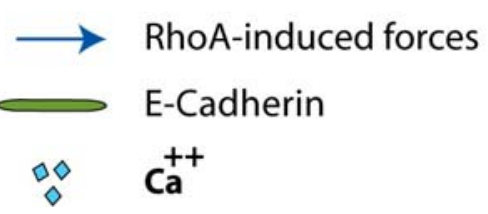

$\otimes \mathrm{Ca}^{++}$

Figure 4.1 A speculative model proposing how Rac and RhoA could cooperate at the front of migrating PGC regulating actin cytoskeleton

A. Schematic representation of the PGC alternating between the RUN and TUMBLING phases B. Comparison between the bleb of the tumbling PGC and the front of the running PGC. During tumbling, Rac and RhoA activities are detected at the cell periphery and in the blebs. Cell acquires polarity upon yet unknown mechanism, possibly through cooperation of Rac with one of the nucleation promoting factors inducing actin polymerization. In the polarized running cell, actin brushes are assembled at the front depending on Rac activity. Actin brushes at the front of the cell could attract components of the contractile machinery such as myosin and MLCK to the front. Myosin activity downstream to RhoA function could in turn result in actin backward flow that might lead to the detachment of the acto-myosin cortex from the plasma membrane and therefore bleb formation. The other proposed function for actin backward flow might be to provide the traction forces by connecting through E-cadherin to the somatic neighboring cell.

\subsection{Rac and RhoA take part in the signalling events}




\subsubsection{Rac and RhoA crosstalk}

In many cell types studied, Rac and RhoA were shown to antagonize each other's functions acting in a mutually exclusive fashion [82, 86, 119]. Distinct patterns of relationship among Rac and Rho activities have been reported. In NIH 3T3 fibroblast it was shown that Rac activation by Tiam1 leads to RhoA down regulation [81]. Rac could also downregulate RhoA activity in fibroblasts by generating reactive oxygen species that suppress a Rho-specific GEF [120]. Conversely, RhoA function might result in Rac activation, as it was shown that in NIH 3T3 fibroblasts [82]. Here, FRET measurement showed, that Rac and RhoA are activated in spatially overlapping fashion in migrating PGCs. Therefore, there must be a mechanism allowing both proteins to act together without inhibiting each other's activities. When co-expressed in equal amounts, constitutively active mutants for Rac and RhoA restored the normal migratory behavior of PGCs rescuing the migratory defects induced by the individual mutants for Rac and RhoA (Figure 3.5). These results suggested that the right balance between Rac and RhoA activities is necessary for proper PGC migration. These findings beg the intriguing question as to why CA Rac1 ${ }^{V 12}$ expressing in PGCs lose their polarity (Figure 3.3B), while CA RhoAV14 expressing PGCs polarize and show a defined back and front (Figure 3.4C, C' and E). It remains to be determined, the exact relationship between Rac and RhoA in PGCs. This could be addressed by measuring the activation of either of the proteins in the presence of the constitutively active mutant form for another protein.

\subsubsection{Signalling downstream of activated Rac}

An important question arising during the course of this work is how exactly Rac activity results in the assembly of actin brushes. Rac activity is detected in the blebs during tumbling (Figure 3.14C). However during tumbling no actin brushes are observed in blebs (Figure 3.2B). These data suggest that Rac function alone is not sufficient to promote actin polymerization. Rac was shown to induce actin polymerization by stimulating nucleation promoting factors such as WASP, that in turn activate the Arp2/3 complex $[11,107,121]$. Experiments with SCAR/WAVE homologs, which belong to WASP family suggest that SCAR/WAVE proteins are unlikely to operate in PGCs (Reichman-Fried M., unpublished).

Activated Rac has the capacity of inducing a number of downstream signalling events via binding to its effectors. In Rac, single amino acids responsible for interaction with its specific downstream signalling partners were identified [101]. 
Therefore, it is possible to shut down one or more signalling pathways induced by CA Rac1 V12 mutant by introducing a second mutation in the Rac1 V12 single mutant (Figure 4.1A). Experiments preventing interactions of Rac1 V12 with either PAK or POR1 homolog have shown that both pathways are likely to operate downstream to activate Rac in PGCs (Figure 3.21 and 4.2).
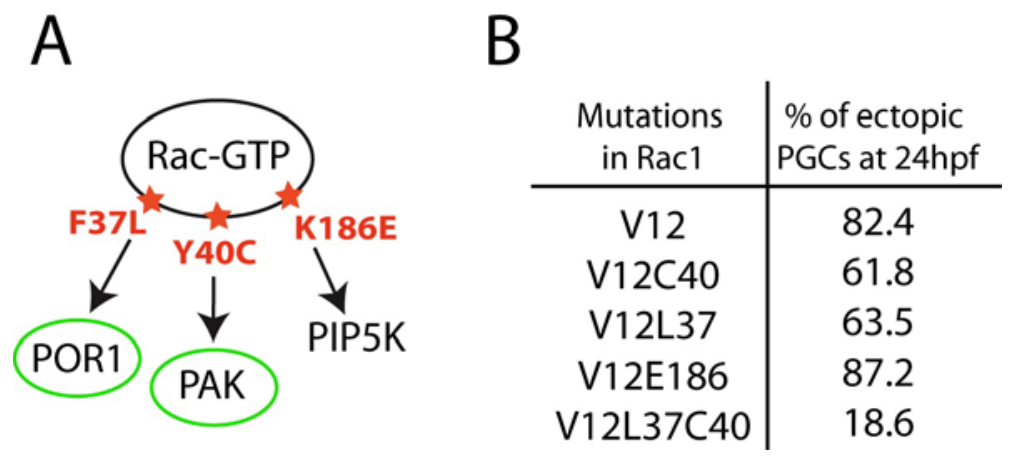

Figure 4.2 Dissecting Rac-induced downstream signalling pathways in PGCs

A. A scheme depicting point mutations in Rac (red) that affect its interaction with specific downstream partners. Green circles mark the possible candidates to operate downstream of activated Rac in PGCs. B. The experimental data supporting $A$. is a summary from the Figure 3.21. POR1 - partner of activated Rac1, PAK - P21 activated kinase, PI-5K - PhosphatidylInositol 5 Kinase.

The Rac1 $\mathrm{V}^{12}$ single mutant results in severe migratory defects accounting for $82.4 \%$ ectopic cells at 24 hours post fertilization (hpf) (Figure 3.21 and 4.1B). Rac1V12C40 mutant that prevents Rac binding to PAK stimulation resulted in a reduced migratory phenotype (Figure 3.21 and 4.1B), while Rac1 $\mathrm{V} 12 \mathrm{~L} 37$, which affects the interaction with the POR1 homolog showed a similar reduction in the migratory phenotype (Figure 3.21 and 4.1B). A triple Rac1 V12L37C40 mutant lead to a strong reduction in the number of ectopic cells at $24 \mathrm{hpf}$ (Figure 3.21 and 4.1B). Taken together these results strongly suggest that both pathway, one operating through PAK stimulation and another one involving interaction with POR1 are likely to be induced by activated Rac in PGCs. How exactly Rac stimulation of either PAK or POR1 homolog result in actin remodelling is still unclear. Stimulation of PAK is believed to regulate actin polymerization/depolymerization events via phosphorylation and activation of LIMK. LIMK activity results in the phosphorylation and inhibition of cofilin, an actin-severing protein. Cofilin regulates actin polymerization by severing existing actin filaments and allowing formation of new filaments $[122,123]$. Inactive cofilin would therefore result in the static behavior of actin filament, which could explain the actin cytoskeleton phenotype caused by CA Rac1V12 mutant (Figure 3.3B). Rac interaction with POR1 
was previously shown to result in membrane ruffles formation in fibroblasts [103]. Therefore, Rac signalling through POR1 could promote actin brushes assembly, while its signalling through PAK, could modulate the actin depolymerization at the front of the cell, distant from the leading edge (Figure 3.1 and 3.2A).

PIP5-kinase functions in generating PIP2 that serves as an adaptor molecule for WASP in actin polymerization events [14, 105]. However, preventing Rac signalling through PIP5-kinase pathway did not rescue the CA Rac1V12 mutantinduced phenotype, making PIP5-kinase an unlikely downstream signalling partner of activated Rac in PGCs (Figure 3.21 and 4.1B).

Although further experiments are required to elucidate the molecular mechanism by which Rac induces actin remodeling in PGCs, data arising from the above-discussed experiments suggest that Rac might signal through the POR1 homologue and PAK resulting in the fine-tuning of actin polymerization/depolymerization events at the front of migrating PGCs. 


\subsection{Imaging protein activities in PGCs using FRET-based biosensors (Technical notes)}

A large amount of effort during this work was dedicated to the establishment of a ratio imaging routine with FRET biosensors in living embryos. There are excellent reviews describing imaging with FRET biosensors in cell culture [59, 60, 124], however ratio imaging of cells migrating in a living embryo is different from that in the cell culture due to differences in expression levels and technical setup. Here, I presented the description of a ratio imaging routine with FRET biosensors in fish embryo. During the FRET imaging setup, I showed how to define the range between the active and inactive states of the Rac-FRET biosensor with the help of mutants. This is the first such demonstration of FRET biosensors being used to determine the range of activation within individual cells in a living organism.

There are several important considerations that must be taken into the account when using FRET-based biosensors in living cells [60, 124]. First, the probe should not interfere with signalling pathways within the cell. The proper arrival of PGCs expressing FRET biosensors to the right location within the embryo at $24 \mathrm{hpf}$, suggested that there was no such interference in my system. Second, the biosensor should provide sufficient signal intensities during measurements, which can be used to generate a ratio image. Due to the sensitivity of the FRET biosensors to bleaching, the imaging is performed at low illumination intensity, usually using only 6 to $12 \%$ of the available power of an illumination source. Third, the probe must localise to the regions within the cell where the endogenous protein normally resides. For FRET biosensors for Rho GTPases this goal is often achieved by adding the targeting sequence to the C-terminus of the probe. Such targeting sequence usually consists of the most C-terminal 20-22 residues of the respective Rho GTPase or of the Ras farnesylation signal that permanently target the sensor to the membrane $[59,60]$. The subcellular localization of the orignal FRET probes for Rac and RhoA differed dramatically from that of Rac and RhoA in PGCs as visualized using their EGFP fusions. During the course of this study, I used several strategies for the intracellular targeting of FRET probes. In the majority of cases the cytosolic biosensor was chosen for measurements as the one most closely resembling the GFP fusion localization for respective Rho GTPase as well as the one providing the highest signal intensity, was chosen for measurements. 


\subsubsection{Interpreting FRET data}

The use of mutants for calibrating biosensors allows for the distinction between the active and inactive states, and offers valuable information regarding the sensitivity of the biosensor (Figure $3.11 \mathrm{~A}$ and $\mathrm{B}$ ). Although the colour coded ratio image provides a straight forward way of observing the activation pattern in the cell, it proves very helpful to accompany such image with the intensity profile along the line through the cell, where the differences are clearly visible (Figure 3.14B, 3.17B, and 3.19B). PGC migration takes place during between 5-24 hours of Zebrafish development. It would be therefore interesting to be able to study Rho GTPases activation at various time points. For unclear reasons, the increase in the ratio signal with time is observed in the Rac-FRET biosensor (Figure 3.12). This could result from the general properties of the FRET biosensors, and not the activation state of Rho GTPase because the increase in energy transfer is also observed with the YpetSECFP tandem (Figure 3.9E). One possibility is the non-equal increase in quantum yield between the donor and acceptor with time resulting in higher signal intensities detected in the FRET channel without increase in FRET. It is therefore important do perform FRET measurements at the same developmental stage when comparing different treatments or the effect of various mutants.

\subsubsection{Limitations of the FRET imaging}

FRET imaging is a powerful tool to study protein function in vivo. With the help of FRET based biosensors I could visualize of the protein activity in real time, which is not possible with any other method available to date. However, there are limitations to this method that a researcher must be aware of. Bleaching: PGCs are fast migrating cells that move with an average speed of $1.8 \mu \mathrm{m} / \mathrm{min}$ [125]. Therefore in order to study the dynamics of Rho GTPases activity in PGCs migration, images must be taken in short intervals (a few seconds) for the duration of time ( 5 min - 30 min). As a result, due to the acceptor bleaching during FRET imaging, after a certain period of time the signal is eventually reduced and the ratio reporting the activation state does not reflect activation accurately. Signal intensity: It is a very important issue in FRET imaging since a very low level of light intensity is usually used for donor excitation (see above). Thus, good signal intensity in both channels is a prerequisite for generating a ratio image. It might be a hard task to achieve high levels of the signal intensities in the cell without saturating the amount of protein expressed to the level, at which it might interfere with proper cell functioning. Image shift: When two images for FRET and CFP channels are acquired sequentially, a cell 
might be displaced between the two images. Even a shift of a few pixels might lead to severe artefact in the ratio image, especially at the edges that often correspond to the membrane where the activation is likely to occur. Another reason for image shift is the optical properties of the filter cubes. Therefore, image registration is an essential step of image processing during generation of the ratio image. Ideally, a device that allows simultaneous acquisition of both images, such as dual view, should be implemented in FRET ratio imaging.

\subsubsection{Dynamic range for the FRET biosensor}

Dynamic range is an important property of the FRET biosensor and it is reflected in a difference between the active and inactive states of the biosensor. Thus, the sensitivity of the biosensor is directly proportional to its dynamic range. In an attempt to improve the dynamic range of the FRET biosensors for Rho GTPases I replaced the Venus, which serves as an acceptor for the energy transfer in the original probe with the Ypet, an acceptor that exhibits stronger energy transfer compared to that of Venus ([91] and Figure 3.9C and D). I propose to calculate the dynamic range of the biosensor according to the following formula:

$$
\left(R_{\text {high }}-R_{\text {low }}\right) / R_{\text {wt }} * 100 \%
$$

Where $R_{\text {high }}$ corresponds to the highest FRET/CFP ratio value and is measured with a positive control for the FRET biosensor (Figure 3.11A, the most left cell), $\mathrm{R}_{\text {low }}$ corresponds to the lowest FRET/CFP ratio value and is measured with the wild type biosensor in the presence of an inhibitor, such as DN Rac1 ${ }^{N 17}$ mutant for Rac-FRET biosensor (Figure 3.11A, cell at the right), and $R_{w t}$ corresponds to the FRET/CFP ratio value obtained in a wild type situation (Figure 3.11A, second cell from the left). To my disappointment, there was no improving in the dynamic range for the RacFRET biosensor, when Venus was replaced with the Ypet (Figure 4.3A). Although a schematic drawing of the FRET biosensor (Figure 1.11) suggests that there should be no energy transfer, when the biosensor is in its inactive state, in reality there is always energy transfer within the biosensor. Therefore, the improved acceptor for FRET results in an increase in the FRET/CFP ratio values when measured as a negative control (Figure 4.3A). Nevertheless, I used the new combination of SECFP with Ypet for the subsequent measurements because the signal intensity of the new biosensor was generally better than that of the old one. 
A

\begin{tabular}{l|c|c}
\multicolumn{1}{c}{ Donor } & \multicolumn{2}{c}{ SECFP } \\
\hline \multicolumn{1}{c|}{ Acceptor } & Venus & Ypet \\
\hline Positive (V12) & 2.47 & 4.46 \\
Negative (N17) & 1.87 & 3.34 \\
WT & 2.27 & 4.14 \\
Dynamic range * $^{*}$ & $26 \%$ & $27 \%$ \\
\hline
\end{tabular}

* Dynamic range $=(\text { Rhigh-Rlow } / \text { Rwt })^{*} 100 \%$
B Conformation of the FRET biosensor

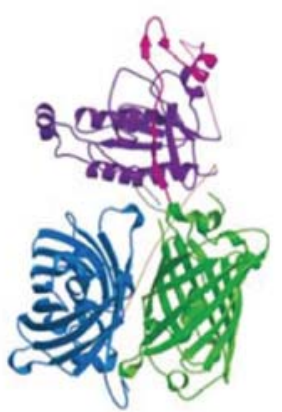

Figure 4.3 Dynamic range for the FRET biosensor

A. The dynamic range for two different donor and acceptor combinations used in the RacFRET biosensor are compared. See the text for details. B. The cartoon shows the conformation for the FRET-based biosensor [126].

\subsection{Summary and conclusions}

In this work I propose that Rac and RhoA cooperate at the front of the migrating PGC to modulatethe actin cytoskeleton thus promoting cell locomotion. Rac function at the front of the migrating PGC results in actin brushes assembly. Interestingly, Rac function resulting in actin polymerization at the front of the PGC is independent of SDF1a/CXCR4b signalling suggesting that Rac activity and actin brushes formation are part of the general motility program of the cell. Actin brushes at the front of the cell provide a physical platform for localizing the contractile machinery, such as myosin and MLCK, thereby ensuring sustained blebbing at the front of the cell. RhoA activity at the front contributes a force for bleb formation by promoting acto-myosin contraction that results in actin backward flow. It is tempting to speculate that Ecadherin based cell-cell adhesion is implicated in PGC migration and that actin backward flow might mediate cell migration by pushing against the neighbouring cells. However, the latter hypothesis requires further experimental proof. It is intriguing that Rac and RhoA both function at the front of the cell without inhibiting each other's activities as they do in other models for cell migration. Further work should focus in elucidating the exact relationship between Rac and RhoA. 


\section{REFERENCES}

1. Kurosaka, S. and A. Kashina, Cell biology of embryonic migration. Birth Defects Res C Embryo Today, 2008. 84(2): p. 102-22.

2. Randolph, G.J., V. Angeli, and M.A. Swartz, Dendritic-cell trafficking to lymph nodes through lymphatic vessels. Nat Rev Immunol, 2005. 5(8): p. 617-28.

3. Martin, P. and S.M. Parkhurst, Parallels between tissue repair and embryo morphogenesis. Development, 2004. 131(13): p. 3021-34.

4. Chambers, A.F., A.C. Groom, and I.C. MacDonald, Dissemination and growth of cancer cells in metastatic sites. Nat Rev Cancer, 2002. 2(8): p. 563-72.

5. Lauffenburger, D.A. and A.F. Horwitz, Cell migration: a physically integrated molecular process. Cell, 1996. 84(3): p. 359-69.

6. Pollard, T.D. and G.G. Borisy, Cellular motility driven by assembly and disassembly of actin filaments. Cell, 2003. 112(4): p. 453-65.

7. Charras, G. and E. Paluch, Blebs lead the way: how to migrate without lamellipodia. Nat Rev Mol Cell Biol, 2008.

8. Olson, M.F. and E. Sahai, The actin cytoskeleton in cancer cell motility. Clin Exp Metastasis, 2008.

9. Blanchoin, L. and T.D. Pollard, Hydrolysis of ATP by polymerized actin depends on the bound divalent cation but not profilin. Biochemistry, 2002. 41(2): p. 597-602.

10. Sept, D. and J.A. McCammon, Thermodynamics and kinetics of actin filament nucleation. Biophysical Journal, 2001. 81(2): p. 667-74.

11. Goley, E.D. and M.D. Welch, The ARP2/3 complex: an actin nucleator comes of age. Nat Rev Mol Cell Biol, 2006. 7(10): p. 713-26.

12. dos Remedios, C.G., et al., Actin binding proteins: regulation of cytoskeletal microfilaments. Physiol Rev, 2003. 83(2): p. 433-73.

13. Stradal, T.E.B. and G. Scita, Protein complexes regulating Arp2/3-mediated actin assembly, in Current Opinion in Cell Biology. 2006. p. 4-10.

14. Takenawa, T. and S. Suetsugu, The WASP-WAVE protein network: connecting the membrane to the cytoskeleton. Nat Rev Mol Cell Biol, 2007. 8(1): p. 37-48.

15. Kovar, D.R., Molecular details of formin-mediated actin assembly. Curr Opin Cell Biol, 2006. 18(1): p. 11-7.

16. Quinlan, M.E., et al., Drosophila Spire is an actin nucleation factor. Nature, 2005. 433(7024): p. 382-8.

17. Chhabra, E.S. and H.N. Higgs, The many faces of actin: matching assembly factors with cellular structures. Nat Cell Biol, 2007. 9(10): p. 1110-21.

18. Medalia, O., et al., Macromolecular architecture in eukaryotic cells visualized by cryoelectron tomography. Science, 2002. 298(5596): p. 1209-13.

19. Paluch, E., et al., Dynamic modes of the cortical actomyosin gel during cell locomotion and division. Trends Cell Biol, 2006. 16(1): p. 5-10.

20. Bretscher, A., K. Edwards, and R.G. Fehon, ERM proteins and merlin: Integrators at the cell cortex, in Nat Rev Mol Cell Biol. 2002. p. 586-599.

21. Geiger, B., et al., Transmembrane crosstalk between the extracellular matrix-cytoskeleton crosstalk. Nat Rev Mol Cell Biol, 2001. 2(11): p. 793-805.

22. Yeatman, T.J., A renaissance for SRC. Nat Rev Cancer, 2004. 4(6): p. 470-80.

23. Mitra, S.K., D.A. Hanson, and D.D. Schlaepfer, Focal adhesion kinase: In command and control of cell motility, in Nat Rev Mol Cell Biol. 2005. p. 56-68.

24. Tepass, U., et al., Cadherins in embryonic and neural morphogenesis. Nat Rev Mol Cell Biol, 2000. 1(2): p. 91-100.

25. Bershadsky, A., Magic touch: how does cell-cell adhesion trigger actin assembly? Trends in Cell Biology, 2004. 14(11): p. 589-93.

26. Wang, Y., Flux at Focal Adhesions: Slippage Clutch, Mechanical Gauge, or Signal Depot. Science's STKE, 2007. 2007(377): p. pe10-pe10.

27. Wang, J. and J. Lin, Cell traction force and measurement methods. Biomech Model Mechanobiol, 2007. 6(6): p. 361-371.

28. Pellegrin, S. and H. Mellor, Actin stress fibres. J Cell Sci, 2007. 120(Pt 20): p. 3491-9.

29. Fackler, O.T. and R. Grosse, Cell motility through plasma membrane blebbing. J Cell Biol, 2008. 181(6): p. 879-84. 
30. Schwartz, M.A. and D.W. Simone, Cell adhesion receptors in mechanotransduction. Curr Opin Cell Biol, 2008.

31. Cunningham, C.C., Actin polymerization and intracellular solvent flow in cell surface blebbing. J Cell Biol, 1995. 129(6): p. 1589-99.

32. Ridley, A.J., et al., Cell migration: integrating signals from front to back. Science, 2003. 302(5651): p. 1704-9.

33. Ware, M.F., A. Wells, and D.A. Lauffenburger, Epidermal growth factor alters fibroblast migration speed and directional persistence reciprocally and in a matrixdependent manner. J Cell Sci, 1998. 111 ( Pt 16): p. 2423-32.

34. Blaser, H., et al., Migration of Zebrafish Primordial Germ Cells: A Role for Myosin Contraction and Cytoplasmic Flow. Developmental Cell, 2006. 11(5): p. 613-627.

35. Riento, K. and A.J. Ridley, Rocks: multifunctional kinases in cell behaviour. Nat Rev Mol Cell Biol, 2003. 4(6): p. 446-56.

36. Hall, A., Rho GTPases and the control of cell behaviour. Biochem. Soc. Trans, 2005. 33(Pt 5): p. 891-5.

37. Heasman, S. and A.J. Ridley, Mammalian Rho GTPases: new insights into their functions from in vivo studies. Nat Rev Mol Cell Biol, 2008. 9(9): p. 690-701.

38. Wennerberg, K., Rho-family GTPases: it's not only Rac and Rho (and I like it). J Cell Sci, 2004. 117(8): p. 1301-1312.

39. Jaffe, A.B. and A. Hall, Rho GTPases: biochemistry and biology. Annu Rev Cell Dev Biol, 2005. 21: p. 247-69.

40. Hakoshima, T., Structural Basis of the Rho GTPase Signalling. Journal of Biochemistry, 2003. 134(3): p. 327-331.

41. Watanabe, T., J. Noritake, and K. Kaibuchi, Regulation of microtubules in cell migration. Trends Cell Biol, 2005. 15(2): p. 76-83.

42. Rossman, K., C. Der, and J. Sondek, GEF means go: turning on RHO GTPases with guanine nucleotide-exchange factors. Nat Rev Mol Cell Biol, 2005. 6(2): p. 167-180.

43. Moon, S.Y. and Y. Zheng, Rho GTPase-activating proteins in cell regulation. TRENDS in Cell Biology 2003. 13(1): p. 10.

44. Dermardirossian, C. and G. Bokoch, GDIs: central regulatory molecules in Rho GTPase activation. Trends in Cell Biology, 2005. 15(7): p. 356-363.

45. Allen, W.E., et al., Rho, Rac and Cdc42 regulate actin organization and cell adhesion in macrophages. J Cell Sci, 1997. 110 ( Pt 6): p. 707-20.

46. Etienne-Manneville, S., Cdc42--the centre of polarity. J Cell Sci, 2004. 117(Pt 8): p. 1291-300.

47. Aspenström, P., A. Fransson, and J. Saras, Rho GTPases have diverse effects on the organization of the actin filament system. Biochem J, 2004. 377(Pt 2): p. 327-37.

48. Feig, L.A., Tools of the trade: use of dominant-inhibitory mutants of Ras-family GTPases. Nat Cell Biol, 1999. 1(2): p. E25-7.

49. Wheeler, A.P., et al., Rac1 and Rac2 regulate macrophage morphology but are not essential for migration. J Cell Sci, 2006. 119(Pt 13): p. 2749-57.

50. Wang, L. and Y. Zheng, Cell type-specific functions of Rho GTPases revealed by gene targeting in mice. Trends in Cell Biology, 2007. 17(2): p. 58-64.

51. Chrzanowska-Wodnicka, M. and K. Burridge, Rho-stimulated contractility drives the formation of stress fibers and focal adhesions. J Cell Biol, 1996. 133(6): p. 1403-15.

52. Hall, A., Rho GTPases and the actin cytoskeleton. Science, 1998. 279(5350): p. 50914.

53. Diekmann, D. and A. Hall, In vitro binding assay for interactions of Rho and Rac with GTPase-activating proteins and effectors. Meth Enzymol, 1995. 256: p. 207-15.

54. Tsien, R.Y. and A. MIYAWAKI, Seeing the machinery of live cells. Science, 1998. 280(5371): p. 1954-5.

55. Jares-Erijman, E.A. and T.M. Jovin, FRET imaging. Nat Biotechnol, 2003. 21(11): p. 1387-1395.

56. Pertz, O. and K.M. Hahn, Designing biosensors for Rho family proteins--deciphering the dynamics of Rho family GTPase activation in living cells. J Cell Sci, 2004. 117(Pt 8): p. 1313-8.

57. Itoh, R.E., et al., Activation of rac and cdc42 video imaged by fluorescent resonance energy transfer-based single-molecule probes in the membrane of living cells. Mol Cell Biol, 2002. 22(18): p. 6582-91. 
58. Kurokawa, K., et al., Coactivation of Rac1 and Cdc42 at lamellipodia and membrane ruffles induced by epidermal growth factor. Mol Biol Cell, 2004. 15(3): p. 1003-10.

59. Kiyokawa, E., et al., Fluorescence (Forster) resonance energy transfer imaging of oncogene activity in living cells. Cancer Science, 2006. 97(1): p. 8-15.

60. Nakamura, T., K. Aoki, and M. Matsuda, Monitoring spatio-temporal regulation of Ras and Rho GTPases with GFP-based FRET probes. Methods, 2005. 37(2): p. 146-153.

61. Cinalli, R., P. Rangan, and R. Lehmann, Germ Cells Are Forever. Cell, 2008. 132(4): p. 559-562.

62. Santos, A.C. and R. Lehmann, Germ cell specification and migration in Drosophila and beyond. Curr Biol, 2004. 14(14): p. R578-89.

63. Raz, E. and M. Reichmanfried, Attraction rules: germ cell migration in zebrafish. Current Opinion in Genetics \& Development, 2006. 16(4): p. 355-359.

64. Weidinger, G., et al., Identification of tissues and patterning events required for distinct steps in early migration of zebrafish primordial germ cells. Development, 1999. 126(23): p. 5295-307.

65. Raz, E., Primordial germ-cell development: the zebrafish perspective. Nat Rev Genet, 2003. 4(9): p. 690-700.

66. Doitsidou, M., et al., Guidance of primordial germ cell migration by the chemokine SDF-1. Cell, 2002. 111(5): p. 647-59.

67. Reichman-Fried, M., S. Minina, and E. Raz, Autonomous modes of behavior in primordial germ cell migration. Developmental Cell, 2004. 6(4): p. 589-96.

68. Blaser, $\mathrm{H}_{\text {., }}$ et al., Transition from non-motile behaviour to directed migration during early PGC development in zebrafish. J Cell Sci, 2005. 118(Pt 17): p. 4027-38.

69. Yoshizaki, H., Activity of Rho-family GTPases during cell division as visualized with FRET-based probes. J Cell Biol, 2003. 162(2): p. 223-232.

70. Westerfield, M., The zebrafish book: a guide for the laboratory use of zebrafish (Danio rerio). 1995.

71. Kimmel, C.B., et al., Stages of embryonic development of the zebrafish. Dev Dyn, 1995. 203(3): p. 253-310.

72. Kawakami, K., et al., A transposon-mediated gene trap approach identifies developmentally regulated genes in zebrafish. Developmental Cell, 2004. 7(1): p. 133-44.

73. Köprunner, M., et al., A zebrafish nanos-related gene is essential for the development of primordial germ cells. Genes \& Development, 2001. 15(21): p. 2877-85.

74. Riedl, J., et al., Lifeact: a versatile marker to visualize F-actin. Nat Meth, 2008. 5(7): p. 605-607.

75. Bishop, A.L. and A. Hall, Rho GTPases and their effector proteins. Biochem J, 2000. 348 Pt 2: p. 241-55.

76. Clarke, S., Protein isoprenylation and methylation at carboxyl-terminal cysteine residues. Annu Rev Biochem, 1992. 61: p. 355-86.

77. Burbelo, P.D., D. Drechsel, and A. Hall, A conserved binding motif defines numerous candidate target proteins for both Cdc42 and Rac GTPases. J Biol Chem, 1995. 270(49): p. 29071-4.

78. Amano, M., et al., Identification of a putative target for Rho as the serine-threonine kinase protein kinase $N$. Science, 1996. 271(5249): p. 648-50.

79. Kimura, K., et al., Regulation of myosin phosphatase by Rho and Rho-associated kinase (Rho-kinase). Science, 1996. 273(5272): p. 245-8.

80. Sahai, E. and C.J. Marshall, Differing modes of tumour cell invasion have distinct requirements for Rho/ROCK signalling and extracellular proteolysis. Nat Cell Biol, 2003. 5(8): p. 711-9.

81. Sander, E.E., et al., Rac downregulates Rho activity: reciprocal balance between both GTPases determines cellular morphology and migratory behavior. J Cell Biol, 1999. 147(5): p. 1009-22.

82. Tsuji, T., et al., ROCK and mDia1 antagonize in Rho-dependent Rac activation in Swiss 3 T3 fibroblasts. J Cell Biol, 2002. 157(5): p. 819-30.

83. Charest, P.G. and R.A. Firtel, Big roles for small GTPases in the control of directed cell movement. Biochem J, 2007. 401(2): p. 377-90.

84. Burridge, K. and K. Wennerberg, Rho and Rac take center stage. Cell, 2004. 116(2): p. 167-79.

85. Rosenfeldt, H., et al., JMolSig06. J Mol Signal, 2006. 1(1): p. 8. 
86. Ohta, Y., J.H. Hartwig, and T.P. Stossel, FilGAP, a Rho- and ROCK-regulated GAP for Rac binds filamin A to control actin remodelling. Nat Cell Biol, 2006. 8(8): p. 80314.

87. Kurokawa, K. and M. Matsuda, Localized RhoA activation as a requirement for the induction of membrane ruffling. Mol Biol Cell, 2005. 16(9): p. 4294-303.

88. Miyagi, C., STAT3 noncell-autonomously controls planar cell polarity during zebrafish convergence and extension. J Cell Biol, 2004. 166(7): p. 975-981.

89. Matthews, H.K., et al., Directional migration of neural crest cells in vivo is regulated by Syndecan-4/Rac1 and non-canonical Wht signalling/RhoA. Development, 2008. 135(10): p. 1771-80.

90. Xia, Z. and Y. Liu, Reliable and global measurement of fluorescence resonance energy transfer using fluorescence microscopes. Biophysical Journal, 2001. 81(4): p. 2395-402.

91. Nguyen, A.W. and P.S. Daugherty, Evolutionary optimization of fluorescent proteins for intracellular FRET. Nat Biotechnol, 2005. 23(3): p. 355-60.

92. Michaelson, D., et al., Differential Localization of Rho GTPases in Live Cells Regulation by Hypervariable Regions and .... J Cell Biol, 2001.

93. Williams, C., The polybasic region of Ras and Rho family small GTPases: a regulator of protein interactions and membrane association and a site of nuclear localization signal sequences. Cell Signal, 2003. 15(12): p. 1071-1080.

94. Van Leeuwen, F.N., et al., Rac activation by lysophosphatidic acid LPA1 receptors through the guanine nucleotide exchange factor Tiam1. J Biol Chem, 2003. 278(1): p. 400-6.

95. Bhattacharya, M., A.V. Babwah, and S.S. Ferguson, Small GTP-binding proteincoupled receptors. Biochem. Soc. Trans, 2004. 32(Pt 6): p. 1040-4.

96. Wong, K., et al., Neutrophil polarization: spatiotemporal dynamics of RhoA activity support a self-organizing mechanism. Proc Natl Acad Sci USA, 2006. 103(10): p. 3639-44.

97. Wedlich-Soldner, R. and R. Li, Spontaneous cell polarization: undermining determinism. Nat Cell Biol, 2003. 5(4): p. 267-70.

98. Krishnan, J. and P.A. Iglesias, Receptor-mediated and intrinsic polarization and their interaction in chemotaxing cells. Biophysical Journal, 2007. 92(3): p. 816-30.

99. Hewavitharana, T., et al., Role of STIM and Orai proteins in the store-operated calcium signalling pathway. Cell Calcium, 2007. 42(2): p. 173-82.

100. Buchsbaum, R., Rho activation at a glance. J Cell Sci, 2007. 120(7): p. 1149-1152.

101. Bustelo, X.R., V. Sauzeau, and I.M. Berenjeno, GTP-binding proteins of the Rho/Rac family: regulation, effectors and functions in vivo. BioEssays: news and reviews in molecular, 2007.

102. Edwards, D.C., et al., Activation of LIM-kinase by Pak1 couples Rac/Cdc42 GTPase signalling to actin cytoskeletal dynamics, in Nat Cell Biol. 1999. p. 253-259.

103. Joneson, T., et al., RAC regulation of actin polymerization and proliferation by a pathway distinct from Jun kinase. Science, 1996. 274 (5291): p. 3.

104. Tolias, K.F., et al., Type lalpha phosphatidylinositol-4-phosphate 5-kinase mediates Rac-dependent actin assembly. Curr Biol, 2000. 10(3): p. 153-6.

105. Janmey, P.A. and T.P. Stossel, Modulation of gelsolin function by phosphatidylinositol 4,5-bisphosphate. Nature, 1987. 325(6102): p. 362-4.

106. Gardiner, E.M., et al., Spatial and temporal analysis of Rac activation during live neutrophil chemotaxis. Curr Biol, 2002. 12(23): p. 2029-34.

107. Eden, S., et al., Mechanism of regulation of WAVE1-induced actin nucleation by Rac1 and Nck. Nature, 2002. 418(6899): p. 790-3.

108. Raftopoulou, M. and A. Hall, Cell migration: Rho GTPases lead the way. Developmental Biology, 2004.

109. $\mathrm{Xu}, \mathrm{J}$. , et al., Divergent signals and cytoskeletal assemblies regulate self-organizing polarity in neutrophils. Cell, 2003. 114(2): p. 201-14.

110. Wong, K., A. Van Keymeulen, and H.R. Bourne, PDZRhoGEF and myosin II localize RhoA activity to the back of polarizing neutrophil-like cells. J Cell Biol, 2007. 179(6): p. 1141-8.

111. Guo, W.H. and Y.L. Wang, Retrograde fluxes of focal adhesion proteins in response to cell migration and mechanical signals. Mol Biol Cell, 2007. 18(11): p. 4519-27. 
112. Schaub, S., et al., Comparative maps of motion and assembly of filamentous actin and myosin II in migrating cells. Molecular Biology of the Cell 2007. 18(10): p. 372332.

113. Alexandrova, A.Y., et al., Comparative dynamics of retrograde actin flow and focal adhesions: formation of nascent adhesions triggers transition from fast to slow flow. PLoS ONE, 2008. 3(9): p. e3234.

114. Huckaba, T., T. Lipkin, and L. Pon, Roles of type II myosin and a tropomyosin isoform in retrograde actin flow in budding yeast. The Journal of Cell Biology, 2006. 175(6): $p$. 957-969.

115. Medeiros, N., D. Burnette, and P. Forscher, Myosin II functions in actin-bundle turnover in neuronal growth cones. Nat Cell Biol, 2006. 8(3): p. 216-226.

116. Cai, Y., et al., Nonmuscle Myosin IIA-Dependent Force Inhibits Cell Spreading and Drives F-Actin Flow. Biophysical Journal, 2006. 91(10): p. 3907-3920.

117. Lecuit, T. and L. Le Goff, Orchestrating size and shape during morphogenesis, in Nature. 2007. p. 189-192.

118. Cano, A., et al., The transcription factor snail controls epithelial-mesenchymal transitions by repressing E-cadherin expression. Nat Cell Biol, 2000. 2(2): p. 76-83.

119. Pestonjamasp, K.N., et al., Rac1 links leading edge and uropod events through Rho and myosin activation during chemotaxis. Blood, 2006. 108(8): p. 2814-20.

120. Nimnual, A.S., L.J. Taylor, and D. Bar-Sagi, Redox-dependent downregulation of Rho by Rac. Nat Cell Biol, 2003. 5(3): p. 236-41.

121. Pollard, T.D., Regulation of actin filament assembly by Arp2/3 complex and formins. Annual review of biophysics and biomolecular structure, 2007. 36: p. 451-77.

122. Ghosh, M., et al., Cofilin promotes actin polymerization and defines the direction of cell motility, in Science. 2004. p. 743-746.

123. Delorme, V., M. Machacek, and C. Dermardirossian, Cofilin Activity Downstream of Pak1 Regulates Cell Protrusion Efficiency by Organizing Lamellipodium .... Developmental Cell, 2007.

124. Nakamura, T., et al., Analysis of the spatiotemporal activation of rho GTPases using Raichu probes. Meth Enzymol, 2006. 406: p. 315-32.

125. Dumstrei, K., Signalling pathways controlling primordial germ cell migration in zebrafish. J Cell Sci, 2004. 117(20): p. 4787-4795.

126. Collinson, A.D., et al., Fluorescence Properties of Green Fluorescent Protein FRET Pairs Concatenated with the Small $G$.... Assay and Drug Development Technologies, 2004. 
